\title{
Preferential Trade Agreements and Their Role in World Trade
}

\author{
Denis Medvedev*
}

\begin{abstract}
This paper investigates the effects of preferential trade agreements (PTAs) on bilateral trade flows using a comprehensive database of PTAs in force and a detailed matrix of world trade. We show that total trade between PTA partners is a poor proxy for preferential trade (trade in tariff lines where preferences are likely to matter): while the former amounted to one-third of global trade in 2000-02, the latter was between one-sixth and one-tenth of world trade. Our gravity model estimates indicate that using total rather than preferential trade to assess the impacts of PTAs leads to a significant downward bias in the PTA coefficient. We find that product exclusions and long phase-in periods significantly limit preferential trade, and their removal could more than double trade in tariff lines above 3 percent most favored nation (MFN) duties. We also show that the effects of PTAs on trade vary by type of agreement and are increasing in the incomes of PTA partners.

JEL classification: F13, F15, F53.
\end{abstract}

World Bank Policy Research Working Paper 4038, October 2006

The Policy Research Working Paper Series disseminates the findings of work in progress to encourage the exchange of ideas about development issues. An objective of the series is to get the findings out quickly, even if the presentations are less than fully polished. The papers carry the names of the authors and should be cited accordingly. The findings, interpretations, and conclusions expressed in this paper are entirely those of the authors. They do not necessarily represent the view of the World Bank, its Executive Directors, or the countries they represent. Policy Research Working Papers are available online at http://econ.worldbank.org.

*Development Prospects Group, World Bank and Department of Economics, American University. I am deeply grateful to Robert Blecker, Paul Brenton, Jeffrey Lewis, Kara Reynolds, and Hans Timmer for valuable comments and suggestions. 


\section{Contents}

1 Introduction $\quad 1$

2 Brief background of the gravity model $\quad 3$

2.1 Advantages and disadvantages of gravity-based PTA analysis . . . . . . . . . . 3

2.2 Review of the empirical literature . . . . . . . . . . . . . . . 5

3 PTA and trade variables revisited $\quad 9$

3.1 Documenting the rise in the number of PTAs . . . . . . . . . . . . . 11

3.2 Estimating the share of world trade covered by PTAs $\ldots \ldots \ldots \ldots$

4 PTAs and the gravity equation $\quad 28$

4.1 Model setup and baseline results . . . . . . . . . . . . . . . . . . . . 29

4.2 Application to exclusions and phase-in periods . . . . . . . . . . . . 38

4.3 Alternative specifications of the PTA variable . . . . . . . . . . . . . . 43

$\begin{array}{llr}5 & \text { Conclusion } & 47\end{array}$

$\begin{array}{ll}\text { A Abbreviations and definitions } & 52\end{array}$

B Theoretical foundations of the gravity equation $\quad 53$

$\begin{array}{ll}\text { C Trade between PTA partners, regional detail } & 57\end{array}$

D Normality of regression residuals $\quad 58$

D.1 Significance of the normality assumption . . . . . . . . . . . . . 58

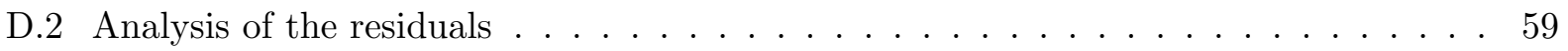

E Preferential Trade Agreements in force through $2004 \quad 62$

F Data sources and data management $\quad \mathbf{7 5}$

F.1 Data source details . . . . . . . . . . . . . . . . . . . 75

F.2 Data transformation . . . . . . . . . . . . . . 76

\section{List of Tables}

1 Distribution of PTAs by geographic region and income level . . . . . . . . . . . 15

2 Number of countries in the trade and tariff database . . . . . . . . . . . . . . 17

3 Zero-duty MFN tariff lines as a share of all MFN ad-valorem tariff lines, percent . . 21

4 Preferential imports as a share of world total under varying ROO thresholds, 2000-02 27

5 Gravity model estimation results . . . . . . . . . . . . . . . . 32

6 Wald test results . . . . . . . . . . . . . . . . . . . 37

7 Gravity model estimation results: preferential trade with exclusions and phase-in

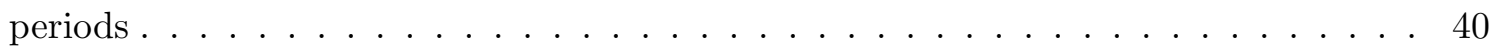

8 Simulation results: removing exclusions and phase-in periods . . . . . . . . . . 41

$9 \quad$ Alternative specification estimation results: preferential imports . . . . . . . . . . . 44

10 Regional abbreviations and country membership . . . . . . . . . . . . . 52 
11 Intra-PTA imports as shares of total imports, in percent . . . . . . . . . . . 57

12 Gravity model estimation results: robust regression . . . . . . . . . . . . . . . 61

13 Variables and their sources . . . . . . . . . . . . . . . . 75

\section{List of Figures}

1 Growth in the number of PTAs . . . . . . . . . . . . . . . 13

2 Imports between PTA partners as a share of total imports (percent) . . . . . . . 18

3 Intra-PTA imports as a share of world imports under varying assumptions (percent) 26

4 Kernel density estimates of regression residuals . . . . . . . . . . . . . . 60 


\section{Introduction}

Preferential trade agreements (PTAs) have been on the forefront of the trade policy agenda for over forty years. The Treaty of Rome, the precursor to today's European Union (EU), became the first such modern agreement to enter into force in 1958. Since then, the number of PTAs has grown dramatically, and their economic significance has expanded. Today, PTAs are receiving an unprecedented amount of public attention and demand a growing amount of political resources. Although the most well-known developments in the PTA arena have been advanced by the traditional heavyweights in the area - such as the EU's pursuit of Economic Partnership Agreements (EPAs) or negotiations of the Central American Free Trade Agreement (CAFTA) ${ }^{1}$ and the Free Trade Area of the Americas (FTAA) by the US - the participation in the propagation of PTAs has been incredibly broad, with 174 countries having signed at least one agreement and the total number of agreements reaching 229 by the middle of 2004 .

The gravity model, drawing its name from Newtonian physics, has been used extensively in analyzing the effects of PTAs on trade. In its most basic form, the gravity equation implies that trade between two partners is proportional to the product of their size and negatively related to the distance between them. The widespread application of the gravity model is mainly due to its ease of implementation and the accuracy with which it describes the volume of bilateral trade flows. Inclusion of PTA-specific variables allows the gravity equation to be used for estimating the trade creation and trade diversion effects of PTAs, making it an attractive tool for ex post analysis. However, despite its ease of application and wide use, the gravity model has been the subject of extensive criticism on several fronts. Recent research in the field has identified two areas as the most serious weaknesses in the gravity framework: improving the theoretical underpinnings of a model perceived largely as a formalization of empirical regularities, and developing new explanatory variables that better reflect the observed heterogeneity in the data.

This paper follows the latter approach by arguing that several variables in the traditional gravity specification used for PTA analysis have been misspecified. The first is the number of PTA variables considered in the analysis - most studies account only for a small subset of all PTAs in

\footnotetext{
${ }^{1}$ See Appendix E for a full list of PTAs in force and their membership details.
} 
existence, making any generalization of findings to the regional or global level difficult to justify. In contrast, this paper relies upon a comprehensive database of PTAs currently in force, where the main addition to existing sources of information on the subject is the inclusion of agreements not notified to the World Trade Organization (WTO), which account for approximately half of all PTAs in existence. The second improvement over the traditional estimates is redefining the dependent variable as trade flows that can be meaningfully considered "preferential." In order to do this, the paper combines the PTA database with detailed data on trade flows to exclude trade in tariff lines with zero or very low MFN rates, where the margin of preference is not high enough to justify importing goods under the preferential regime. We generate two sets of gravity estimatesone using total bilateral trade as the dependent variable, and one where only preferential trade is considered. The main finding is that, while many control variables are insignificantly different across the two specificaitons, the PTA coefficient is significantly larger in the latter model. The "preferential" specification allows us to estimate the impact of product exclusions and long phasein periods on trade between PTA members, as well as the potential benefits of liberalizing these provisions. We also explore how various types of PTAs affect bilateral trade, finding that the effects vary significantly with the income level of PTA partners and the WTO notification status of the PTA, but are indistinguishable when bilateral PTAs are contrasted with agreements with more than two members.

This paper is organized as follows. Section 2 provides the background on the gravity model of trade, including the main arguments for its use, its theoretical underpinnings, and a brief literature survey. Section 3 summarizes the information in the PTA database, details the methodology used in calculating the share of world trade covered by PTAs, and presents the estimates. Section 4 builds a gravity model of preferential trade, presents the estimates, and uses the model to evaluate the impact of product exclusions and phase-in periods. Section 5 offers concluding remarks. 


\section{Brief background of the gravity model}

\subsection{Advantages and disadvantages of gravity-based PTA analysis}

The main challenge in empirical PTA analysis is to clearly trace the effects of preferential liberalization on trade flows of sample countries or regions. Two different methodologies have been employed to achieve this: ex ante analysis using CGE models, and ex post analysis using regression techniques. Gravity models belong to, and in fact dominate, the second class. The main postulate of gravity models - and in fact the source of their name - is a proposition that bilateral trade flows are greater between partners that are more similar in size and located closer to each other. A "traditional" gravity specification used for quantifying the effects of preferential liberalization on trade takes the following form:

$$
\ln x_{i j}=\alpha+\beta_{1} \ln y_{i}+\beta_{2} \ln y_{j}+\sum_{k=1}^{K} \beta_{k+2} \ln z_{i j}^{k}+\sum_{m=1}^{M} \gamma_{m} P T A_{i j}^{m}+\epsilon_{i j}
$$

where

$x_{i j} \quad$ is the value of bilateral exports from country $i$ to country $j$

$y_{i}$ and $y_{j}$ are GDPs of partners $i$ and $j$

$z_{i j}^{k} \quad$ is a set of $K$ variables (including distance) which affect trade between $i$ and $j$

$P T A_{i j}^{m} \quad$ is a set of $M$ PTA-related variables (e.g. PTA dummies)

$\epsilon_{i j} \quad$ is the error term

Criticisms of the traditional gravity approach focus on two main areas: taking issue with the fundamental appropriateness of the framework - such as questioning the model's ability to fully account for all important PTA-related changes - and arguing that empirical applications have been misguided due to incorrect functional form, poor variable definitions, and other factors. A major limitation of gravity models is their narrow focus on trade volumes and inability to generate predictions in other areas such as the direction of trade or distributional impacts. In addition, proponents of the ex ante simulation methodology point out that in contrast to CGE models, which provide explicit links between changing production/consumption patterns and changes in trade 
policy, ${ }^{2}$ traditional gravity models approximate PTA-related changes in countries' trade structure by relying on sets of one or more PTA dummy variables. This approach is problematic because the dummy variables may also capture a range of other effects contemporaneous with PTA implementation. A futher difficulty is that the dummy variable methodology cannot distinguish the extent of preferential liberalization vis-á-vis the multilateral counterfactual, although several recent studies have attempted to correct for this by creating continuous "liberalization indices" to replace the traditional 0-1 PTA dummies. Another criticism of gravity studies is their inability to take into account the terms-of-trade adjustments accompanying preferential liberalization, which can have significant effects on changes in trade flows and welfare (see Burfisher et al., 2004). Furthermore, the traditional gravity equation has little theoretical basis; although gravity-type equations have been derived as reduced-form expressions of general equilibrium models of trade, they are different from the "traditional" specification in equation (1) and rely on a set of behavioral and technology assumptions that are quite restrictive. ${ }^{3}$ Finally, critics have argued that physical distance between trading partners - a standard variable in most gravity specifications - is a very bad proxy for transportation costs, pointing out the faulty underlying assumption that these costs are the same for equidistant countries. A number of studies (see, for example, World Bank, 2001) have shown that transportation costs over the same distance vary widely for different trading partners. For example, it costs twice as much to ship a container from Baltimore, MD, to La Paz, Bolivia, as it does to ship the same container from Baltimore to Durban, South Africa, despite the fact that Durban is twice as far away from Baltimore as La Paz.

Notwithstanding the above-mentioned shortcomings of the gravity model, the approach has enjoyed continued popularity due to its two major advantages: ease of implementation and superior empirical performance. The data requirements of the traditional model are low and rely on widely available information, while the estimation procedure is straightforward through OLS or GLS. With regard to the second advantage, the empirical success of gravity models in forecasting the volumes

\footnotetext{
${ }^{2}$ In turn, CGE models are often criticized for imposing strong assumptions about the structure of an economy, including specific functional forms and closure rules. In addition, the results are to a large extent determined by base year conditions and the chosen values for various model elasticities - most importantly the elastiticity of substitution between domestic and imported goods (the Armington elasticity; see Armington, 1969) and the income elasticity of household demand.

${ }^{3}$ See Appendix B for a more detailed discussion and derivation of a theory-based gravity equation.
} 
of bilateral trade is well-documented. Rose (2002) notes that the gravity-estimated "elasticities of trade with respect to both income and distance are consistently signed correctly, economically large, and statistically significant in an equation that explains a reasonable proportion of the crosscountry variation in trade." Leamer and Levinsohn (1995) suggest that the gravity equation has provided "some of the clearest and most robust empirical findings in economics." In addition, the argument that gravity models cannot clearly trace the links between trade policy and changes in trade flows does not disprove the validity of the gravity equation as long as one interprets the PTA coefficient(s) as the ex post total effect on trade, reflecting not only the tariff reduction clauses of a PTA but also other provisions that may enhance or diminish the liberalization potential of an agreement along with possible implementation problems. Finally, a number of recent studies have gone a long way towards addressing many of the criticisms of the model. The following section discusses these efforts in more detail.

\subsection{Review of the empirical literature}

One of the main criticisms of the traditional gravity model has been its lack of a solid theoretical foundation. However, recent literature has shown that the gravity equation is consistent with a reduced form solution of several models of trade, albeit under fairly strong assumptions about consumer preferences, market structure, and transportation costs. These studies include Redding and Venables (2000), Baier and Bergstrand (2001), Anderson and van Wincoop (2003), and Anderson and van Wincoop (2004), among others. The theoretical gravity equation derived from the last two studies is quite similar to the traditional formulation (1) and takes the following form (see Appendix B for a detailed derivation):

$$
\ln x_{i j}=m+\ln y_{i}+\ln y_{j}+\rho_{i j}(1-\sigma) \ln d_{i j}+\rho_{i j}(1-\sigma) \sum_{k=1}^{K} \ln z_{i j}^{k}-(1-\sigma) \ln P_{i}-(1-\sigma) \ln P_{j}
$$

The variable definitions remain as before, but now we explicitly identify bilateral distance $d_{i j}$ as an independent variable and also include aggregate multilateral price indices $P_{i}$ and $P_{j} \cdot{ }^{4}$ Note that due to CES preferences, the coefficients on both income variables are constrained to unity. ${ }^{5}$ One

\footnotetext{
${ }^{4}$ These are essentially the Armington prices - see Appendix B.

${ }^{5}$ Anderson (1979) builds a case for non-unitary income elasticities in the presence of a non-traded good.
} 
remaining area of ambiguity is the contents of the $\mathbf{z}_{\mathbf{i j}}$ vector of variables, which have little theoretical justification while varying widely across empirical applications. The most common candidates include differences and similarities in size (GDP, GDP per capita, or population), a country's remoteness (usually a GDP- or trade-weighted distance metric) and geographical characteristics (whether it is landlocked, and island, etc.), membership in a PTA, close ties to trading partners (through a common border, colonial history, or common language), exchange rate fluctuations, and quality of institutions. If the gravity model is used to analyze both within- and between-country trade flows, the border dummy variable in the $\mathbf{z}_{\mathbf{i j}}$ vector will capture the marginal contribution of the so-called "border effects" - the additional costs due solely to the fact that the traded goods must cross one or more international borders in order to reach their final destination. ${ }^{6}$ In applications focusing exclusively on international trade, the border effect is usually not relevant since the counterfactual of no international borders is not considered in the model.

The inclusion of price indices for both trading partners is a critical difference from the traditional model. Since these indices are themselves functions of distance and $\mathbf{z}_{\mathbf{i j}}$ parameters through the trade costs function, ${ }^{7}$ failure to include them in the model specification leads to omitted variable issues and biases the distance and $\mathbf{z}_{\mathbf{i j}}$ coefficient estimates. ${ }^{8}$ Anderson and van Wincoop (2004) and Feenstra (2004) suggest that the theoretical gravity equation may be estimated in one of the following three ways: collecting data on price indices and estimating the relationship through OLS, as in Baier and Bergstrand (2001); using custom programming to simultaneously obtain values for transportation costs as a function of $\mathbf{z}_{\mathbf{i j}}$ observables and estimate the structural equation using nonlinear least squares, as in Anderson and van Wincoop (2003); and estimating the equation with GLS while replacing importer and exporter price indices with region-specific fixed effects, as in Anderson and van Wincoop (2003) and Rose and van Wincoop (2001). ${ }^{9}$ All three approaches produce reasonable and significant estimates of the main parameters of the gravity model, but

\footnotetext{
${ }^{6}$ The origins of the large literature on border effects are usually attributed to McCallum (1995), who found that the US-Canada border reduced trade between Canadian provinces and US states by a factor of 20 .

${ }^{7}$ See equations (19) and (23) in Appendix B.

${ }^{8}$ See section 3.5 of Anderson and van Wincoop (2004) for a more detailed discussion and a simple example of this estimation bias.

${ }^{9}$ Rose (2004b) notes that under symmetry, a single set of fixed effects may serve the estimation purposes equally well. An alternative strategy, employed in Rose (2004a), relies on pair-wise fixed effects, which, in addition to the unobserved price indices, control for any other characteristic specific to a given pair of countries.
} 
Anderson and van Wincoop (2004) note that it is difficult to infer theoretical price indices from published price data since the latter include nontradables and are affected by taxes and nominal rigidities. Feenstra (2004) suggests that both the second and third methodologies produce consistent estimates of the equation parameters; while direct estimation of the trade cost function is likely to result in more efficient estimates, the benefit may not be worth the computational difficulty associated with departure from the fixed-effects approach.

Since the main focus of the above studies is estimating a theoretically correct version of the gravity equation, they do not pay explicit attention to the role of preferential liberalization in affecting trade flows. In fact, only Rose and van Wincoop (2001) include a PTA membership dummy in their analysis; although this variable is positive and significant, they do not emphasize this finding since their main concern is estimating the effects of a currency union. On the other hand, the literature on the effects of PTAs on trade is quite extensive, although most of these studies do not root their estimation techniques in the theoretical gravity equation. The efforts within this strand of gravity literature have been mainly focused on determining the effects of PTAs on trade creation and diversion between members and non-members. Thus, the original analysis of preferential liberalization by Aitken (1973), who pioneered the use of a single PTA dummy to measure the effects of PTAs on trade, was extended by Bayoumi and Eichengreen (1995) and Frankel (1997), who suggested the use of two dummy variables to distinguish between intra-bloc and extra-bloc effects. More recently, Soloaga and Winters (2001) have proposed three dummies to separate the extra-bloc effects on imports and exports - that is, identifying PTA trade creation, import diversion, and export diversion. This approach has gained popularity in recent studies featuring gravity models, including ADB (2002, Chapter 3) and Lederman et al. (2005, Chapter 6). Other authors, including Li (2000) and Adams et al. (2003), have focused on further redefining PTA variables by replacing the traditional dummies with continuous variables measuring the extent of liberalization in several different areas of a PTA, such as market access in different sectors, rules of origin, customs cooperation, and harmonization of standards.

Adams et al. (2003) provide an extensive review of the empirical findings of the above studies as well as eight other gravity papers. For each agreement and each study, the authors calculate the net effect of a PTA on trade by summing the point estimates of trade creation and trade diversion semi- 
elasticities. To determine the "consensus" effect of a particular PTA on trade, the authors add the number of positive and negative results. If the difference between the positive and negative findings is two or more studies, the "consensus" effect is signed accordingly, otherwise, the result is deemed inconclusive. ${ }^{10}$ The authors show that, on average, the Andean Pact, the Australia-New Zealand Closer Economic Relations (CER) trade agreement, Association of Southeast Asian Nations FTA (AFTA), the EU, and European Free Trade Area (EFTA) have been found to be net trade-creating. The net outcome for North American Free Trade Agreement (NAFTA) is trade-diverting, while the results for Latin American Integration Association (LAIA) and the Southern Cone Common Market (MERCOSUR) have been inconclusive. Their own estimates, which rely on the fixed effects methodology ${ }^{11}$ are somewhat different from these conclusions: the Andean Pact, LAIA, US-Israel FTA, and South Pacific Regional Trade and Economic Co-operation Agreement (SPARTECA) are found net trade-creating, while AFTA, EFTA, the EU, MERCOSUR, NAFTA, CER, EUSwitzerland, Chile-Colombia, Australia-Papua New Guinea, Chile-MERCOSUR, EU-Egypt, and EU-Poland FTAs are net trade-diverting. Thus, contrary to much of the earlier findings, their analysis classifies virtually all of the large and well-known PTAs in their sample as trade-diverting. ${ }^{12}$

A more sophisticated technique of combining results from different studies is meta-analysis, which takes parameter estimates from various papers and tests the hypothesis that the mean value is statistically different from zero. ${ }^{13}$ This approach is employed in chapter 3 of World Bank (2004), which collects coefficient estimates of the trade impact of 19 PTAs from 17 research studies. Two types of impacts are considered: the overall effect, which is the PTA semi-elasticity of total imports, and the internal effect, which is the PTA semi-elasticity of intra-PTA imports. Among the 254 and

\footnotetext{
${ }^{10}$ Note that this methodology assigns equal weights to each result, irrespective of the strength of the findings. Thus, for example, a weak finding of trade creation and a highly significant estimate of trade diversion would exactly offset each other.

${ }^{11}$ Adams et al. (2003) do not refer to the theoretical gravity equation in their work, but their use of fixed effects is consistent with that methodology. Although, as discussed earlier, this addresses a possible omitted variable bias, there is another source of concern regarding the Adams et al. (2003) estimates. The authors make use of a Tobit estimation procedure owing to their assumption that trade flow data are censored at the lower bound (zero). However, it is not clear whether an observation of zero trade between two partners is a consequence of a combination of observables, or whether it represents a missing observation. If the latter is the case, as one would expect for trade flows between many small and/or developing countries, then assuming censoring will introduce bias into the estimates.

${ }^{12}$ Although the LAIA is undoubtedly large, it is a loosely-defined association of states without clear tariff reduction schedules, specific commitments, or timetables.

${ }^{13}$ See Stanley (2001) for a detailed discussion of the meta-analysis methodology, and Rose and Stanley (2005) for an application to gravity studies investigating the effects of currency unions on trade.
} 
362 point estimates of each effect, respectively, ${ }^{14}$ the technique finds that 76 and 66 percent are statistically significant. The mean value for the overall impact is -0.31 with a standard error of 1.12 , and the mean value for the internal impact is 0.79 with a standard error of 1.30 . Thus, while the average values suggest that PTAs tend to be trade-creating among members and net trade-diverting overall, the variance about the means is very large and in fact both effects may not be different from zero. Although these results are not encouraging for the impact of PTAs on world trade, it is important to keep in mind that the primary purpose of meta-analysis is to present average findings from a sample of studies. This approach does not give greater weight to more recent research, which generally tends to rely on tighter theoretical structure and use more sophisticated econometric techniques. Therefore, these findings do not suggest that PTAs have insignificant effects on trade, but rather that the existing literature has not yet provided a cohesive answer to that question.

\section{$3 \quad$ PTA and trade variables revisited}

Although substantial progress has been made in enhancing the empirical performance and theoretical foundations of gravity models, a number of areas for improvement remain. This paper focuses on two such areas: the number of PTAs considered by the analysis, and the domain of trade flows explained by the model. Most gravity studies of preferential liberalization take explicit account of only a handful of PTAs in force; while this approach is reasonably well-suited for analyzing the effects of individual agreements, it is not appropriate for making generalizations about the average effect of all PTAs in existence. We are not aware of any empirical works that consider all PTAs in force in a gravity framework, and the fact that existing studies usually limit their attention to larger and more well-known PTAs could easily bias any aggregation of these estimates. Therefore, the first part of this section will discuss a new comprehensive database of PTAs, which improves upon the existing data sources by including a large number of agreements not notified to the WTO. Relying on this database will allow our model to track the average effects of PTAs on trade directly,

\footnotetext{
${ }^{14}$ The sample was obtained by collecting individual agreement dummy coefficient estimates from each study. The requirements for choosing a study were either a published article or an NBER working paper.
} 
without having to scale up estimates from individual agreements. ${ }^{15}$

The second part of this section relies on an observation that PTAs may have varying impacts on trade in different products. The implicit assumption of any gravity model that uses total imports or exports as its dependent variable is that all trade flows are affected in the same fashion by the set of independent variables. While this reasoning is likely to hold for the majority of variables usually included in the gravity specification (e.g. aggregate output levels, price indices, etc.), such generalization may not be appropriate for PTA membership variables. There are several reasons why bilateral merchandise trade flows in different tariff lines may respond differently to PTAs. First, tariff lines where the MFN duty is zero have become a large share of the overall number of tariff lines for many countries. Therefore, trade that takes place in these lines cannot be considered preferential since the same (zero) margin of preference is extended to all trading partners, regardless of PTA membership. Second, even if the MFN duty is above zero, an exporter may choose to forego the preferences and bring the goods in under MFN rates if the costs of complying with the relevant rules of origin (ROO) are too high. ${ }^{16}$ Thus, trade that takes place in tariff lines where the MFN duty level is low enough to dissuade an exporter from proving origin must also be taken out of the definition of preferential flows. Third, virtually all PTAs in existence limit trade liberalization by means of sensitive lists and product exclusions, and frequently incorporate long phase-in periods and encounter implementation problems. Therefore, the effective liberalization potential of a given PTA is limited to a set of tariff lines where the MFN duty is above a certain ROO threshold, taking

\footnotetext{
${ }^{15}$ Note that simply including a large number of PTAs in the model may not represent a strict improvement over earlier efforts due to large variation in the size and scope of agreements. In extreme cases (consider a PTA vector that includes both NAFTA and a Georgia-Armenia PTA), the interpretation of an "average effect" becomes quite difficult. Nonetheless, relying on a comprehensive database of PTAs offers several advantages. First, the average effect, if significant, suggests that PTAs of all sizes have a noticeable effect on trade, and second, the richness of the database allows us to test various combinations of PTAs (e.g. North-South vs. South-South, WTO notified vs. unnotified, etc.) and compare these estimates to the average effect.

${ }^{16}$ The rules of origin are the criteria needed to determine the national source of a product. ROO are used to determine whether a shipment falls within a quota limitation, qualifies for a tariff preference, or is affected by an anti-dumping duty. Under any preferential scheme, ROO are required to prevent third parties from exporting to the country with the lowest level of external protection and subsequently re-exporting to other members at preferential rates. Therefore, ROO are present in both bilateral and unilateral preference regimes, and become obsolete only at the highest levels of integration such as a customs union with a common external tariff (since all members have the same level of protection). ROO are implemented through different means, and vary from country to country and from one PTA to the next. It is not uncommon for the same exporter to face very different ROO, such as Mexican firms exporting to the US under NAFTA and to the EU under the EU-Mexico free trade agreement. The most often used ROO criterion is substantial transformation of the product, but other requirements such as change in tariff classificaiton (Harmonized System chapter, heading, or sub-heading), certain ad valorem percentage, or specific manufacturing or processing operation are also common.
} 
into account the relevant exclusions and phase-in delays. Combining a PTA database developed in the first part of this section with data on trade flows at the national tariff line level, the second part of the section will estimate the share of world trade that, given the above considerations, can be meaningfully considered "preferential." We will then use these data to test if the findings of a gravity model change depending on whether the dependent variable is defined as all trade or only "preferential" trade among the members of a PTA.

\subsection{Documenting the rise in the number of PTAs}

The pursuit of PTAs has a long history, and their numbers have been rising particularly fast in recent years even as (and partly because) progress on the multilateral front had slowed. By 1990, 53 regional and bilateral agreements were in force. Through the first quarter of 2004, that number has grown to $229,{ }^{17}$ and the trend shows no signs of slowing down. Despite the growing importance of PTAs in the global trading system, there is no overarching body that monitors their progress or sets standards for compliance. Therefore, the task of collecting data on PTAs is a difficult one. The PTA database published by the WTO is the single consistent publicly available source of this information, but it includes only those agreements that have been notified to the WTO. Thus, agreements between non-WTO members are omitted from the data, ${ }^{18}$ and even PTAs involving WTO members often go unreported since the organization does not enforce PTA reporting or compliance. $^{19}$

Although PTAs represent a fundamental departure from the core WTO principles of nondiscrimination and Most Favored Nation (MFN) status, the WTO affords its members a large degree of flexibility in entering new PTAs. Within the WTO framework, countries can join preferential agreements by meeting the requirements of General Agreement on Trade and Tariffs (GATT) Ar-

\footnotetext{
${ }^{17}$ This estimate counts the 25-member European Union as a single agreement. The main reason for this approach is that the EU negotiates all of its PTAs with outside countries as a single body, with new members becoming automatic signatories to earlier agreements. Since we are interested in the number of PTAs in force rather than their historical evolution, other methods of dealing with the EU, such as regarding each round of accession as a new agreement, would lead to double-counting.

${ }^{18}$ For example, Russia (the largest country in the world that is not a WTO member) participates in two regional PTAs and is actively negotiating several others.

${ }^{19}$ The WTO database does not include the SADC and SACU agreements in Africa, even though a WTO member (South Africa) is party to both. Similarly, the India-Nepal and India-Bhutan bilateral agreements in South Asia remain unreported despite India's membership in the WTO. We will provide more detail on the unreported agreements, including the data sources used in their identification, later in this section.
} 
ticle XXIV, General Agreement on Trade in Services (GATS) Article V, or the Enabling Clause. Paragraphs 4 to 10 of GATT Article XXIV contain provisions covering the formation of customs unions and free trade areas in merchandise trade, while GATS Article V covers agreements in services, and the Enabling Clause (The 1979 Decision on Differential and More Favorable Treatment, Reciprocity and Fuller Participation of Developing Countries) deals with trade in goods between developing countries. The provisions of each of the above disciplines generally require that countries entering a PTA do not raise trade barriers with the rest of the world, but are extremely vague on the specifics. For example, despite specifying that preferential liberalization should eliminate barriers on "substantially all trade," neither Article XXIV itself nor any subsequent legal document quantifies this requirement. Similarly, member countries are required to notify the Secretariat of any PTAs they enter, and agreement provisions can be reviewed by the WTO. However, any such examination is voluntary, and the outcome of the report (of which few have been completed) has no bearing on the WTO attitude towards or legality of the agreement. Therefore, there appears to be no enforcement mechanism that guarantees accurate reporting of PTAs by WTO members and the administrative framework to ensure PTA compliance with WTO principles is non-existent. ${ }^{20}$

In order to create a single dataset for both the WTO notified and unnotified agreements, we undertook an extensive data-gathering exercise to supplement the official WTO database, relying on unpublished WTO data as well as other available information. ${ }^{21}$ The main source has been unofficial communication from the WTO, who compiled a large database of agreements not formally notified to them (both PTAs that have been concluded and those in various stages of negotiations) by collecting information from various newspaper articles. These data were supplemented by information from the websites of the Office of the US Trade Representative and the EU Trade Commission. Still more PTAs were added through various print and web media searches. The scope of data collected is similar to the format used by the WTO's PTA database: for each agreement, we specify the name, country members, date of signing, and date of entry into force, classify

\footnotetext{
${ }^{20}$ The lack of a PTA enforcement mechanism suggests that the WTO does not view the pursuit of PTAs as a threat to the multilateral outcome. There is a large literature that supports the "building block" view of PTAs, including Schott (2004), Lawrence (1991), and Winham (1986) (cited in World Bank, 2004). On the other hand, studies such as Saggi (2004), Saggi and Yildiz (2004), and Limão (2003) caution that the pursuit of PTAs may reduce the motivation to lower multilateral tariffs and slow the progress towards global free trade.

${ }^{21}$ The results of this exercise were presented briefly in World Bank (2004).
} 
the PTA as bilateral or plurilateral (more than two members), and determine whether it has been notified to the WTO. Unlike the WTO data, which includes agreements on trade in services as well as goods, our database focuses on merchandise trade agreements only. The distinguishing feature of the new database is the inclusion of agreements that have not been notified to the WTO, which outnumber the notified PTAs by 130 to 99 (see Figure 1). ${ }^{22}$

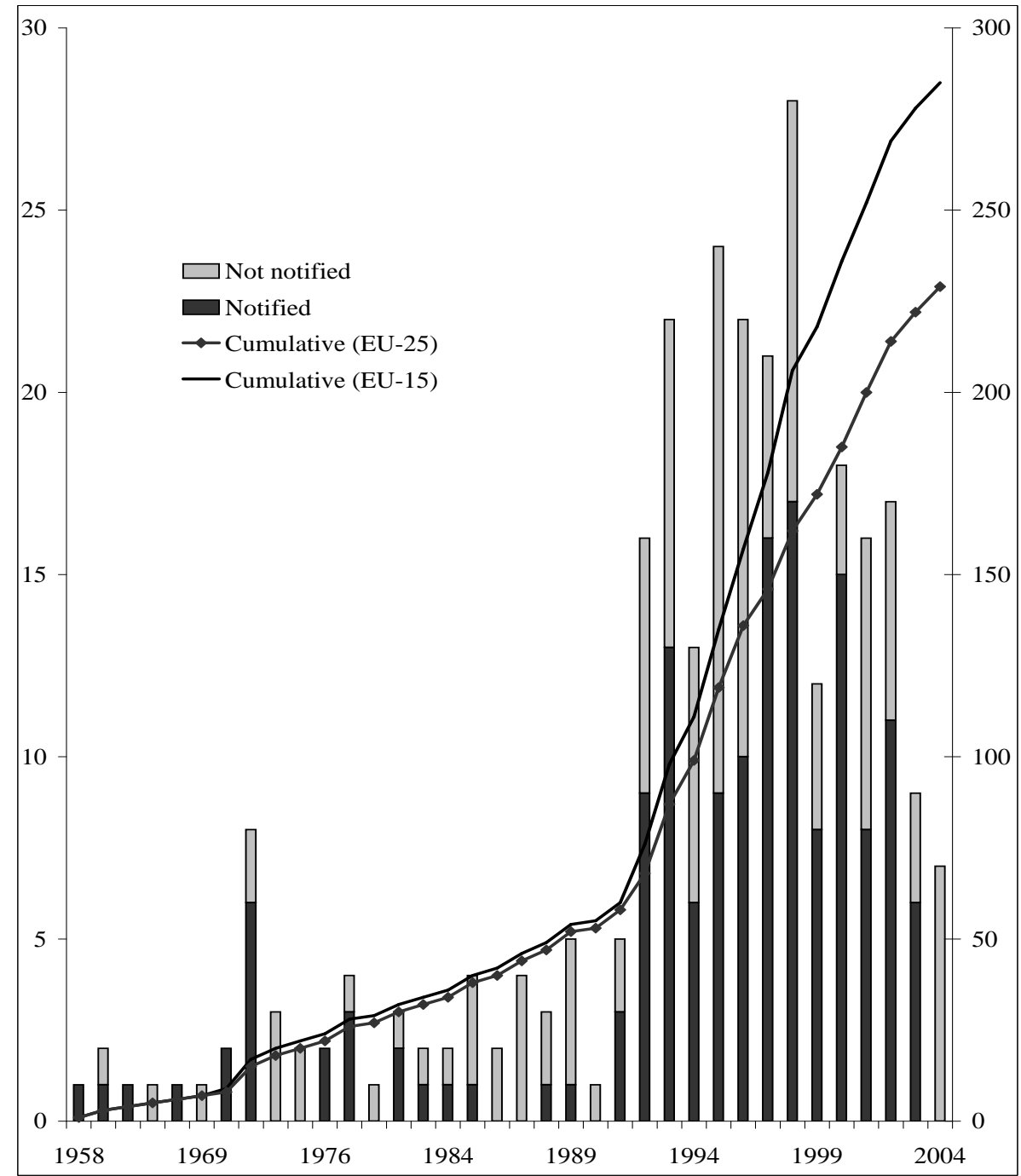

Figure 1: Growth in the number of PTAs Source: WTO and author's estimates.

The left axis of Figure 1 shows the number of PTAs signed in a given year, using stacked columns

\footnotetext{
${ }^{22}$ As before, this estimate counts the EU-25 as a single agreement. If EU-15 is treated as a single agreement instead (implying that all PTAs between the EU and the new accession countries, as well as between the accession countries themselves, are included in the estimate), the number of unnotified agreements remains the same, but the number of notified PTAs rises to 155.
} 
to differentiate whether an agreement has or has not been notified to the WTO. The right axis shows the cumulative number of PTAs signed by a given year, and provides two separate estimates (the two lines on the diagram) that depend on whether the fifteen or twenty-five member EU is counted as a single agreement. In the fifteen member case, all PTAs between the EU-15 countries are counted as one, including the acession agreements. The same treatment is maintained in the twenty-five member case, which means that the original EU agreement is counted as a single PTA, and all agreements between the acession countries and the EU, as well as among the acession countries, are discounted. This explains the increasing gap between the two cumulative lines, which grows as the recent acession countries sign PTAs with the EU-15 and each other (the so-called Europe Integration Agreements).

An important feature of the rise in the number of PTAs is the broad participation of countries of all geographic and income groups - and consequently the growing "spaghetti bowl" of overlapping agreements. For example, PTAs between WTO members outnumber the countries by a factor of almost two, and Mongolia is the only WTO member who has not signed a single PTA. On a global scale, an average country has entered into five PTAs (see Table 1). Although this number is biased upward by few countries with an abnormally large number of PTAs (for example, the EU is party to 29 PTAs with outside countries), more than 80 percent of all countries are an active member of at least one preferential agreement.

While the drive towards PTAs is generally associated with the Eastern European and Latin American developing regions, Table 1 reveals that this movement is incredibly broad, with more than two-thirds of countries in each region signing at least one PTA. At the same time, although the data suggest that no single region is being left out of the PTA movement, the rising number of agreements is a growing concern due to the heavy burden that multiple and often overlapping PTAs can place on a country's administrative capacity. Multiple agreements imply different sets of ROO, tariff regimes, and varying customs procedures - which, at a minimum, can lead to inefficiencies at customs and delays at the border, or even to incompatible or conflicting rules and requirements. In the most extreme case, consider "perfectly overlapping" PTAs - those where the same country pair is party to more than one agreement. For example, Kenya and Uganda are both members of the EAC and COMESA, and Georgia and Armenia are both members of the CIS agreement but 
Table 1: Distribution of PTAs by geographic region and income level

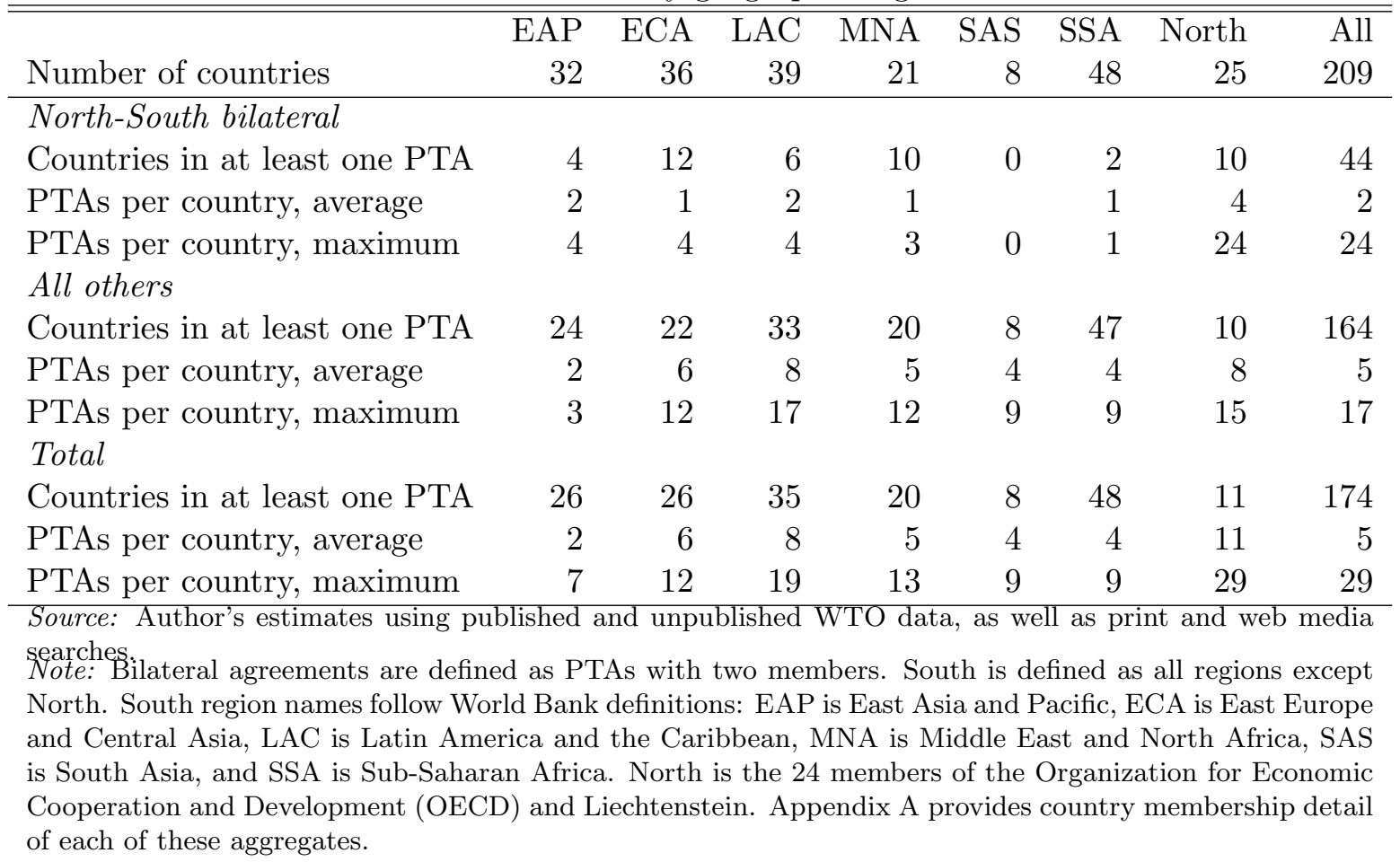

also have a bilateral FTA. For the world as a whole, approximately 44 percent of country pairs in our PTA database participate in "perfectly overlapping" PTAs, although this number underlies a significant degree of regional variation. Of course, this finding does not necessarily imply that a large number of PTAs are in effect duplicates. There may be some logic in "nesting" PTAs in the sense that different sets of issues are more easily addressed in different forums. Thus, for example, sectorspecific liberalization commitments or border transit facilitation may be most efficiently handled in a bilateral context, while mutual recognition of standards, competition policies, or movement of labor may be more easily dealt with through regional negotiations. Nonetheless, if trade flows between a large number of PTA members fall under the provisions of more than one agreement, the aggregate effect of PTAs on trade could be less than the sheer number of agreements may indicate. Of course, it is not possible to discern the role of PTAs in world trade by simply considering the number of countries that have entered into these agreements. The next section will show that the PTA members' tariff structure can have a significant effect on the share of intra-PTA trade that may be meaningfully considered "preferential." 


\subsection{Estimating the share of world trade covered by PTAs}

As argued earlier, the effects of PTAs on trade in different tariff lines may not be uniform. Specifically, due to the growing importance of zero MFN duty lines in the tariff schedules of many countries, the significant costs of meeting ROO requirements, the presence of exclusions and sensitive lists, and other factors, a large share of trade between PTA partners may take place on a MFN rather than preferential basis. This reasoning highlights a bias in most estimates of preferential trade as a share of world total (see, for example, WTO, 2003; Kommerskollegium, 2003), which tend to overstate the amount of preferential trade by considering all merchandise trade flows between PTA partners as preferential. In contrast, this paper will use a highly detailed world trade matrix to focus specifically on trade flows where preferences are likely to matter.

We begin by establishing some terminology: in the following discussion, the terms "covered" or "preferential" trade will refer to only those trade flows that take place under meaningful reciprocal preferences, ${ }^{23}$ not to the total trade between the members of a PTA. In this section, we make no assumptions about the magnitude of trade flows that would have existed between PTA partners in the absence of preferences. In other words, rather than attempting to quantify PTA trade creation, the aim here is to carefully apply the above definition of preferential trade in order to arrive at a better understanding of the quantitative significance (magnitude) of preferential flows in world trade.

For this exercise, we collect bilateral merchandise trade and tariff data at the national tariff line level (6 or 8 digit Harmonized System codes) for a panel of 150 countries over the 2000-02 period. The import data are obtained from UN COMTRADE, and the tariff data from UN TRAINS databases. The two sources are merged together into a single dataset, and countries are included only if they report both trade and tariff information for at least one of the years. Due to gaps

\footnotetext{
${ }^{23}$ Therefore, trade that takes place under unilateral preference schemes such as General System of Preferences (GSP), USA's African Growth and Opportunity Act (AGOA) or EU's Everything but Arms (EBA) will not be considered preferential. There are several reasons for this choice of definition. First, unilateral preferences lie outside the WTO definition of PTAs because preferences are not mutual. Second, these schemes are of limited duration and require periodic renewal, which is not guaranteed. Third, because preferences granted under these scheme are essentially one-sided "concessions," they tend to exclude important export products, leading to concentration of production in low value-added activities and slow development (see Panagariya, 2002; Lamy, 2002). Reflecting these criticisms, the EU is now moving away from unilateral preferences to a system of reciprocal liberalization under the Economic Partnership Agreements (EPAs). Admitedly, none of the above arguments qualify as a sufficient condition for exclusion of unilateral preferences from the definition of "preferential" trade. Ultimately, the choice to focus on reciprocal preferential agreements is made largely for convenience and to ease data gathering requirements.
} 
in reporting (for any given year, a number of countries fail to report their tariff schedules and/or imports), we take averages of both trade flows and tariff duties over the three-year period, so that a country is excluded only if it reports no trade or tariff data in all three years. The resulting database consists of 3,412,606 import flows between 56 reporter and 192 partner countries ${ }^{24}$ (see Table 2), and covers approximately 69 percent of world trade over the relevant time period.

Table 2: Number of countries in the trade and tariff database

\begin{tabular}{lrrrrrrr}
\hline \hline & East & East & Latin & Middle & South & Sub-Sah. & North \\
& Asia & Europe & America & East & Asia & Africa & \\
\hline Importer & 7 & 11 & 19 & 2 & 2 & 6 & 9 \\
Exporter & 32 & 35 & 39 & 20 & 8 & 48 & 10 \\
\hline Source: UN COMTRADE and UN TRAINS databases.
\end{tabular}

In order to estimate the share of world trade that takes place between PTA partners, we merge the PTA database with the above matrix of world trade flows. We only consider PTAs that have come into force prior to 2002 - thus the trade flows between sample countries are covered by 141 PTAs. In order to obtain the value of trade between PTA partners, we classify imports as intra- or extra-PTA at the tariff line level and calculate the regional and global shares by summing the values in each category. This is equivalent to estimating the shares as import-weighted averages, therefore allowing countries with large trade volumes to dominate the results. By contrast, calculating the relevant shares as unweighted averages of individual country intra-PTA trade ratios would give equal weights to countries of different sizes. Therefore, this approach would produce average rather than total shares of world trade between PTA partners. Since the primary goal of this section is to estimate the relative magnitude of preferential flows in world trade, the weighted average is the better vehicle for our explorations. Thus, unless explicitly specified, the following discussion as well as subsequent tables and figures will refer to import-weighted averages.

The main results are shown in Figure 2, while Table 11 with full regional detail is relegated to Appendix C. The height of the left stacked column for each region represents imports between PTA partners as a share of total intra-regional imports. Therefore, approximately 12 percent of intra-EAP trade takes place between countries who have signed at least one PTA with each other, while the comparable number for South Asia is over 98 percent. At the global level, trade flows

\footnotetext{
${ }^{24} \mathrm{UN}$ definitions of "partner" and "reporter" correspond in this case to importer and exporter, respectively.
} 
between PTA partners account for approximately 32 percent of world trade. Therefore, our results show that most global trade takes place outside PTAs. This is not particularly surprising, since three of the world's largest economies - the EU, the US, and Japan - are not in a PTA with each other, and the two largest developing countries - China and India - re involved only in PTAs with small regional partners ${ }^{25}$.

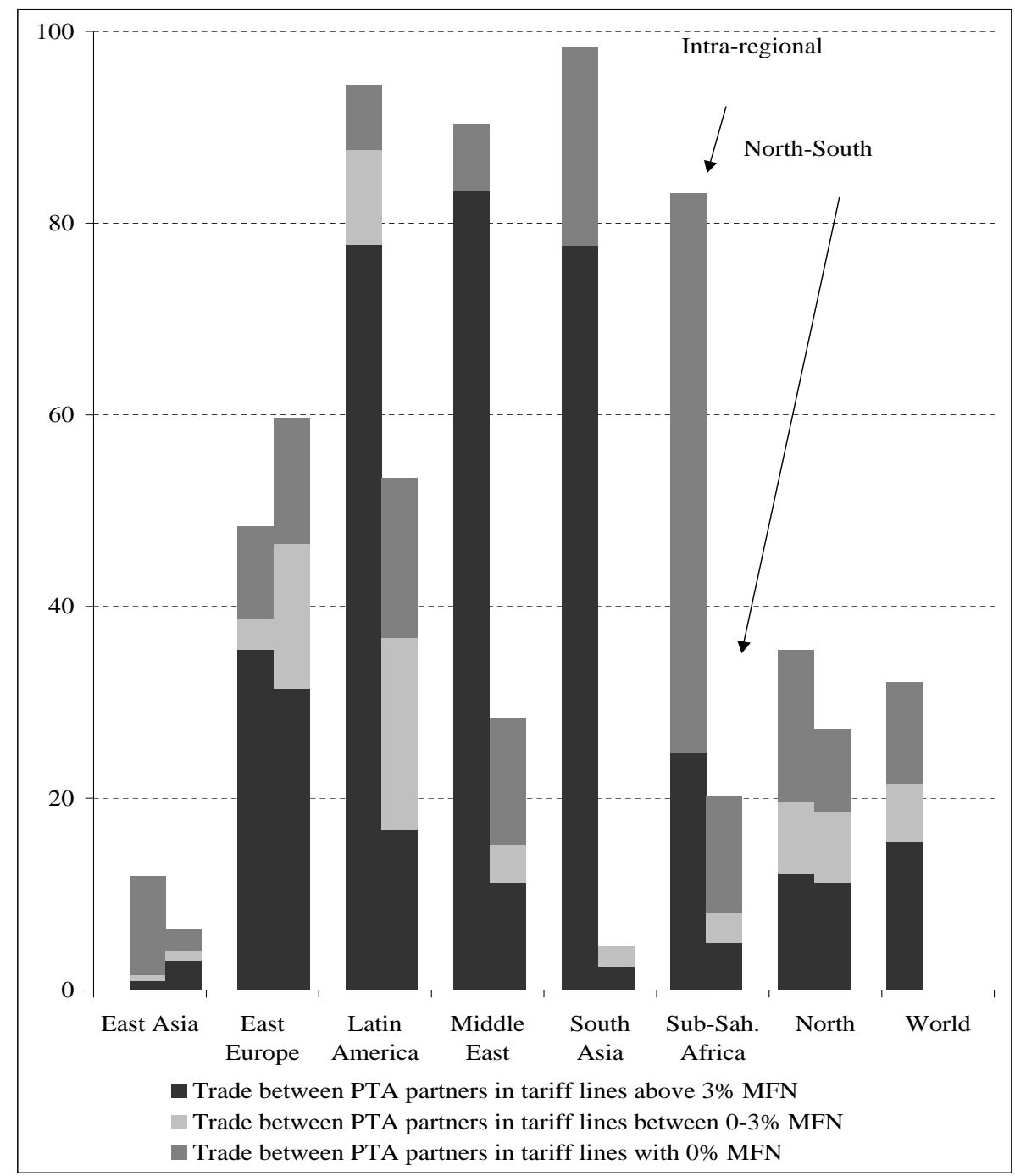

Figure 2: Imports between PTA partners as a share of total imports (percent) Source: Author's estimates.

The variation in the intra-regional trade between PTA members is one measure of the effectiveness with which PTAs are used as a trade policy tool. For now, we confine our analysis to

\footnotetext{
${ }^{25}$ Currently, China, India, and Japan are all involved in PTA negotiations with ASEAN. If these countries join the ASEAN FTA, the importance of preferential trade for the region and the world as a whole may increase as a result.
} 
the overall height of the stacked bars, which take total imports between PTA members as the numerator. Since all trade between PTA partners is included, the results are largely driven by the number and scope of the agreements signed in each region. However, the trade shares are also indicative of whether these PTAs are concluded with the largest and most important trading partners. Therefore, very large intra-regional trade shares for Latin America and South Asia indicate that preferential agreements have been signed with nearly all significant trading partners, while a small share for East Asia shows that most trade in that region (in volume terms) takes place between countries that are not linked by a PTA. In other words, East Asian countries have not pursued preferential agreements as a means of establishing ties with their largest trading partners in the region, while Latin America and South Asia have been very effective in doing so.

The height of the right stacked column for each region represents that region's exports to high income PTA partners as a share of the region's total exports to the North. The only exception is the right stacked column for high income countries (North), which shows the trade-weighted average of all developing country exports to the PTA partners in the North. Similar to intra-regional imports, there is large variation in the value of North-South trade across the developing country regions: while only sixty percent of East Asian exports to the North are destined towards PTA partners, 60 percent of Eastern Europe's North-South trade takes place with PTA partners. This implies that for Eastern Europe and Latin America, PTAs represent an important vehicle of getting access to high income markets, as evidenced by their high North-South PTA import shares. On the other hand, there is relatively little North-South PTA trade with East and South Asia, and, to a lesser extent, Sub-Saharan Africa. This suggests that these regions have had either little interest or little success in negotiating PTAs with their significant trading partners in the North. For developing countries as a whole, exports to PTA partners in the North account for 27 percent of total NorthSouth exports. Since this share is considerably lower than the Latin America or Eastern Europe averages, Figure 2 implies that developing countries who have signed few PTAs with high income partners (such as the East Asia and Pacific region) are responsible for most of the North-South trade in our sample.

Although East Asian economies have largely eschewed preferential liberalization as a trade policy tool, they have been the most successful exporters to the North and are also the fastest growing 
developing countries today (in fact, their experiences have embodied the concept of export-led growth). This suggests that PTAs are not a necessary condition for successful trade and growth performance; in fact, our results demonstrate that most of the action on the global trade stage takes place outside of PTAs. Therefore, it is important to emphasize that the discussion in this paper is very narrowly focused on defining preferential trade and exploring the impact of reciprocal preferences on trade flows at the margin. The finding that preferential trade is more important for certain sets of countries than others does not bear any implications on the overall trade position of those countries, or whether larger preferential trade shares are growth-inducing or welfare-enhancing. All of these issues are extremely important, and have spawned an extensive literature on the effects of trade and trade policy on growth as well as the effects of preferential liberalization on welfare. ${ }^{26}$ We respectfully defer the discussion of these issues to this other literature, and remind the reader that our results do not attempt to draw any growth or welfare implications, however important and significant they may be.

The previous analysis only considered total trade between PTA members, and is therefore likely to overstate the importance of PTAs if the MFN tariffs on certain products are low enough so that PTA partners do not enjoy significant market access advantage vis-à-vis non-PTA countries. Over the last decade, multilateral and unilateral liberalization has contributed to significant decreases in average tariff rates. One of the driving forces behind this movement towards lower tariffs has been the emergence of zero duty MFN tariff lines, which now constitute a large share of tariff schedules for many countries (see Table 3). Since both PTA and non-PTA member countries enjoy the same level of market access in products with zero MFN duties, failure to account for the presence of these tariff lines is likely to lead to a significant upward bias in any estimate of preferential trade. For instance, Sapir (1998) examined EU imports in 1995 under bilateral and unilateral preference schemes and found that while 51 percent of extra-EU imports came from preference-receiving partners, only 30 percent of imports were preferential according to the above definition. While examining NAFTA's preference utilization rates, Anson et al. (2003) note that the utilization rate in 2000 rises from 64 percent when all tariff lines are included to 83 percent when only lines with positive MFN duties

\footnotetext{
${ }^{26}$ See Rodriguez and Rodrik (2001) for a review of early studies on the relationship between trade and growth as well as the seminal critique. For later contributions, see, for example, Dollar and Kraay (2003). See Burfisher et al. (2004) for a review of literature on the trade and welfare effects of PTAs.
} 
are considered.

Table 3: Zero-duty MFN tariff lines as a share of all MFN ad-valorem tariff lines, percent

\begin{tabular}{lrr}
\hline \hline & 1996 & 2001 \\
\hline Australia & 40.8 & 48.0 \\
Canada & 32.9 & 49.6 \\
Colombia & 1.7 & 2.8 \\
European Union (EU-15) & 13.9 & 18.0 \\
Indonesia & 19.2 & 21.9 \\
Poland & 1.5 & 5.5 \\
Thailand & 2.5 & 3.6 \\
United States & 20.8 & 35.2 \\
South Africa & 40.1 & 46.4 \\
\hline Source: Author's estimates using the UN TRAINS \\
database.
\end{tabular}

Effectively, zero MFN duties represent an erosion of preferences for PTA partners, who receive no tariff concessions in these tariff lines. The top (dark grey) section of the stacked columns in Figure 2 illustrates the effects of explicitly accounting for zero MFN duties in our sample. For example, removing trade in zero MFN tariff lines from the numerator lowers the share of intraPTA trade in the world total to less than 22 percent, compared with 32 percent of world trade when all trade between PTA partners is included. Large negative effects can also be observed at the regional level, where the left column height (without the top portion) declines significantly for East Asian, African, and Northern importers, but changes relatively little for Latin America, Middle East, and South Asia. For the former regions, the results in Figure 2 imply that the "value" of their intra-regional PTA tariff concessions is eroded considerably by the large share of zero MFN duty lines in their tariff schedules. For example, although 12 percent of intra-regional trade in East Asia takes place between PTA members, only 1.6 percent of intra-regional trade receives nonzero preference margins. For the Latin America, Middle East and North Africa, and South Asia regions, our findings suggest that intra-regional preferential liberalization has been taking place mostly behind high external tariff walls. With regard to North-South trade, all regions except East and South Asia experience a large erosion of preferential access to their PTA partners in the North as a result of zero MFN tariffs. Although the Asian regions exhibit a less marked decline, recall that the total shares of North-South PTA trade in these regions are very low. This suggests that even for developing countries that have been successful in negotiating PTAs with their important 
trading partners in the North, the value of these preferences is potentially reduced by the presence of zero MFN duty lines.

In addition to the impact of zero MFN lines, ROO distortion costs can also have significant effects on trade between PTA partners. As discussed earlier, ROO are required to prevent trade deflection in any PTA short of a customs union, where non-beneficiary goods could enter a PTA partner with the lowest level of external protection and subsequently enjoy preferential access to other PTA members. However, as noted inter alia by Brenton (2003), Brenton and Ikezuki (2004), and Brenton and Manchin (2003), ROOs are often more strict than necessary to accomplish this goal, resulting in higher costs for exporters and consequently under-utilization of preferences. ${ }^{27}$ Several studies have attempted to provide empirical estimates of the costs associated with complying with different sets of ROO. One of the most oft-cited examples is Herin (1986), who applied a revealed preference methodology in analyzing preference utilization rates in the EU and EFTA. His approach used preference margins in sectors with the utilization rate close to 100 percent as an upper bound for the costs of satisfying ROO, and preference margins in sectors with the utilization rate close to 0 as the lower bound. The underlying assumption is that for sectors with nearly complete preference utilization, the tariff preference is revealed superior to the costs of satisfying ROO, while the converse is true for sectors with near zero utilization. For other sectors, assuming homogeneous preferences across exporting firms implies that exporters would be indifferent between shipping the goods under the MFN or preferential regime, and therefore the tariff preference would be revealed equal to compliance costs. Using this methodology, Herin (1986) estimated the costs of ROO compliance for exporting firms to be at least 2 percent of shipment value, with the total costs, including the administrative costs of border formalities required to prove origin, ranging from 3 to 5 percent. More recent studies using similar revealed preference reasoning, such as Anson et al. (2003) and Carrère and de Melo (2004) for NAFTA, estimate total compliance costs to be 5 and 6

\footnotetext{
${ }^{27}$ These studies also show that costs of meeting ROO tend to be higher in PTAs and unilateral preference schemes involving high income partners. Thus, ROO often go beyond simply means of preventing trade deflection and become an instrument of protection, similar to other non-tariff barriers. On the other hand, ROO can also create trade in certain sectors and therefore lead to an increase in preference utilization. This has occurred with automobile and textile and clothing industries within NAFTA, where strict ROO encouraged industrial development in the member states and buttressed cross-border trade in the above sectors. Of course, more trade and higher rates of preference utilization only last as long as the artificial policy barriers that created them, and we have witnessed this with the decline of Mexican textile and apparel exports to the US following the phase-out of the Multi-Fiber Arrangement (MFA) quotas.
} 
percent respectively, with slightly less than 2 percent attributable to administrative costs. Carrère and de Melo (2004) also build an econometric model using a version of an ROO restrictiveness index developed by Estevadeordal (2000) to capture the heterogeneity across different sectors and types of ROO (such as change of heading, chapter, or local content requirements). They estimate compliance costs (net of administrative costs) to be 3.86 percent for the total sample, with subsample estimates ranging from 2.04 percent for intermediate goods to 4.17 percent for final goods, and as high as 13.01 percent for textiles and apparel.

The above discussion suggests that for tariff lines where the MFN duty rate is relatively low (between 0 and 3-6 percent), the costs of satisfying ROO requirements are likely to exceed the value of preferences in those lines and hence the preferences will remain unutilized (or under-utilized, if ROO compliance costs are non-homogeneous across exporting firms). Recognizing the bias introduced by ROO compliance costs, Grether and Olarreaga (1999) use the estimates presented in Herin (1986) to define preferential trade as trade flows between PTA partners that take place in tariff lines above a 3 percent MFN duty threshold. The authors use only those PTAs that have been notified to the WTO (or the GATT prior to the WTO); however, they also include unilateral preferences such as the GSP scheme in their definition of preferential trade. They apply this threshold to a sample of 53 countries (counting the EU as a single entity) over two time periods, 1988-92 and 1993-97, although not all countries have observations for both time periods and, within each period, country data is available only for a single year. The results show that during the 1988-92 period, preferential $\operatorname{trade}^{28}$ accounted for 41 percent of the world total using the import-weighted average method, and 21 percent using the simple average method. By 1993-97, the preferential shares increased to 42 percent and 27 percent, respectively. Three main conclusions can be drawn from these findings: first, preferential trade represents a large share of the world total; second, this share has increased over time; and third, the results are quite sensitive to individual country size and degree of trade openness. The latter is clearly illustrated by the large disparity between preferential trade shares calculated using the two different methods, and suggests that the results in both periods are driven by large countries with high preferential trade shares (some possibilities that come to mind include EU trade with EFTA countries and US trade with Canada). At the same time, the large increase

\footnotetext{
${ }^{28}$ In this paragraph, we use the term "preferential trade" as it was defined by Grether and Olarreaga (1999).
} 
in the unweighted share of preferential trade suggests that as the number of PTAs rose between the two periods, the amount of trade between PTA partners (many of them smaller countries) also grew, thus driving up the share of preferential trade flows in world trade. Today, the relevance of these estimates is limited because the majority of sample observations are pre-Uruguay Round (1995), and therefore do not fully reflect the significant multilateral liberalization that took place with the establishment of the WTO. Furthermore, although the number of PTAs has more than doubled since the mid-1990s, the number of zero and low duty MFN tariff lines has also increased appreciably during that time (Table 3). On the other hand, the methodology proposed by the authors is very useful, and we will follow their approach in adjusting estimates of preferential trade by ROO compliance costs.

In order to assess the impact of ROO costs on trade between PTA partners, we refine the definition of preferential trade to include only trade flows in tariff lines where the MFN duty is above 3 percent. Although the costs of meeting various ROO may well be higher than that, we begin by considering the 3 percent threshold as a conservative estimate. At the regional level, the effects of using this definition are shown in the bottom (black) section of the stacked columns in Figure 2. With regard to intra-regional trade, these results further reinforce our earlier conclusions regarding the structure of border protection across regions. For example, notice that the middle (gray) section contributes relatively little to the overall column height in all developing country regions, and is virtually non-existent in the Middle East and North Africa, South Asia, and Sub-Saharan Africa regions. Since the combined impact of zero and low MFN duty lines does not significantly reduce the overall column height in all regions except for East Asia (and, to a lesser extent, Sub-Saharan Africa), the implication is that very little South-South preferential trade takes place in products with low MFN duties. This reaffirms our argument that preferential liberalization in many parts of the developing world has mostly been taking place behind relatively high tariff walls - the so-called "closed regionalism." On the other hand, notice that the both the absolute and relative height of the grey segment is always larger in the North-South column. This suggests that in addition to the impact of zero MFN tariff lines, a large share of developing countries' preferential access to high income markets is eroded by the presence of low duty lines. The differences are particularly striking for Latin America and Eastern Europe, where 20 and 16 percent, respectively, of their trade with 
PTA partners in the North takes place in tariff lines with the MFN duty between 0 and 3 percent. Clearly, tariff concessions granted to these regions in the course of PTA negotiations are worth significantly less if a large share of intra-PTA trade takes place in tariff lines where preferences are unlikely to matter.

At the global level, preferential trade accounts for 15.4 percent of the world total-less than one half of the baseline estimate of 32 percent when all trade between PTA partners is included (Figure 3). Thus, it appears that despite the growing number of agreements and increased resources dedicated to PTA negotiations, the role of PTA tariff preferences in global trade is relatively small (that is, less than half of all trade flows between PTA members can be meaningfully classified as preferential). This result also holds when we disaggregate PTAs into those that have been notified to the WTO and those that have not: preferential trade between members of notified PTAs amounts to 48 percent of their total trade, while preferential trade between members of unnotified PTAs is 48.5 percent of their total trade. This disaggregation is shown in Figure 3, but the results are dominated by the notified agreements - the relative contribution of unnotified PTAs to trade between PTA members is less than 1 percent of all trade between PTA partners, regardless of what MFN threshold is used to define preferential trade. Therefore, the inclusion of unnotified PTAs does not appear to significantly influence the estimates of preferential trade, despite the fact that these agreements represent 57 percent of all PTAs in force.

It is worth emphasizing that while our methodology is quite similar to that of Grether and Olarreaga (1999), any comparison of their estimates with the preferential trade shares above is complicated by the issues of different sample size and composition, and their inclusion of unilateral preferences, which we have omitted. Therefore, we cannot conclude that the share of preferential trade in world total has experienced a large decline from 42 percent in 1993-97 to 15.4 percent in 2000-02. On the other hand, given the large effect of low MFN duty lines on the estimates of global and regional preferential trade shares, it is likely the case that the continued unilateral and multilateral liberalization as well as the increasing use of ROO as instruments of protection has at least somewhat offset the growing number of PTAs. In particular, consider that up to this point our estimates have been based on the fairly conservative estimate of ROO compliance costs at 3 percent of shipment value. It is easy to test the sensitivity of our results to other estimates of ROO 


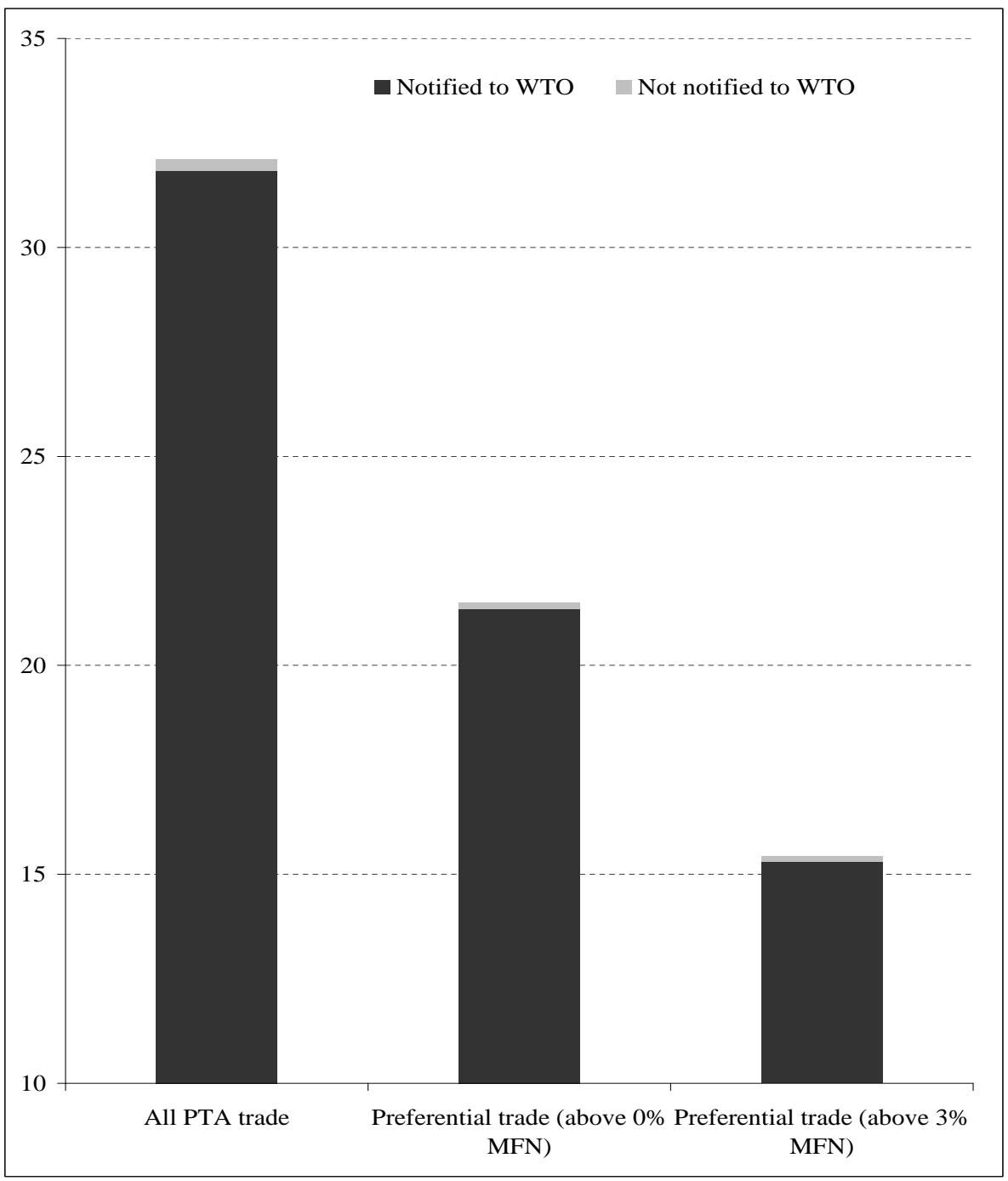

Figure 3: Intra-PTA imports as a share of world imports under varying assumptions (percent) Source: Author's estimates.

costs, such as those reported in Anson et al. (2003) and Carrère and de Melo (2004). Table 4 shows the evolution of the global results when ROO thresholds of 4, 5, and 6 percent MFN tariffs are used to define preferential trade. We also construct a set of scenarios where the ROO thresholds differ for agricultural and manufactured goods. This is motivated by an observation that preference utilization rates in the US and the EU seem to be consistently lower in agriculture trade. Although PTAs with agriculture-specific ROO are much less common than PTAs with sector-specific ROO in textile, apparel, or automotive industries, agricultural ROO (often found in the EU or EFTA agreements with third countries) tend to be of the more restrictive speficic processing variety and 
often require that products be wholly obtained in the member states (Moïsé, 2002). To reflect this, we impose a somewhat ad hoc requirement that the ROO threshold in agriculture must be 1.5 times the threshold in manufactured goods (which remains equal to the overall ROO threshold in earlier scenarios). When evaluated at the aggregate level, the results are dominated by manufactured goods, which make up for more than $90 \%$ of all tariff lines and $94 \%$ of the trade in our sample. Therefore, the differences between the set of scenarios where the ROO costs differ by sector and the set where they do not are negligible when total trade is considered. To emphasize the effects of allowing ROO costs to vary by sector, Table 4 also shows preferential trade shares for agriculture and manufacturing.

Table 4: Preferential imports as a share of world total under varying ROO thresholds, 2000-02

\begin{tabular}{|c|c|c|c|}
\hline Tariff Threshold (MFN duty level) & $\%$ of all trade & $\%$ of agr. trade & $\%$ of mnf. trade \\
\hline $0.0 \%$ in all sectors & 21.5 & 23.5 & 21.4 \\
\hline $3.0 \%$ in all sectors & 15.4 & 20.0 & 15.1 \\
\hline $4.0 \%$ in all sectors & 14.3 & 19.5 & 14.0 \\
\hline $5.0 \%$ in all sectors & 12.8 & 18.8 & 12.3 \\
\hline $6.0 \%$ in all sectors & 11.4 & 18.1 & 11.0 \\
\hline $3.0 \%$ in $\mathrm{mnf}, 4.5 \%$ in agr & 15.4 & 19.4 & 15.1 \\
\hline $4.0 \%$ in mnf, $6.0 \%$ in agr & 14.2 & 18.1 & 14.0 \\
\hline $5.0 \%$ in mnf, $7.5 \%$ in agr & 12.7 & 17.3 & 12.3 \\
\hline $6.0 \%$ in mnf, $9.0 \%$ in agr & 11.3 & 15.9 & 11.0 \\
\hline
\end{tabular}

Note that the estimates of this section report the liberalization potential rather than the extent of effective liberalization by region and income level - that is, the share of trade that could be considered preferential if no products were excluded and all relevant agreement provisions were immediately and effectively implemented. However, virtually all PTAs currently in force contain such exclusions and limitations, and, while a true measure of the significance of preferential flows in world trade would take account of them, they are extremely difficult to quantify. We will return to the problem of accounting for exclusions and sensitive lists as well as phase-in schedules at a later point in the paper. For now, we simply emphasize that the estimates in Table 4 represent the upper limit of the magnitude of preferential flows, while the true numbers are likely to be smaller. 


\section{PTAs and the gravity equation}

The previous section has argued that the incidence of low and zero MFN duty lines in the PTA members' tariff schedules may effectively limit the direct impact of PTAs on trade to a (potentially small) subset of trade flows in which the PTA preferences actually matter. While it is possible that PTA membership and more liberal agreement provisions affect flows in high and low MFN duty lines alike due to various kinds of spillover effects, determination of whether that is the case should be a result of an empirical investigation rather than an a priori assumption. In this section, we will build a gravity model of bilateral trade and apply it to both total and "preferential" trade between countries. We will use trade in all tariff lines and trade in tariff lines with a MFN duty above 3 percent as two alternative dependent variables, and, using the same set of independent variables, compare coefficient estimates across the two specifications. The expectation is that while coefficients on the standard control variables such as distance and similarity in trading partners' GDP are likely to be the same across the two models, the coefficients on the PTA membership variable will differ significantly (and the coefficient value will be higher when only "preferential" trade is used as the dependent variable). Furthermore, by using the PTA database of section 3.1, our model will have the added advantage of estimating the average global effect of PTAs on trade directly, without having to scale up individual agreement estimates.

We will also use the "preferential" gravity model to assess the potential impact of product exlcusions and long liberalization phase-in schedules on trade flows between PTA members. In order to do this, we will add explicit controls for both provisions to our gravity model and simulate the effect of removing exclusions and phase-in periods using the estimated coefficients. Finally, we will investigate alternative specifications of the PTA variable, such as including separate dummies for agreements that have and have not been notified to the WTO, distinguishing between PTAs with two or more members, adding explicit controls for North-North, North-South, and South-South PTAs, and testing whether income similarity has a significant effect on preferential trade. 


\subsection{Model setup and baseline results}

We begin with the theoretical gravity equation (2), and model bilateral imports as a function of importer and exporter incomes, distance and other factors affecting trading costs, and importer and exporter aggregate price indices. Following standard practice in existing studies (such as Rose and van Wincoop, 2001; Adams et al., 2003), our trade costs function includes controls for similarity in preferences, geography, cultural linkages, and membership in a PTA. We follow the logic of Feenstra (2004) (see section 2.2) in deciding to model multilateral price indices indirectly using importer and exporter fixed effects. The equation that we estimate is therefore

$$
\begin{aligned}
x_{i j t} & =\alpha+\gamma_{i}+\theta_{j}+\lambda_{t}+\beta_{1} Y_{i t}+\beta_{2} Y_{j t}+\beta_{3} d G D P p c_{i j t}+\beta_{4} G D P \text { sim }_{i j t} \\
& +\beta_{5} \text { dist }_{i j}+\beta_{6} \text { comlang }_{i j}+\beta_{7} \text { border }_{i j}+\beta_{8} \text { colony }_{i j}+\beta_{9} P T A_{i j t}+\epsilon_{i j t}
\end{aligned}
$$

where

$$
\begin{array}{ll}
x_{i j t} & \text { is the log of total or preferential imports from country } j \text { to } i \text { in time period } t \\
\alpha, \gamma_{i}, \theta_{j}, \lambda_{t} & \text { are the constant, importer, exporter, and time fixed effects } \\
Y_{i t}, Y_{j t} & \text { are the logs of GDPs of countries } i \text { and } j \text { in } t^{29} \\
d G D P p c_{i j t} & \text { is the log of the absolute difference in per capita GDPs of } i \text { and } j \text { in } t \\
\text { GDPsim }_{i j t} & \text { is the index of similarity between the GDPs of } i \text { and } j \text { in time period } t^{30} \\
\text { dist }_{i j} & \text { is the } \log \text { of the geographical distance between the largest cities of } i \text { and } j \\
\text { comlang }_{i j} & \text { equals } 1 \text { if } i \text { and } j \text { share a common official language } \\
\text { border }_{i j} & \text { equals } 1 \text { if } i \text { and } j \text { share a land border } \\
\text { colony }_{i j} & \text { equals } 1 \text { if } i \text { and } j \text { have colonial linkages } \\
{\text { PT } A_{i j t}}_{\epsilon_{i j t}} & \text { equals } 1 \text { if } i \text { and } j \text { are members of the same PTA at time } t \\
\end{array}
$$

\footnotetext{
${ }^{29}$ Note that the theoretical gravity equation implies a unity constraint on the coefficients of both income terms: $\beta_{1}=\beta_{2}=1$. Some gravity studies, such as Anderson and van Wincoop (2003), impose this constraint a priori by dividing the dependent variable by the product of exporter and importer incomes (or subtracting the latter from the former after taking logs). Other studies, such as McCallum (1995), estimate non-unitary income elasticities, and Anderson (1979) provides a theoretical framework for income elasticities different than one by including non-traded goods in the analysis. Anderson and van Wincoop (2003) show that even in cases when the income elasticities are significantly different from one, imposing the unity constraint has little effect on the estimates of other model coefficients.
} 
A notable exclusion from the set of control variables is the importer's average tariff, frequently used as a measure of trade policy. We estimated an alternative specification that included the average tariff (both as a simple and import-weighted average) and found the results to be very similar to the estimates without it, with the coefficient on the tariff variable negative and significant. However, we omit the tariff variable from the base model due to the fact that in subsequent specifications, we will condition the dependent variable on the tariff variable - that is, exclude trade flows in certain tariff lines. In addition to creating potential empirical difficulties, including the tariff variable is problematic because once we move to trade in tariff lines above a certain tariff threshold, the coefficient on the average tariff becomes significantly positive. The reason is quite simple - the lower the average tariff, the more trade takes place in low-duty lines and therefore less trade takes place in tariff lines above the threshold. Another explanation for the positive sign is that for countries in a PTA, the tariff variable measures the value of preferences - it captures the price advantage that PTA partners gain vis-á-vis the non-members. However, the positive coefficient on the average tariff is confusing and counter-intuitive at first glance and the variable itself does not add much explanatory power to the model (the improvement in $R^{2}$ is less than one percent). Therefore, the tariff variable was excluded from all model specifications in this paper.

Several other variables common in gravity specifications have been excluded from the model on econometric grounds. These include the real exchange rate as well as island and landlocked dummy variables. The bilateral real exchange rate is meant to control for relative price fluctuations between trading partners - a real depreciation increases the local currency cost of a foreign basket of goods and therefore is expected to decrease imports. However, the coefficient on this variable was not significant in any model specifications, most likely due to the brief time dimension of the panel which does not allow for much movement in exchange rates. The $0-1$ country-specific dummies (e.g. island and landlocked variables) are not appropriate in a fixed effects framework

${ }^{30}$ This index is due to Egger (2000). It is calculated as:

$$
G D P \operatorname{sim}_{i j t}=\ln \left(1-\left(\frac{G D P_{i t}}{G D P_{i t}+G D P_{j t}}\right)^{2}-\left(\frac{G D P_{j t}}{G D P_{i t}+G D P_{j t}}\right)^{2}\right)
$$

Following differentiated product trade theory, the index is meant to capture the contribution of intra-industry trade to total trade and ranges from $-\infty$ to $\ln (0.5)$. 
since their inclusion does not add any explanatory power to the model (see, for example, section 2.2 of Baltagi, 2001). More precisely, in a model with country fixed effects, a landlocked dummy is simply an average of the fixed effects coefficients of landlocked countries. The problem is similar to a violation of the full rank assumption-if, controlling for all other factors, country $i$ trades less with its partners, is it because it is landlocked or due to other unobserved country characteristics (country fixed effect)? In this case, dropping the landlocked dummy will simply scale the country fixed effect coefficient without reducing the explanatory power of the model. Therefore, excluding the island and landlocked dummies allows their effects to be absorbed by the importer and exporter fixed effects without any loss of model predictive power, while including them reduces efficiency and could lead to multicollinearity problems.

Our dataset is an unbalanced panel of 13,317 observations for 55 importers and 169 exporters for the years 2000 through 2002. All values are expressed in current US dollars. The GDP and real exchange rate series were collected from the World Development Indicators (WDI) data provided by the World Bank, distance and control dummies from Centre d'Etudes Prospectives et d'Informations Internationales (CEPII), and the PTA variable was obtained from the PTA database developed in section 3.1. The dependent variables - $\log$ of total bilateral imports and log of preferential bilateral imports - were calculated from the dataset discussed in section 3.2 by summing trade flows by country of origin and destination across all tariff lines for the former and across tariff lines with the MFN duty above 3 percent for the latter. Following earlier discussion, the model was estimated using importer and exporter fixed effects - a specification supported both by theoretical considerations and empirical tests. ${ }^{31}$ Since our specification adds a (short) time-series dimension to the theoretical gravity equation, we also include year fixed effects in the model. The estimation

\footnotetext{
${ }^{31}$ Random effects are a common alternative to estimating panel data using fixed effects. In general, fixed effects are more appropriate when differences between panels can be best characterized by parametric shifts in the functional relationship. The underlying restriction is that the unobserved characteristics must remain the same within the panels, but may vary across panels. On the other hand, random effects allow the unobserved characteristics to vary both within and across panels by assuming that the dataset is a random sample drawn from a larger population. Therefore, the fixed effects estimator is always consistent but may be inefficient, while the random effects approach may be more efficient but does not guarantee consistency. A common method to decide between the two approaches is a Hausman test, which takes advantage of the above properties of the estimators. Specifically, the Hausman test checks a more efficient specification against a less efficient but consistent model to make sure that the more efficient model also gives consistent results. The null hypothesis is that the random effects estimates are the same as the fixed effects estimates, and the test statistic is distributed as a $\chi^{2}$ with the degrees of freedom equal to the number of panels. In our model, the $\chi^{2}$ is 681.70 and significant at the 1 percent level, which confirms that estimating the model with random effects would be inconsistent
} 
results (excluding the fixed effects and the constant) are presented in Table 5 .

Table 5: Gravity model estimation results

\begin{tabular}{lcccc}
\hline \hline $\begin{array}{l}\text { Dep. var. (ln) } \\
\text { Variable }\end{array}$ & \multicolumn{2}{c}{ Total imports } & \multicolumn{2}{c}{ Preferential imports } \\
Coefficient & Std. Err. & Coefficient & Std. Err. \\
\hline Ym & $1.216^{* *}$ & 0.408 & $1.104^{* *}$ & 0.411 \\
Yx & -0.001 & 0.234 & -0.168 & 0.258 \\
dGDPpc & 0.001 & 0.019 & -0.011 & 0.020 \\
GDPsim & $0.099^{* *}$ & 0.016 & $0.154^{* *}$ & 0.018 \\
dist & $-1.276^{* *}$ & 0.033 & $-1.341^{* *}$ & 0.036 \\
comlang & $0.608^{* *}$ & 0.063 & $0.597^{* *}$ & 0.069 \\
border & $0.276^{*}$ & 0.124 & $0.288^{*}$ & 0.130 \\
colony & $0.473^{* *}$ & 0.139 & $0.642^{* *}$ & 0.155 \\
PTA & $0.762^{* *}$ & 0.077 & $0.864^{* *}$ & 0.080 \\
\hline \multicolumn{5}{c}{13317} \\
\hline
\end{tabular}

Significance levels : $\quad \dagger 10 \% \quad * 5 \% \quad * * 1 \%$

Note: Preferential imports are defined as imports in tariff lines above 3 percent MFN.

Total imports. We begin with the discussion of results for total imports. Due to the presence of heteroscedasticity in the data (Breusch-Pagan $\chi_{(1)}^{2}=1253.44, p=0.00$ ), the model is estimated with Huber-White robust standard errors. The $R^{2}$ is high and the $F$ statistic is significant at the 1 percent level, indicating that the overall fit of the model is quite good. The residual distribution is approximately normal (see figure 4 in Appendix D), although formal tests reject normality of the errors. ${ }^{32}$ Despite the violation of the normality assumption, the deviations from normality are small and are not likely to have a significant impact on the results (see Appendix D for a more detailed discussion). The fixed effects are significant as a group $\left(F_{(224,13083)}=20.41, p=0.00\right)^{33}$ and most of the model coefficients are significant, carry the expected sign, and take on values that are consistent with estimates reported in other gravity studies. Since the dependent variable is expressed in logs, the coefficient estimates should be interpreted as elasticities for the GDP, GDP

\footnotetext{
${ }^{32}$ The distribution is slightly skewed to the left and its tails are about one and a half times as thick as expected from a normal distribution.

${ }^{33}$ Furthermore, a Wald test shows that both importer and exporter fixed effects are significant as individual groups $\left(F_{(54,13083)}=23.63, p=0.00\right.$ and $F_{(168,13083)}=19.44, p=0.00$, respectively), indicating substantial cross-section variation in the data. On the other hand, the year fixed effects are not significant either individually or together $\left(F_{(2,13083)}=0.08, p=0.92\right)$. This is likely due to the short time duration of the panel and, consequently, relatively little time-series variation in the variables.
} 
similarity, difference in per capita incomes, and distance variables, and semi-elasticities for the other variables.

The importer and exporter GDP serve as proxies for the level of aggregate demand for imports and the level of aggregate supply of exports. As expected, the coefficient on importer's GDP is significant and positive. Furthermore, the coefficient value is insignificantly different from oneconsistent with the theoretical gravity equation which imposes unitary income elasticities for both importers and exporters. On the other hand, the coefficient on exporter's GDP is insignificantly different from zero. Although this finding is inconsistent with the theoretical model, the result is probably indicative of shortcomings in the data. In a pure cross-sectional framework with full coverage of trading partners, one would expect the coefficients on both importer and exporter incomes to be zero, as the effects of these variables on imports would be picked up entirely by the relevant fixed effects. ${ }^{34}$ With panel data, the time-series variation in income variables should yield significant coefficient estimates. However, this expectation is driven by the assumption that the data provide complete coverage of trade flows between importers and exporters. On the other hand, our data has much better coverage of importers than exporters - while for a given importer, nearly all trading partners are identified, the identification of exporter's markets is much more scarce (recall there are 55 importer and 169 exporter countries in the data). Since only a subset of a given exporter's markets are present in the data, the exporter's income coefficient is likely to diminish in significance. This observation, combined with a very short time dimension of the panel, is the likely cause of exporter fixed effects entirely picking up the influence of exporter's GDP and leaving the coefficient on the income variable insignificant. ${ }^{35}$

The absolute difference in per capita incomes of importers and exporters is meant to capture differences in relative factor endowments, and, if the Hecksher-Ohlin model explains trade patterns

\footnotetext{
${ }^{34}$ To see this more clearly, consider a version of equation (3) that eliminates the time-series dimension

$$
\begin{aligned}
x_{i j} & =\alpha+\gamma_{i}+\theta_{j}+\beta_{1} Y_{i}+\beta_{2} Y_{j}+\beta_{3} d G D P p c_{i j}+\beta_{4} G_{D P s i m} \operatorname{sim}_{i j} \\
& +\beta_{5} \text { dist }_{i j}+\beta_{6} \text { comlang }_{i j}+\beta_{7} \text { border }_{i j}+\beta_{8} \text { colony }_{i j}+\beta_{9} P T A_{i j}+\epsilon_{i j}
\end{aligned}
$$

Notice that the terms $\left(\gamma_{i}+\beta_{1} Y_{i}\right)$ and $\left(\theta_{j}+\beta_{2} Y_{j}\right)$ can be written as $\beta_{1}\left(\beta_{1}^{-1} \gamma_{i}+Y_{i}\right)$ and $\beta_{2}\left(\beta_{2}^{-1} \theta_{j}+Y_{j}\right)$, respectively, which makes the income effects empirically indistinguishable from the fixed effects. In fact, it is exactly this reasoning that led Anderson and van Wincoop (2003), Anderson and van Wincoop (2004), and Feenstra (2004) to suggest the use of fixed effects to capture the effects of multilateral price indices in addition to unobserved country characteristics.

${ }^{35}$ In other words, if the model is estimated without exporter fixed effects, the coefficient on exporter's income is significant and correctly signed. However, as discussed earlier, this specification is inconsistent with the theoretical gravity equation and biases other coefficient estimates, and therefore these results are not reported.
} 
well (that is, trade is of an inter-industry nature), should be positively related to imports. On the other hand, if international trade mostly takes place in differentiated products and is hence of an intra-industry nature, similarity in country size should bear a positive relationship to imports. Since only the latter variable is significant and correctly signed, it appears that our model mostly captures trade flows of intra-industry variety - or perhaps that absolute difference in per capita GDP is not a good predictor of inter-industry trade, at least in our sample. The geographic distance between countries serves as a main proxy for trading costs, and has a negative effect on imports. The signs on the dummy variables of the model are largely self-explanatory-countries are likely to trade more if they share a common official language, a land border, or have colonial ties.

The coefficient on the PTA dummy variable is positive and significant, indicating that, controlling for all other factors, entering a preferential agreement tends to increase trade flows between member countries by 114 percent. ${ }^{36}$ Although this variable is specified so that it is equal to zero in the years before a particular PTA enters into force, the short time dimension of the model does not allow us to clearly distinguish whether the PTA variable is capturing the threshold effects of signing a PTA or the "natural trading partner" effect for a given pair of countries. In any case, our model supports the notion that PTAs are associated with increased imports from partner countries, although the value of the PTA coefficient is considerably lower than individual agreement dummy estimates from the earlier literature (which, if significant, tend to be greater than one and commonly reach double digits). This discrepancy is likely due to the fact that the number of PTAs in our model (163) is much greater than in the previous gravity studies of preferential trade, which generally confine their analysis to a sample of up to twenty of the most well-known agreements. Therefore, while the estimates reported in the previous literature focused on the PTAs that are the largest and most likely to influence trade flows, our estimates reflect the contribution of all PTAs to bilateral trade. Consequently, our estimates are lower since the larger and more significant effects of bigger agreements are diluted by the lower and, possibly, insignificant effects of the smaller PTAs. $^{37}$

\footnotetext{
${ }^{36}$ Because the dummy implies a discrete change in the value of the dependent variable, its coefficient cannot be interpreted as a semi-elasticity unless it is very small. In other words, $d \ln (y)$ becomes a poor approximation to $\frac{\Delta y}{y}$ as its absolute magnitude rises. However, it is always the case that $\frac{\Delta y}{y}=e^{\beta}-1$, where $\beta$ is the dummy coefficient.

${ }^{37}$ We use the term "smaller" here to refer not only to the PTAs that create a smaller common market, but also to the agreements that are likely to have small (if any) effects on trade due to poor design and/or implementation.
} 
Several qualifications are in order before any further discussion of the results. First, a direct comparison of our estimates with those of other studies is difficult since the time dimension of our dataset (three years) is significantly shorter than the majority of panels used in gravity analyses. In fact, due to a limited time duration of our sample, it is not easy to discern whether the PTA coefficient captures the increased trade effects of PTAs or larger trade between natural trading partners. Therefore, it cannot be determined with certainty whether the lower estimates in our sample are due purely to the larger number of PTAs used in the analysis. A related qualification to our results is the possible endogeneity of the PTA variable. Clearly, this concern is not unique to our estimates, but is shared by all gravity studies relying on the dummy variable approach of evaluating the effects of PTAs on trade in an ex post setting. On the one hand, it is very difficult to clearly isolate the effects of preferential liberalization from a number of other simultaneous shocks to the economy. On the other, some of the variables that help explain bilateral trade in a gravity setting may also be important determinants of whether the same pair of countries are likely to be in a PTA (for example, sharing a land border or a common language may facilitate forming a PTA, while very distant countries may be less likely to sign a preferential agreement). Finally, there is a question of causality - do countries trade more because they are in a PTA, or do countries form a PTA because they already trade a lot with each other? Many of the criticisms of the trade and growth literature by Rodriguez and Rodrik (2001) are likely to be applicable in this case as well. In light of these issues, gravity results in general and the estimates of this paper in particular should be interpreted with caution. Without implying causality, our results simply suggest that countries belonging to the same PTA tend to trade more than countries with similar income, geographical, and cultural characteristics outside the PTA.

Notice that the estimation approach of using a single PTA vector prevents us from determining whether the positive effect of PTAs on bilateral trade comes from additional trade that would not have existed in the absence of a preferential agreement (trade creation) or from substituting imports from the lowest-cost suppliers to the now cheaper products made in PTA member countries (trade diversion). There is no easy way to estimate trade creation and diversion in our framework, since the usual approach of using multiple PTA dummies per agreement does not apply when countries 
are allowed to participate in more than one PTA. ${ }^{38}$ This is by no means a shortcoming of our approach, since our objective is not to estimate the PTA welfare gains or the net impact of PTAs on their members' trade balance. However, this does imply an important qualifier: our discussion of increased bilateral trade due to PTAs does not distinguish where the increased trade is coming from, or whether it enhances or reduces the welfare of the member countries or the world.

Preferential imports. Revisiting the argument presented in the beginning of this section, we now turn to comparing the model of total PTA trade with the model of preferential trade, which is defined as trade flows in tariff lines with the MFN duty above 3 percent. With the exception of the definition of the dependent variable, the model specification and estimation approach are the same. The number of observations drops to 11,846 because the remaining countries trade with each other exclusively in the $0-3$ percent MFN duty band. The overall fit of the model remains good with less than a one percentage point decrease in the $R^{2}$ and the results are quite similar to the earlier specification. As before, the errors follow an approximately normal distribution, although formal skewness-kurtosis tests reject normality (see Appendix D). All estimated coefficients retain their significance levels from the baseline model, and, for the most part, their values are very close to the original estimates. The notable exceptions to the latter observation include the index of GDP similarity and, most importantly, the PTA dummy. A more formal way of evaluating coefficient stability across specifications is a Chow test, which for a linear regression with a conventionally estimated variance-covariance matrix is equivalent to performing a Wald test. Since the Chow test does not generalize to other methods of estimating the variance-covariance matrix (such as the Huber-White sandwich estimator), we perform a Wald test with a null hypothesis that the two sets of coefficient estimates in Table 5 are the same. The results, shown in Table 6 , largely confirm the qualitative observations above. ${ }^{39}$

\footnotetext{
${ }^{38}$ Consider the Frankel (1997) approach of using two PTA dummies: one for intra-bloc trade, and one for the bloc members' trade with third countries. Suppose we are interested in the effects of NAFTA on US imports. Under this framework, the first dummy will equal one when the US trades with Canada and Mexico, and zero otherwise. The second dummy will equal one when the US trades with countries other than its NAFTA partners. Now, allow the US to participate in the US-Chile FTA and construct the same set of dummy variables for this agreement. We now find that the NAFTA extra-bloc dummy and the US-Chile intra-bloc dummy are perfectly collinear for Chile's exports to the US. A similar argument can be applied to the three dummy variable approach of Soloaga and Winters (2001), where identification of intra- and extra-bloc effects becomes even more difficult.

${ }^{39}$ The Wald test shows that four coefficient values are significantly different across specifications: GDP similarity, distance, colonial links, and the PTA dummy. The same is true even if we control for differences in sample size by re-estimating the total imports model only for countries with a positive trade value in tariff lines above three
} 
Table 6: Wald test results

\begin{tabular}{lrr}
\hline \hline Variable & $\chi^{2}$ & $p$-value \\
\hline Ym & 0.117 & 0.733 \\
Yx & 0.551 & 0.458 \\
dGDPpc & 0.821 & 0.365 \\
GDPsim & 23.625 & 0.000 \\
dist & 6.997 & 0.008 \\
comlang & 0.044 & 0.834 \\
border & 0.037 & 0.847 \\
colony & 3.051 & 0.081 \\
PTA & 4.588 & 0.032 \\
\hline
\end{tabular}

The results of Table 5 and Table 6 indicate that the coefficient on the PTA dummy is significantly larger for preferential trade rather than total trade. This result is consistent with the expectations expressed in the beginning of this section and shows that the estimated effects of preferential liberalization on bilateral imports are diluted by the inclusion of low tariff lines where the margin of preference is close to zero. However, the magnitude of change in the PTA coefficient suggests that the extent of this dilution is much smaller than expected. Section 3.2 has shown that, using a 3 percent MFN threshold, trade in tariff lines where preferences are likely to matter is less than half of the total trade between PTA partners. If the only effect of PTAs is to liberalize trade in tariff lines above 3 percent MFN, the expected change in bilateral trade flows implied by the PTA coefficient should be at least twice as large in the preferential specification as in the total trade specification (since the change in the level of imports should be the same across specifications, but the denominator is more than two times larger when total imports are used as the dependent variable). Instead, we observe that the value of the PTA coefficient increases by just over 13 percent, and the implied semi-elasticity is 137 percent instead of 114 percent.

There are two potential explanations for this finding. On the one hand, it is possible that product exclusions, sensitive lists, phase-in periods, and implementation problems limit the domain of PTAs to a much smaller subset of trade than what is captured by our 3 percent threshold. In this case, our coefficient estimate continues to represent the diluted effect of preferential liberalization

percent MFN. In this case, the coefficients on GDP similarity and the PTA dummy are significantly different across specifications at the one percent level, while the coefficients on distance and colonial links are significantly different at two and five percent, respectively. 
and gives little indication of the true effect. On the other hand, PTAs may tend to create more trade than what would be expected from simple elimination of customs duties. This result could be driven by several reasons - for example, a plant's inputs could be imported in low or zero MFN duty lines whereas the output could be exported in tariff lines with significant preference margins. Alternatively, a factory established to take advantage of trade preferences may also be an efficient producer of goods in lower tariff lines, therefore creating additional trade. The time dimension can also be important - the current export production structure in some PTA members may have been established at the time of higher average tariffs. Thus, even though the recent rounds of multilateral or unilateral liberalization have eroded preference margins, the fixed costs of establishing production facilities have already been met and exports remain competitive even in the absence of significant tariff preferences. Finally, other PTA provisions such as standards harmonization, customs cooperation, or investment liberalization may lead to increased trade in some products even if the margin of tariff preference for them is insignificant. Overall, our finding of a relatively small change in the PTA coefficient across specifications is probably driven by both sets of effects. In the following section, we attempt to assess the relative importance of exclusions and phase-in periods on the trade impact of PTAs by adding controls for these provisions to our model.

\subsection{Application to exclusions and phase-in periods}

The starting point for our analysis is the model of preferential trade shown in Table 5 . To account for the importance of sensitive lists, exclusions, and phase-in periods, we re-estimate this model with two additional variables that reflect the presence of exclusions and the length of phase-in schedules and simulate the trade impact of liberalizing these provisions. As the data on exclusions and phase-in periods for all 163 PTAs in the sample are not available, we will rely on a smaller subset of PTAs for which we do have this information.

In order to compile the required data, we turn to the Member Liberalization Index (MLI) developed by Adams et al. (2003). The authors calculate the index for 18 PTAs of which either Australia or one or more of its major trading partners are a member. ${ }^{40}$ The aggregate MLI ranks each agree-

\footnotetext{
${ }^{40}$ These include the Andean Pact, EFTA, the EU, LAIA, MERCOSUR, NAFTA, SPARTECA, Australia-New
} 
ment on the scale of 0 to 1 , with 1 being the most liberal and 0 being the least. The MLI considers only the textual provisions of an RTA and is therefore a measure of the ambition of the agreement rather than the actual steps taken towards its implementation. The aggregate MLI is calculated by ranking 34 categories on a sliding scale between 0 and 1 and assigning varying weights to different categories. The categories cover four broad areas of the agreements under consideration-trade in agriculture, trade in manufactured goods, services, and a "general measures" category. We are particularly interested in four categories of the MLI - those that cover exclusions and phase-in periods for agricultural and manufactured goods - and combine them into two variables for estimation purposes.

The MLI phase-in category assigns the most liberal value (one) to a PTA that calls for all relevant tariff reductions to take place on the date of a PTA's entry into force or by January 1, 2001, whichever is later. Progressively lower scores are assigned to PTAs that have longer phase-in periods, and the lowest score (zero) is given to PTAs with no explicit tariff reduction schedules. The MLI choice of January 1, 2001, as the base period is fortunate since the majority of observations in our sample are for years 2000 and 2001. We combine the MLI scores for agricultural and manufactured goods into a single variable dyrs $=\left(1-\min \left(M L I_{\text {phase-in }}^{\text {agr }}, M L I_{\text {phase-in }}^{\text {mnf }}\right)\right)$. At its minimum value of zero, this variable implies that tariff reductions in both sectors are scheduled to be completed by the beginning of 2001 or on the PTA commencement date (if the agreement enters into force after January 1, 2001). The variable reaches its maximum value of one when phase-in schedules are not specified in at least one sector. Therefore, a lower value of the variable is indicative of a PTA with shorter phase-in schedules and we expect dyrs to carry a negative coefficient. By construction, the variable assigns lower scores to PTAs with balanced tariff reduction timelines and a given PTA can only do as well as its slowest-liberalizing sector. For PTAs for which we do not have the MLI data, this variable is set to zero which carries an implicit assumption that all tariff reduction provisions in these agreements were to be implemented by year-end 2000. Finally, dyrs is also zero for countries who are not members of a PTA, and is therefore implicitly interacted with the PTA dummy.

Zealand, EU-Switzerland, Chile-Colombia, Chile-Mexico, US-Israel, Australia-Papua New Guinea, Singapore-New Zealand, Chile-MERCOSUR, EU-Egypt, EU-Poland, and AFTA. Since the EU is treated as a single country in our model, we do not use the EU score. 
The MLI exclusion category assigns the score of one to a PTA that has no exclusion provisions, the score of one-half to a PTA that allows for variable tariffs in sensitive products, and a score of zero to a PTA that excludes certain products from liberalization. We combine the MLI exclusion scores in the agricultural and manufactured goods categories as follows: $\operatorname{dexc}=\left(e^{M L I_{\text {excl }}^{a g r}}+e^{M L I_{\text {excl }}^{m n f}}\right)$. This variable ranges from 2, meaning that a given PTA specifies exception lists in both sectors, to approximately 5.44, meaning that no exclusions are featured in either sector. Therefore, we expect the dexc variable to enter the estimated equation with a positive sign. The variable is set to zero for PTAs which do not have MLI data (again implying implicit interaction with the PTA dummy) as well as for countries not party to a PTA. Table 7 presents the results of adding these two variables to the estimated equation.

Table 7: Gravity model estimation results: preferential trade with exclusions and phase-in periods

\begin{tabular}{|c|c|c|}
\hline \multirow{2}{*}{$\begin{array}{l}\text { Dep. var. (ln) } \\
\text { Variable }\end{array}$} & \multicolumn{2}{|c|}{ Preferential imports } \\
\hline & Coefficient & Std. Err. \\
\hline Ym & $1.106^{* *}$ & 0.410 \\
\hline $\mathrm{Yx}$ & -0.163 & 0.258 \\
\hline dGDPpc & -0.011 & 0.020 \\
\hline GDPsim & $0.156^{* *}$ & 0.018 \\
\hline dist & $-1.339^{* *}$ & 0.036 \\
\hline comlang & $0.584^{* *}$ & 0.071 \\
\hline border & $0.237^{\dagger}$ & 0.132 \\
\hline colony & $0.634^{* *}$ & 0.155 \\
\hline PTA & $0.827^{* *}$ & 0.085 \\
\hline dexc & $0.188^{* *}$ & 0.053 \\
\hline dyrs & $-0.403^{*}$ & 0.181 \\
\hline $\mathrm{N}$ & \multicolumn{2}{|c|}{11846} \\
\hline $\mathrm{R}^{2}$ & \multicolumn{2}{|c|}{0.751} \\
\hline $\mathrm{F}_{(234,11611)}$ & \multicolumn{2}{|c|}{201.546} \\
\hline $\begin{array}{l}\text { Significance levels: } \\
\text { Note: Preferential } \\
\text { tariff lines above } 3\end{array}$ & $\begin{array}{l}\dagger 10 \% \\
\text { aports are define }\end{array}$ & $\begin{array}{l}* * 1 \% \\
\text { as impo }\end{array}$ \\
\hline
\end{tabular}

The results are very similar to the earlier preferential specification, with all common coefficients retaining their sign, significance, and value up to the first decimal place. Both models report an identical $R^{2}$, the $F$ statistics are nearly the same, and the residuals are similarly distributed. Both new variables, dexc and dyrs, are significant and carry the expected signs. However, a direct comparison of the magnitudes of the coefficients is misleading due to the different scale of the 
variables. Therefore, in order to assess the relative impact of each of the above on the dependent variable, we implement a simple simulation using the coefficient estimates from Table 7.

The object of the simulation is to calculate the effect that eliminating exclusions and delays in tariff reductions would be likely to have on trade flows in tariff lines above 3 percent MFN between members of the 17 PTAs for which we have MLI data. Although the number of PTAs in the simulation is small relative to the total number of PTAs considered in the regression model (163), trade flows between the simulation countries account for approximately 18.6 percent of world trade, which is more than half of all trade between PTA partners in our sample. This is due to the fact that the simulation covers most of the large PTAs in our sample (such as NAFTA, EFTA, and MERCOSUR). We estimate the effects of removing exclusions and phase-in periods by means of three simple simulations. First, we give every PTA with a positive dexc value the maximum score for this variable $(\approx 5.44)$, effectively eliminating exclusions and sensitive lists for the agreements that feature them. We then construct a second simulation by reducing the value of the dyrs variable to zero for any PTA that is scheduled to continue implementing tariff reductions beyond 2001, therefore eliminating phase-in periods for the agreements that have them. Finally, we implement a third simulation where we fully liberalize the exclusions and phase-in delays simultaneously to account for any potential non-linearities in the model. The results of these simulations are summarized in Table 8.

Table 8: Simulation results: removing exclusions and phase-in periods

\begin{tabular}{lrr}
\hline \hline & Trade in tariff lines above 3\% MFN (USD) & Percent Change \\
\hline Initial & $93,716,155$ & \\
Exclusions & $156,697,583$ & 67.2 \\
Years & $117,554,741$ & 25.4 \\
Both & $196,556,763$ & 109.7 \\
\hline
\end{tabular}

Source: Author's estimates.

The first column of Table 8 reports the average trade in tariff lines with the MFN duty above 3 percent between the members of the 17 PTAs for which we have data on exclusions and phase-in periods. The "initial" row contains the average predicted trade value $\left(\hat{x}_{i j}\right)$ for these countries, calculated using the coefficient estimates from Table 7. The next three rows show the average trade value following each of the above simulations, while the "percent change" column reports 
percentage changes from the initial (first row) values. The results show that eliminating exclusions and sensitive lists would increase preferential trade by 67 percent, while reducing phase-in delays would contribute to a 25 percent rise in the value of preferential trade. This suggests that, for the countries in our sample, exclusions represent a greater obstacle to trade than long tariff reduction schedules. Taken together, the liberalization of these two measures would more than double the value of trade in lines above 3 percent MFN between the sample countries, as shown in the bottom row of Table 8. Thus, the effects of the two variables are not strictly additive, although this is likely due to the fact that the set of PTAs for which we liberalize exclusions is not the same as the set for which we liberalize the phase-in periods. Overall, the results suggest that the impact of exclusions and phase-in periods on preferential trade is quite large, and lend support to the hypothesis that the subset of trade for which tariff preferences truly matter is significantly smaller than what is captured by the 3 percent MFN threshold.

The last part of section 4.1 suggested that product exclusions and other distortions may be one of the reasons behind the smaller than expected increase in the value of the PTA coefficient. Simulation results of Table 8 offer support for this contention by showing that liberalizing exclusion lists and phase-in delays can more than double the value of trade in tariff lines above 3 percent MFN. At the same time, these simulation results need to be heavily qualified for several reasons. First, the simulations do not cover all trade between PTA members in our sample. Second, the MLI scores are somewhat arbitrary, and, more importantly, only rank the relevant PTA provisions "on paper," with no regard to how well these provisions are implemented in reality. This means that the MLI scores may not accurately reflect the actual status of the variables they are supposed to measure, and any results obtained by applying the MLI values to observed trade flows need to be treated with caution. A related problem is that the results can be quite sensitive to the choice of countries and PTAs. Therefore, including PTAs which are very ambitious on paper but whose members trade relatively little with each other will have a large downward effect on the simulated gains from liberalization. ${ }^{41}$ Calculating the simulation results as import-weighted averages will not

\footnotetext{
${ }^{41}$ To see this more clearly, consider a PTA that calls for all tariff reductions to commence by the end of 2001 and the main texts of which do not exclude any products from liberalization (one example of such agreement is Common Market of Eastern and Southern Africa (COMESA), which is not considered in our analysis because we do not have trade and tariff data for any COMESA importers). Such PTA would receive the highest score for the exclusions variable and the lowest score for the phase-in variable (the "best practice" scores) and would therefore experience no
} 
address this issue because the results will then be determined by the MLI scores of two or three of the largest agreements; if these PTAs include sensitive lists and longer tariff reduction schedules, this approach will bias the results upward. Finally, the variables used in the simulations represent only one way of combining the relevant MLI categories into explanatory variables. Thus, alternative definitions of dexc and dyrs variables may have an impact on the results. For there reasons, it is difficult to conclude that product exclusions and length of tariff reduction schedules alone are responsible for the smaller than expected increase in the PTA dummy coefficient. Although the liberalization of these distortions is likely to yield a large increase in the value of preferential trade, PTAs may still affect trade in lines where the margin of tariff preference is negligible.

\subsection{Alternative specifications of the PTA variable}

One of the main advantages of the PTA sample used in this study is its breadth of coverage - we can distinguish between PTAs that have been notified to the WTO and those that have not, PTAs with two or more members, and North-South vs. South-South vs. North-North agreements. However, up to this point our econometric estimates considered only the aggregate effects of all PTAs, without taking advantage of the richness of the data. Using the preferential model of Table 5 as a baseline, this section will investigate whether meaningful insights can be gained from disaggregating our sample into various types of PTAs. The estimates are summarized in Table 9, which reports regression results from four alternative specifications of the PTA variable. For convenience and ease of comparison with the baseline estimates, column (1) repeats the preferential results from Table 5. In each subsequent model, the number of observations remains the same as the original specification, the $F$ statistic shows that the coefficients are significant as a group, and the $R^{2}$ remains unchanged at the two decimal level. Therefore, the estimated coefficients can be readily compared across the alternative specifications.

Column (2) of Table 9 shows the results of estimating a model with two PTA dummy variablesone for agreements notified to the WTO, PTAnt, and one for agreements that have not been notified,

trade gains in the simulation. If we also assume that the members of this PTA are small countries (again consider the COMESA example), their intra-PTA trade is going to be small compared to intra-PTA trade of large agreements like NAFTA and MERCOSUR. Following the simulated removal of exclusions and phase-in periods, this already small intra-PTA trade value will remain unchanged and will considerably lower the overall average, therefore reducing the simulated gains. 
Table 9: Alternative specification estimation results: preferential imports

\begin{tabular}{|c|c|c|c|c|c|}
\hline \multirow[b]{2}{*}{ Variable } & $\overline{(1)}$ & $\overline{(2)}$ & (3) & $(4)$ & $\overline{(5)}$ \\
\hline & \multicolumn{5}{|c|}{ Coefficient } \\
\hline \multirow[t]{2}{*}{$\mathrm{Ym}$} & $1.104^{* *}$ & $1.100^{* *}$ & $1.104^{* *}$ & $1.114^{* *}$ & $1.104^{* *}$ \\
\hline & $(0.411)$ & $(0.411)$ & $(0.411)$ & $(0.410)$ & $(0.411)$ \\
\hline \multirow[t]{2}{*}{$Y x$} & -0.168 & -0.168 & -0.168 & -0.142 & -0.168 \\
\hline & $(0.258)$ & $(0.258)$ & $(0.258)$ & $(0.259)$ & $(0.258)$ \\
\hline \multirow[t]{2}{*}{ dGDPpc } & -0.011 & -0.014 & -0.011 & -0.009 & -0.014 \\
\hline & $(0.020)$ & $(0.020)$ & $(0.020)$ & $(0.021)$ & $(0.020)$ \\
\hline \multirow[t]{2}{*}{ GDPsim } & $0.154^{* *}$ & $0.155^{* *}$ & $0.154^{* *}$ & $0.152^{* *}$ & $0.158^{* *}$ \\
\hline & $(0.018)$ & $(0.018)$ & $(0.018)$ & $(0.018)$ & $(0.018)$ \\
\hline \multirow[t]{2}{*}{ dist } & $-1.341^{* *}$ & $-1.343^{* *}$ & $-1.341^{* *}$ & $-1.311^{* *}$ & $-1.362^{* *}$ \\
\hline & $(0.036)$ & $(0.036)$ & $(0.036)$ & $(0.036)$ & $(0.036)$ \\
\hline \multirow[t]{2}{*}{ comlang } & $0.597^{* *}$ & $0.595^{* *}$ & $0.597^{* *}$ & $0.546^{* *}$ & $0.604^{* *}$ \\
\hline & $(0.069)$ & $(0.069)$ & $(0.070)$ & $(0.070)$ & $(0.069)$ \\
\hline \multirow[t]{2}{*}{ border } & $0.288^{*}$ & $0.259^{*}$ & $0.290^{*}$ & $0.302^{*}$ & $0.277^{*}$ \\
\hline & $(0.130)$ & $(0.131)$ & $(0.130)$ & $(0.126)$ & $(0.131)$ \\
\hline \multirow[t]{2}{*}{ colony } & $0.642^{* *}$ & $0.636^{* *}$ & $0.641^{* *}$ & $0.562^{* *}$ & $0.638^{* *}$ \\
\hline & $(0.155)$ & $(0.156)$ & $(0.155)$ & $(0.153)$ & $(0.156)$ \\
\hline \multirow[t]{2}{*}{ PTA } & $0.864^{* *}$ & & & & \\
\hline & $(0.080)$ & & & & \\
\hline \multirow[t]{2}{*}{ PTAnt } & & $0.988^{* *}$ & & & \\
\hline & & $(0.086)$ & & & \\
\hline \multirow[t]{2}{*}{ PTAun } & & $0.667^{* *}$ & & & \\
\hline & & $(0.128)$ & & & \\
\hline \multirow[t]{2}{*}{ PTAbl } & & & $0.846^{* *}$ & & \\
\hline & & & $(0.116)$ & & \\
\hline \multirow[t]{2}{*}{ PTApl } & & & $0.870^{* *}$ & & \\
\hline & & & $(0.089)$ & & \\
\hline \multirow[t]{2}{*}{ PTAnn } & & & & -0.396 & \\
\hline & & & & $(0.270)$ & \\
\hline \multirow[t]{2}{*}{ PTAns } & & & & $0.233^{*}$ & \\
\hline & & & & $(0.098)$ & \\
\hline \multirow[t]{2}{*}{ PTAss } & & & & $1.227^{* *}$ & \\
\hline & & & & $(0.100)$ & \\
\hline \multirow[t]{2}{*}{ PTAmx } & & & & & $0.016^{* *}$ \\
\hline & & & & & $(0.002)$ \\
\hline $\mathrm{N}$ & 11846 & 11846 & 11846 & 11846 & 11846 \\
\hline $\mathrm{R}^{2}$ & 0.751 & 0.751 & 0.751 & 0.752 & 0.751 \\
\hline $\mathrm{F}$ & 203.591 & 201.889 & 202.925 & 210.758 & 201.967 \\
\hline
\end{tabular}


PTAun. The estimated coefficients on other model variables retain their significance levels from the baseline specification, and their values are very similar to column (1). Both of the PTA variables are significant at the one percent level; while participating in the WTO-notified agreement tends to increase trade between members by almost 169 percent, participation in a unnotified agreement appears to result in a 95 percent increase in trade. A Wald test shows that the difference between the two semi-elasticities is statistically significant $\left(F_{(1,11612)}=5.39, p=0.02\right)$, rejecting the null hypothesis that the estimated coefficients are the same at the 2 percent level. This suggests that while both types of PTAs have significant positive effects on trade among their members, the agreements that have not been notified to the WTO have an impact that is one-third weaker than the notified PTAs. The result for the unnotified PTAs is particularly interesting, since, as we have seen in section 3.2, trade between members of these PTAs represents a very small fraction of world trade. Thus, although these agreements do not cover much trade (at least in volume terms), they appear to be successful at stimulating significant additional trade between their members, albeit to a lesser extent the WTO-notified PTAs.

Column (3) of Table 9 shows the results of classifying PTAs into bilateral agreements, PTAbl, or agreements with more than two members, PTApl. As before, the values and significance levels of other model coefficients change only marginally. Both of the PTA variables are significant at the 1 percent level and their values are very similar. This suggests that both bilateral and plurilateral PTAs have similar effects on intra-PTA trade, although the magnitude of the latter is slightly larger. However, the difference is not statistically significant, as confirmed by a Wald test $\left(F_{(1,11612)}=0.03, p=0.85\right)$. The values are also very close to the baseline specification, where all PTA dummies are combined into a single vector. Therefore, we find no evidence that the number of PTA members has a significant effect on intra-PTA trade, at least when bilateral agreements are constrasted with those with more than two members.

Column (4) of Table 9 separates the sample PTAs into North-North, PTAnn, North-South, PTAns, or South-South agreements, PTAss. The estimated coefficients show that PTAs between high income partners do not appear to have a significant effect on intra-PTA trade, while both North-South and South-South agreements have a positive impact. North-South PTAs appear to increase trade by just over 26 percent, while the estimated increase in trade from South-South 
agreements is 241 percent. Wald tests confirm that the differences between all three coefficients are systematic and significant at the 1 percent level $\left(F_{(2,11611)}=39.16, p=0.00\right)$. Although these results suggest that South-South PTAs are much more effective at stimulating intra-PTA trade than the North-South agreements, we do not know whether the additional trade is generated by trade creation or trade diversion effect. However, given the large difference in the estimated coefficients, our results provide at least circumstancial evidence against the hypothesis that North-South PTAs tend to be trade-creating and have larger effects on imports than mainly trade-diverting SouthSouth PTAs. ${ }^{42}$

There are several potential reasons for why we find no significant trade effects in North-North PTAs and why the effects of South-South PTAs dominate those of the North-South agreements. First, high income countries generally trade a lot with each other, and the volume of North-South trade is much larger than South-South trade. Therefore, South-South PTAs may have a greater impact on intra-bloc trade at the margin. ${ }^{43}$ Second, the effects of North-North agreements in our sample may be significantly muted by treating the EU-15 as a single country. This could also affect our estimates of trade gains from North-South PTAs, since many countries could trade a lot with some individual EU members and relatively little with others. Third, since the average level of external protection in the developing countries tends to be much higher than in the North, PTAs involving low and middle income countries should produce larger trade gains as a result of the removal of these barriers. In addition, South-South PTAs, although generally less wellimplemented than the North-South agreements, tend to have less restrictive ROO as well as fewer product exclusions. Finally, at least on paper, South-South PTAs are more ambitious with regards to many "deep integration" issues, which can have a large effect on trade.

In the last column of Table 9, we consider potential interactions between the PTA dummy variable and the incomes of PTA partners. The new variable PTAmx $=P T A *(Y m+Y x)$ is positive and significant at the 1 percent level, which implies that the intra-PTA trade creation effect is increasing in income. Since both the independent and the dependent variable are continuous,

\footnotetext{
${ }^{42}$ See, for example, Schiff and Winters (2003) and World Bank (2000), who build a theoretical argument (and provide policy advice based on it) that South-South PTAs, particularly between small countries, generate little to no trade creation and simply divert imports away from the most efficient suppliers.

${ }^{43}$ In other words, the gravity model will estimate a larger coefficient for a larger percentage change in the dependent variable, even if that change is from a very low base and therefore small in absolute terms.
} 
the PTAmx coefficient should be interpreted as an elasticity, and its value implies that preferential trade tends to increase by 0.16 percent for every 10 percent increase in the combined (multiplied) incomes of the PTA partners. ${ }^{44}$ This finding offers a potential explanation for the values of the PTA dummy coefficients estimated in this paper, which we noted are much lower than estimates reported in previous studies. Since the trade effects are increasing in income and previous estimates have been mostly confined to PTAs between large partners, it may not be surprising that the estimated magnitudes in the earlier studies were larger. In contrast, our sample includes many PTAs between smaller trading partners, and the estimated coefficients are consequently much lower.

It is important to acknowledge that while the above discussion sheds new evidence on many aspects of preferential trade, many other issues remain outside the scope of our analysis. For example, we do not formally estimate the trade creation and trade diversion effects, and therefore do not know whether the positive association between PTAs and higher bilateral trade is driven by the former or the latter. One implication of this is that we cannot conclude that South-South agreements are more trade-creating or have greater overall effects on trade than North-South agreements. Although the point estimate of the former is much larger than the latter, it could be the case that increased intra-bloc South-South trade is generated entirely through trade diversion, while North-South PTAs create trade in products that would have otherwise been produced domestically. Similarly, our aggregate results offer no insights into the sectoral distribution of the new trade flows, or the identities of the gainers and losers from trade. Thus, our results focus on only a subset of the important PTA issues, and should be interpreted accordingly.

\section{Conclusion}

Preferential trade agreements have been growing at a pace that has already resulted in PTAs outnumbering WTO members and shows no signs of slowing down. We compile an extensive database of PTAs in force, which shows that by the middle of 2004, 229 PTAs were in effect between 174 countries with an average country having signed at least five agreements. It would thus appear that preferential trade should account for a large share of global trade, but instead,

\footnotetext{
${ }^{44}$ Recall that $Y m$ and $Y x$ are natural logarithms of importer and exporter incomes, respectively. Therefore, the term $(Y m+Y x)$ is multiplicative in levels.
} 
trade flows between PTA members amounted to just under one-third of the world total in 2000-02. However, even this low percentage is misleading because not all trade flows between PTA members can be considered truly preferential. Unilateral and multilateral liberalization have resulted in a growing number of tariff lines with zero or very low MFN duties, in which the margin of preference for PTA members is negligible and the preferences are likely to remain unutilized. In fact, as long as the MFN tariff is at or below the costs of complying with the relevant ROO, exporters have no incentive to take advantage of preferences and therefore trade flows in these products cannot be considered preferential. The literature on ROO compliance costs estimates them to range between 3 and 6 percent of shipment value and, using these figures, we calculate the share of preferential trade in world total at 15.4 to 11.4 percent, respectively. This implies that trade in tariff lines where preferences are likely to matter amounts to less than one-half of all trade between PTA partners, and between one-tenth and one-sixth of total world trade. On the regional level, most preferential trade is undertaken by Eastern European and Latin American countries, both within their respective regions and with high income partners. On the other hand, East Asian countries have very low preferential trade shares for South-South and North-South trade alike.

Our paper offers an alternative to the common practice in gravity literature - estimating the effects of PTAs on trade by specifying the dependent variable as total imports or exports. Our results show that total trade is a very poor proxy for preferential trade, implying that the traditional approach for estimating the intra-bloc trade effects of preferential agreements is not correct. In addition, existing gravity studies usually scale-up their estimates of PTA trade effects from point estimates of individual PTAs, which may introduce an upward bias if the PTAs selected are large and more likely to affect trade. We construct an empirical gravity model that addresses both of these concerns by including all known PTAs in the analysis and creating an alternative dependent variable that is limited to preferential trade, conservatively defined as a set of trade flows in tariff lines with a MFN duty rate above 3 percent. Using total imports as the dependent variable, our baseline model shows that PTAs are associated with a 114 percent increase in intra-bloc trade. This effect is significantly smaller than individual agreement estimates from the literature, supporting the hypothesis that scaling up PTA point estimates is a biased approach to calculating the effects of preferential liberalization at the global level. 
Our second specification switches to using preferential imports as the dependent variable and finds that while the coefficients on most other control variables are insignificantly different across the two models, the PTA coefficient is 13 percent higher when the dependent variable is limited to trade in tariff lines with a duty rate above 3 percent MFN. This finding supports the hypothesis that including trade in low tariff lines in the dependent variable dilutes the estimates of the effects of PTA on trade. On the other hand, the implied semi-elasticity of trade with respect to preferential liberalization rises from 114 percent to 137 percent-significantly less than the two-fold increase suggested by our calculations of the share of preferential trade in the world total. There are two possible reasons for this result: first, product sensitive lists, long tariff reduction schedules, and implementation problems can combine to reduce the scope of preferential trade far beyond the 3 percent MFN threshold; and second, due to a variety of factors, PTAs may promote trade even in tariff lines in which the margin of tariff preference is insignificant. We investigate this further by adding explicit controls for exclusions and phase-in periods to our gravity model, and find that both factors have significant negative impacts on preferential trade. In addition, our numerical simulations using the model coefficient estimates suggest that removing exclusions and immediately implementing all tariff reduction provisions can more than double preferential trade. However, both the original estimates and the simulation results are based on a rather small subset of PTAs and can be quite sensitive to the choice of agreements, member countries, the exact definitions of control variables, and the way simulations are implemented. Therefore, these findings are largely illustrative and should not be interpreted as conclusive proof that PTAs affect trade only in tariff lines above 3 percent MFN.

Our detailed database of preferential agreements and trade flows allows us to test whether certain sub-groups of PTAs have varying effects on preferential trade. We find that PTAs that have been notified to the WTO have trade effects that are 70 percent larger than the agreements that have not been notified, although both types of PTAs have significant positive effects on preferential trade at the margin. On the other hand, the effects of bilateral PTAs vs. agreements with more than two members are insignificantly different from each other. We also find that North-North agreements do not significantly affect intra-bloc trade, while both North-South and South-South PTAs are associated with increased intra-bloc trade. Furthermore, the effects of South-South 
agreements are almost ten times greater than their North-South counterparts. Finally, we find that the positive relationship between PTAs and greater bilateral trade is increasing in income, offering a potential explanation for the lower estimates of the trade effects of all PTAs when contrasted with point estimates of large individual agreements in the previous literature.

A major implication of these findings is that while total trade is a very poor proxy for preferential trade (as shown in the first half of the paper), the loss in the PTA coefficient precision from estimating the effects on the former rather than the on the latter is much more mild. Therefore, unless one is interested in particular aspects of preferential trade (e.g. the effects of exclusions), using total trade may provide a reasonable approximation without the burden of collecting detailed data at the tariff line level. At the same time, a researcher must be aware that estimating the effects of PTAs on total imports will lead to biased estimates and while the average discrepancy for all PTAs is not very large, individual agreement biases can be much more severe.

The estimates of preferential trade in the first part of this paper present a puzzling policy question: if the share of global trade covered by PTAs is quite low due to widening multilateral and unilateral liberalization, why is so much political capital invested in new PTA negotiations? Our gravity results provide some answers by showing that PTAs have significant positive effects on preferential trade at the margin, and that large gains can be expected from liberalization of exclusions and phase-in periods. On the other hand, it may be the case that PTAs are associated with increased trade even in tariff lines in which tariff preferences are unlikely to matter. In addition, countries could seek to enter new PTAs or expand membership in existing ones for a variety of reasons beyond pure market access, including gaining security of said market access, dissatisfaction with the slow progress of multilateral negotiations, a chance to lock in domestic reforms, various political reasons, or simply policy fads and excessive or unrealistic expectations of the parties. It could also be that countries pursue PTAs to gain a perceived advantage, albeit slight and temporary, over their competitors, or that the negotiation of concessions in trade is a necessary precursor to entering into "deep integration" agreements, which cover such issues as trade in services, investment, and labor mobility. The investment motivation could be particularly important, since FDI can be an important vehicle of knowledge and technology spillovers, and therefore serve as a catalyst for growth, create new industries, and raise overall productivity. In fact, the expectation of increased 
FDI has been often mentioned by policymakers as a primary motivation behind the pursuit of new PTAs. Overall, it is difficult to identify a singular motivation for the continued pursuit of preferential trade agreements, which is most likely fueled by some combination of all reasons stated in this paragraph. However, as multilateral and unilateral liberalization continue to erode preference margins, the tariff reduction motive is likely to become a less important part of the story. 


\section{A Abbreviations and definitions}

Table 10: Regional abbreviations and country membership

\begin{tabular}{|c|c|c|c|}
\hline $\begin{array}{l}\text { LAC } \\
\text { Latin America, Caribbean }\end{array}$ & $\begin{array}{l}\text { EAP } \\
\text { East Asia, Pacific }\end{array}$ & $\begin{array}{l}\text { ECA } \\
\text { Europe, Central Asia }\end{array}$ & $\begin{array}{l}\text { SSA } \\
\text { Sub-Saharan Africa }\end{array}$ \\
\hline Antigua-Barbuda & American Samoa & Albania & Angola \\
\hline Argentina & Brunei & Andorra & Benin \\
\hline Aruba & Cambodia & Armenia & Botswana \\
\hline Bahamas & China & Azerbaijan & Burkina Faso \\
\hline Barbados & Fiji & Belarus & Burundi \\
\hline Belize & French Polynesia & Bosnia-Herzegovina & Cameroon \\
\hline Bolivia & Guam & Bulgaria & Cape Verde \\
\hline Brazil & Hong Kong & Channel Islands & Central African Republic \\
\hline Cayman Islands & Indonesia & Croatia & Chad \\
\hline Chile & Kiribati & Cyprus & Comoros \\
\hline Colombia & Korea, Dem. Rep. & Czech Republic & Congo, Dem. Rep. \\
\hline Costa Rica & Lao PDR & Estonia & Congo, Rep. \\
\hline Cuba & Macao & Georgia & Cote d'Ivoire \\
\hline Dominica & Malaysia & Greenland & Equatorial Guinea \\
\hline Dominican Republic & Marshall Islands & Hungary & Eritrea \\
\hline Ecuador & Micronesia & Isle of Man & Ethiopia \\
\hline El Salvador & Mongolia & Kazakhstan & Gabon \\
\hline Grenada & Myanmar & Kyrgyz Republic & Gambia, The \\
\hline Guatemala & N. Mariana Islands & Latvia & Ghana \\
\hline Guyana & New Caledonia & Lithuania & Guinea \\
\hline Haiti & Palau & Macedonia, FYR & Guinea-Bissau \\
\hline Honduras & Papua New Guinea & Moldova & Kenya \\
\hline Jamaica & Philippines & Monaco & Lesotho \\
\hline Mexico & Samoa & Poland & Liberia \\
\hline Netherlands Antilles & Singapore & Romania & Madagascar \\
\hline Nicaragua & Solomon Islands & Russian Federation & Malawi \\
\hline Panama & Thailand & San Marino & Mali \\
\hline Paraguay & Timor-Leste & Serbia-Montenegro & Mauritania \\
\hline Peru & Tonga & Slovak Republic & Mauritius \\
\hline Puerto Rico & Taiwan & Slovenia & Mayotte \\
\hline St. Kitts-Nevis & Vanuatu & Tajikistan & Mozambique \\
\hline St. Lucia & Vietnam & Turkey & Namibia \\
\hline St. Vincent-Grenadines & & Turkmenistan & Niger \\
\hline Suriname & & Ukraine & Nigeria \\
\hline Trinidad and Tobago & & Uzbekistan & Rwanda \\
\hline Uruguay & & Faeroe Islands & Sao Tome-Principe \\
\hline Venezuela, RB & & & Senegal \\
\hline Virgin Islands (U.S.) & & & Seychelles \\
\hline \multirow[t]{10}{*}{ Bermuda } & & & Sierra Leone \\
\hline & & & Somalia \\
\hline & & & South Africa \\
\hline & & & Sudan \\
\hline & & & Swaziland \\
\hline & & & Tanzania \\
\hline & & & Togo \\
\hline & & & Uganda \\
\hline & & & Zambia \\
\hline & & & Zimbabwe \\
\hline SAS & \multicolumn{2}{|c|}{ MNA } & NORTH \\
\hline South Asia & Middle East & North Africa & High income \\
\hline Afghanistan & Bahrain & Algeria & Australia \\
\hline Bangladesh & Iran & Djibouti & Canada \\
\hline Bhutan & Iraq & Egypt & Switzerland \\
\hline India & Israel & Libya & EU-15 \\
\hline Maldives & Jordan & Malta & Iceland \\
\hline Nepal & Kuwait & Morocco & Japan \\
\hline Pakistan & Lebanon & Tunisia & Korea, Rep. \\
\hline Sri Lanka & Oman & & Liechtenstein \\
\hline & Qatar & & Norway \\
\hline & Saudi Arabia & & New Zealand \\
\hline & Syrian Arab Republic & & United States \\
\hline & United Arab Emirates & & \\
\hline & West Bank-Gaza & & \\
\hline & Yemen & & \\
\hline
\end{tabular}




\section{B Theoretical foundations of the gravity equation}

This appendix shows the detailed derivation of the theoretical gravity equation. The discussion here will mostly follow Anderson and van Wincoop (2003) and Anderson and van Wincoop (2004) in obtaining the equation under monopolistic competition, or product differentiation by region of origin. We begin with a standard CES utility function for country $j$

$$
U_{j}=\left(\sum_{i}^{N} \alpha_{i}^{\rho} c_{i j}^{\rho}\right)^{\frac{1}{\rho}}
$$

which is maximized by consumers subject to

$$
y_{j}=\sum_{i}^{N} p_{i j} c_{i j}
$$

where

$\alpha_{i} \quad$ is the CES share parameter

$c_{i j} \quad$ is the consumption of goods from $i$ by consumers in $j$

$y_{j} \quad$ is the nominal income of consumers in $j$

$p_{i j} \quad$ is the c.i.f. price of goods from $i$ in region $j$

The first order condition with respect to $c_{i j}$ is

$$
\alpha_{i}^{\rho}\left(\frac{U_{j}}{c_{i j}}\right)^{1-\rho}-\lambda p_{i}=0
$$

and the solution to the maximization problem becomes

$$
c_{i j}=a_{i}^{1-\sigma}\left(\frac{P_{j}}{p_{i j}}\right)^{\sigma} \frac{y_{j}}{P_{j}}
$$

In the solution, we introduce a new parameter $a_{i}=\alpha_{i}^{-1}$, rely on the standard definition of the 
elasticity of substitution $\sigma=\frac{1}{1-\rho}$, and specify the aggregate price index as

$$
P_{j}=\left(\sum_{i}^{N}\left(a_{i} p_{i j}\right)^{1-\sigma}\right)^{\frac{1}{1-\sigma}}
$$

Now, assume that prices differ between locations due to transportation costs, and define $p_{i}$ as the exporter FOB price and $t_{i j} \geq 1$ as the transportation cost factor between $i$ and $j$, so that $p_{i j}=t_{i j} p_{i}$. This is the "iceberg" costs model of transportation costs, where a fraction $\left(t_{i j}-1\right)$ of each unit shipped "melts" along the way. This formulation implies that the CIF value of exports from $i$ to $j$ is composed of two parts: value of production at the origin (the FOB value) and the shipment cost. The total income of an exporting region $i$ under market clearance is therefore

$$
y_{i}=\sum_{j}^{N} x_{i j}=\sum_{j}^{N} p_{i j} c_{i j}=\sum_{j}^{N}\left(p_{i} c_{i j}+\left(t_{i j}-1\right) p_{i} c_{i j}\right)=\sum_{j}^{N} p_{i} t_{i j} c_{i j}
$$

where $x_{i j}$ is the exports from $i$ to $j$ valued at importer's prices, such that

$$
x_{i j}=p_{i} t_{i j} c_{i j}
$$

Inserting equation (7) into (10) yields the solution for bilateral exports

$$
x_{i j}=\left(\frac{a_{i} p_{i} t_{i j}}{P_{j}}\right)^{1-\sigma} y_{j}
$$

We can now re-write the market-clearing condition in the first part of equation (9) as

$$
y_{i}=\sum_{j}^{N} x_{i j}=\sum_{j}^{N} y_{j}\left(\frac{a_{i} p_{i} t_{i j}}{P_{j}}\right)^{1-\sigma}=\left(a_{i} p_{i}\right)^{1-\sigma} \sum_{j}^{N} y_{j}\left(\frac{t_{i j}}{P_{j}}\right)^{1-\sigma}
$$

In order to derive the gravity equation, we will use equation (12) to solve for the scaled prices $a_{i} p_{i}$ and insert the solution into equation (11). Re-arranging terms in equation (12), we obtain:

$$
\left(a_{i} p_{i}\right)^{1-\sigma}=y_{i}\left(\sum_{j}^{N} y_{j}\left(\frac{t_{i j}}{P_{j}}\right)^{1-\sigma}\right)^{-1}
$$


Denote world income $y_{w}=\sum_{j}^{N} y_{j}$ and define a price index $\Pi_{i}$ such that

$$
\Pi_{i}=\left(\sum_{j}^{N} \frac{y_{j}}{y_{w}}\left(\frac{t_{i j}}{P_{j}}\right)^{1-\sigma}\right)^{\frac{1}{1-\sigma}}
$$

Re-arrange terms to obtain

$$
\sum_{j}^{N} y_{j}\left(\frac{t_{i j}}{P_{j}}\right)^{1-\sigma}=y_{w} \Pi_{i}^{1-\sigma}
$$

and insert the result into equation (13)

$$
\left(a_{i} p_{i}\right)^{1-\sigma}=y_{i}\left(\Pi_{i}^{1-\sigma} y_{w}\right)^{-1}=\frac{y_{i}}{y_{w}}\left(\frac{1}{\Pi_{i}}\right)^{1-\sigma}
$$

We can now insert the implicit solution of equation (16) into equation (11)

$$
x_{i j}=\frac{y_{i} y_{j}}{y_{w}}\left(\frac{t_{i j}}{\Pi_{i} P_{j}}\right)^{1-\sigma}
$$

Notice that the price index in equation (8) can be re-written as

$$
P_{j}=\left(\sum_{i}^{N} \frac{y_{i}}{y_{w}}\left(\frac{t_{i j}}{\Pi_{i}}\right)^{1-\sigma}\right)^{\frac{1}{1-\sigma}}
$$

Assuming that transportation costs are symmetric $\left(t_{i j}=t_{j i}\right)$ or, alternatively, allowing $t_{i j}=t_{j i}$ to represent the average of transportation costs in both directions, leads to a simplification $\Pi_{i}=P_{i}$. Therefore, we can re-write equation (18) as

$$
P_{j}=\left(\sum_{i}^{N} \frac{y_{i}}{y_{w}}\left(\frac{t_{i j}}{P_{i}}\right)^{1-\sigma}\right)^{\frac{1}{1-\sigma}}
$$

which gives us the gravity equation

$$
x_{i j}=\frac{y_{i} y_{j}}{y_{w}}\left(\frac{t_{i j}}{P_{i} P_{j}}\right)^{1-\sigma}
$$

Note that the gravity equation (20) is a generalization of a multiple product categories model, where 
$e_{i}^{m}$ represents region $i$ 's expenditure on product class $m$ and $y_{i}^{m}$ represents the region's output of that product. The gravity equation with $M$ product classes is

$$
x_{i j}^{m}=\frac{y_{i}^{m} e_{j}^{m}}{y_{w}^{m}}\left(\frac{t_{i j}^{m}}{P_{i}^{m} P_{j}^{m}}\right)^{1-\sigma_{m}}
$$

with the price indices defined as

$$
P_{j}^{m}=\left(\sum_{i}^{N} \frac{e_{i}^{m}}{y_{w}^{m}}\left(\frac{t_{i j}^{m}}{P_{i}^{m}}\right)^{1-\sigma_{m}}\right)^{\frac{1}{1-\sigma_{m}}}
$$

The final step in arriving at an empirically testable version of the gravity equation is to specify a relationship between the unobservable trade cost factor $t_{i j}$ and distance between trading partners $i$ and $j$. Assume that trade costs are proportional to distance so that

$$
t_{i j}=\left(d_{i j}\right)^{\rho_{i j}} \prod_{k}^{K} z_{i j}^{k}
$$

where $d_{i j}$ is the bilateral distance and the vector $\mathbf{z}_{\mathbf{i j}}$ is a set of parameters controlling for all other factors that may affect trade costs between $i$ and $j$. Substituting equation (23) into (20), writing the latter in natural logarithms, and expressing world income as a constant $m=-\ln y_{w}$, we obtain the final version of the gravity equation

$$
\ln x_{i j}=m+\ln y_{i}+\ln y_{j}+\rho_{i j}(1-\sigma) \ln d_{i j}+\rho_{i j}(1-\sigma) \sum_{k=1}^{K} \ln z_{i j}^{k}-(1-\sigma) \ln P_{i}-(1-\sigma) \ln P_{j}
$$




\section{Trade between PTA partners, regional detail}

Table 11: Intra-PTA imports as shares of total imports, in percent

\begin{tabular}{|c|c|c|c|c|c|c|c|c|}
\hline $\begin{array}{l}\text { Importer } \\
\text { Exporter }\end{array}$ & EAP & ECA & LAC & MNA & SAS & SSA & North & World \\
\hline \multicolumn{9}{|c|}{ Total trade between PTA partners } \\
\hline EAP & 11.9 & 0.2 & 29.4 & & 75.4 & & 6.3 & 9.1 \\
\hline ECA & 0.2 & 48.3 & 7.9 & & 4.5 & & 59.7 & 52.9 \\
\hline LAC & 9.1 & 15.8 & 94.4 & & 93.2 & & 53.4 & 57.9 \\
\hline MNA & 7.2 & 26.3 & 61.1 & 90.4 & 25.8 & 1.7 & 28.3 & 25.9 \\
\hline SAS & 42.1 & 8.8 & 93.4 & & 98.4 & & 4.6 & 15.1 \\
\hline SSA & 0.6 & & 51.9 & 36.6 & 15.3 & 83.1 & 20.2 & 20.3 \\
\hline North & 8.9 & 83.9 & 61.0 & 50.0 & 5.9 & 49.3 & 35.4 & 36.6 \\
\hline World & 10.0 & 68.3 & 64.1 & 46.5 & 29.1 & 37.3 & 31.5 & 32.1 \\
\hline \multicolumn{9}{|c|}{ Trade between PTA partners in tariff lines above 0\% MFN } \\
\hline EAP & 1.6 & 0.1 & 25.8 & & 65.7 & & 4.1 & 4.3 \\
\hline ECA & 0.1 & 38.8 & 7.3 & & 4.5 & & 46.6 & 41.4 \\
\hline LAC & 2.7 & 10.8 & 87.6 & & 92.6 & & 36.8 & 43.4 \\
\hline MNA & 2.5 & 11.6 & 38.9 & 83.3 & 20.1 & 1.5 & 15.2 & 14.0 \\
\hline SAS & 21.6 & 6.0 & 90.8 & & 77.7 & & 4.6 & 11.3 \\
\hline SSA & 0.1 & & 45.8 & 31.7 & 15.2 & 24.7 & 8.0 & 9.0 \\
\hline North & 7.0 & 69.5 & 55.7 & 43.0 & 4.6 & 15.9 & 19.6 & 24.3 \\
\hline World & 4.6 & 55.9 & 58.5 & 40.9 & 25.0 & 12.0 & 19.1 & 21.5 \\
\hline \multicolumn{9}{|c|}{ Trade between PTA partners in tariff lines above $3 \% \mathrm{MFN}$} \\
\hline EAP & 0.9 & 0.1 & 23.4 & & 65.6 & & 3.1 & 3.4 \\
\hline ECA & 0.1 & 35.5 & 7.1 & & 4.5 & & 31.5 & 29.6 \\
\hline $\mathrm{LAC}$ & 0.8 & 5.9 & 77.8 & & 92.6 & & 16.7 & 25.9 \\
\hline MNA & 0.0 & 8.6 & 18.0 & 83.3 & 20.1 & 1.5 & 11.2 & 10.1 \\
\hline SAS & 19.4 & 5.6 & 72.3 & & 77.7 & & 2.5 & 8.9 \\
\hline SSA & 0.1 & & 13.0 & 31.7 & 15.2 & 24.7 & 4.9 & 5.3 \\
\hline North & 6.8 & 59.4 & 48.5 & 39.3 & 4.6 & 15.9 & 12.2 & 18.1 \\
\hline World & 4.1 & 48.2 & 50.7 & 38.6 & 25.0 & 12.0 & 11.7 & 15.4 \\
\hline
\end{tabular}




\section{Normality of regression residuals}

In discussing the estimation results of section 4.1, we observed that regression residuals violated a skewness-kurtosis test for a normal distribution, but argued that this departure from normality would not have significant effects on coefficient estimates and inference. This appendix addresses that argument in more detail. First, we offer a general discussion of the importance of the normality assumption for the OLS and GLS estimators. Second, we present kernel density plots of regression residuals to illustrate the apparent departures from normality and discuss other model specifications that explicitly address this issue.

\section{D.1 Significance of the normality assumption}

The assumption of normally distributed regression residuals is one of the pillars of the classical regression model since it allows the exact identification of the distribution of the least squares estimator and several test statistics. On the other hand, normal distribution of disturbances is only a special case of a much larger class of applications where normality is likely to be violated, such as panel data and time series models (Greene, 2000). Fortunately, most of the familiar properties of the LS estimator and relevant test statistics can be derived asymptotically, without relying on the normality assumption. ${ }^{45}$

Before moving to large sample results, it is worth noting that even in finite samples, normality is not necessary to establish that least squares is a minimum variance linear unbiased estimator, which is a direct consequence of the Gauss-Markov theorem. However, the assumption of normal disturbances is needed to derive the exact distributions of $t$ and $F$ statistics, and normality or other specific distributional assumptions are required to extend the Gauss-Markov result to all estimators rather than just the linear category.

It can be easily shown that the LS estimator is asymptotically consistent and normally distributed. These properties do not depend on the normality of residuals; they are a direct consequence of the Lindber-Feller central limit theorem and only require that the disturbances be independent and uncorrelated. In addition, the sample variance is an asymptotically consistent

\footnotetext{
${ }^{45}$ The following two paragraphs rely heavily on chapter 9 of Greene (2000).
} 
estimator of $\sigma$, and the $F$ and Wald statistics converge to a $\chi^{2}$ distribution in large samples - even if the errors are not normally distributed. Therefore, normality is not required to verify that the LS estimator is unbiased and consistent, as well as to allow for hypothesis testing. However, there is no asymptotic equivalent to the extension of the Gauss-Markov result in the previous paragraph, whcih implies that the large sample least squares is only efficient within the class of linear unbiased estimators and may not be the optimal estimator.

Although the possible loss of efficiency is worrisome, this may not be a significant issue in panel or cross-sectional applications where heteroscedasticity is a concern. Specifically, the White VCE sandwich estimator used to correct for unknown forms of heteroscedasticity is not efficient in the first place, since this estimator makes no assumptions about the underlying distribution. Therefore, the heteroscedasticity-consistent VCE matrix may not result in efficient estimates even with no violations of the normality assumption and concerns about asymptotic efficiency under non-normal disturbances become less important.

Finally, Sall and Jones (2004) provide Monte Carlo evidence that as long as departures from normality are not too large, the probability of a type I error (rejecting the null when it is true) is at or below 0.05 with a 95 percent confidence interval. To establish this result, the authors draw multiple samples from both double exponential and skewed normal distributions and test for the equality of means. The implication is that small departures from normality ${ }^{46}$ do not appear to influence hypothesis testing in large samples since they do not affect the probability of a type I error.

\section{D.2 Analysis of the residuals}

Figure 4 shows kernel density plots of regression residuals from each of the three models estimated in the paper. As mentioned in section 4.1, although visually departures from normality are not severe, skewness-kurtosis tests reject normality at all conventional confidence intervals. The previous section has argued that large sample departures from normality are not likely to have significant effects on the properties of the LS estimator or the outcomes of hypothesis testing. In order to add

\footnotetext{
${ }^{46}$ The double exponential distribution is symmetric but has a kurtosis of 6 - twice that of the normal distribution. The skewed normal used by the authors was obtained by moving 5 percent of the simulated distribution three standard deviations to the left.
} 
to that discussion, this section will present some additional estimates of the baseline model to test the sensitivity of the results.
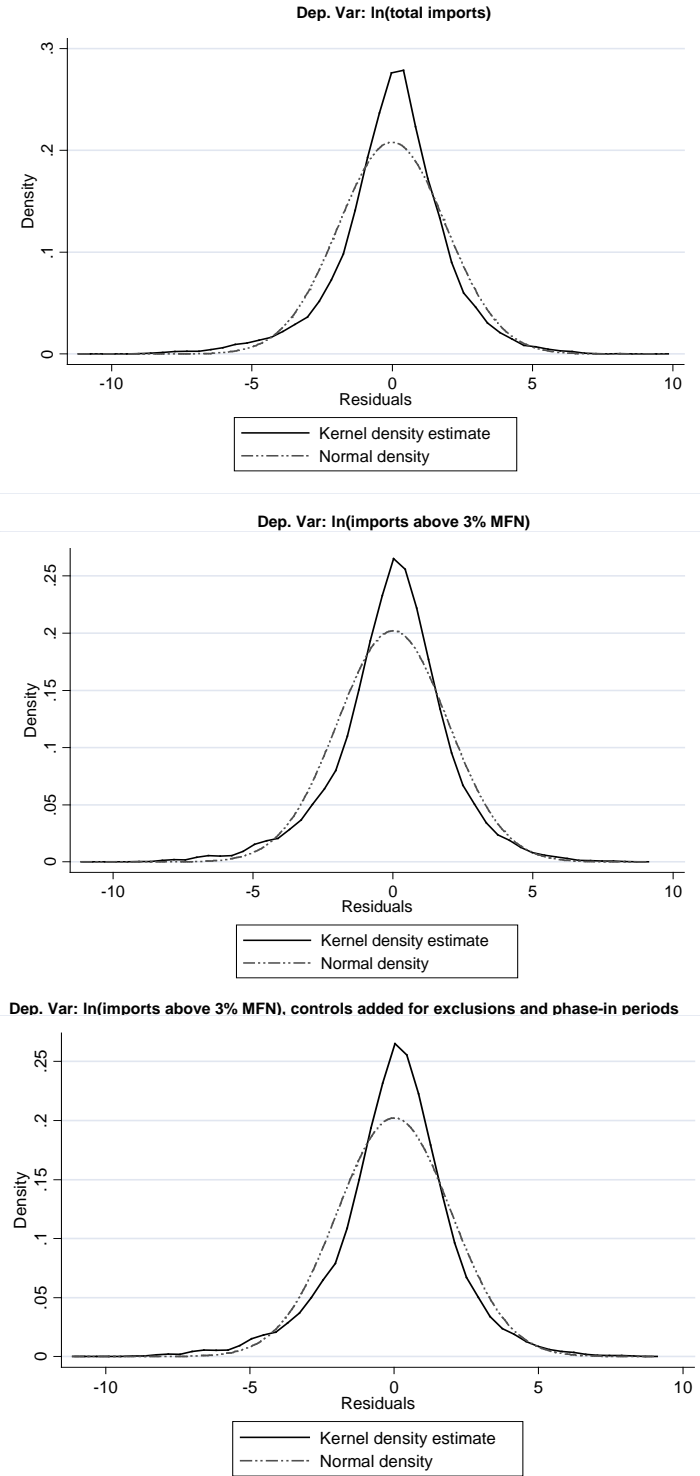

Figure 4: Kernel density estimates of regression residuals Source: Author's estimates.

One approach of dealing with data that may not be well-behaved is robust regression. This procedure implements iteratively reweighted least squares by assigning a weight to each observation with higher weights given to better behaved observations. In fact, extremely deviant cases, those with Cook's D greater than 1, can have their weights set to missing so that they are not included in the analysis at all. Table 12 presents the robust regression estimates of the baseline model (first 
two columns of Table 5).

Table 12: Gravity model estimation results: robust regression

\begin{tabular}{lcc}
\hline \hline \multirow{2}{*}{$\begin{array}{c}\text { Dep. var. (ln) } \\
\text { Variable }\end{array}$} & \multicolumn{2}{c}{ Total imports } \\
\cline { 2 - 3 } Coefficient & Std. Err. \\
\hline Ym & $1.305^{* *}$ & 0.363 \\
Yx & -0.139 & 0.225 \\
dGDPpc & 0.019 & 0.017 \\
GDPsim & $0.050^{* *}$ & 0.015 \\
dist & $-1.255^{* *}$ & 0.030 \\
comlang & $0.564^{* *}$ & 0.057 \\
border & $0.390^{* *}$ & 0.120 \\
colony & $0.446^{* *}$ & 0.156 \\
PTA & $0.718^{* *}$ & 0.074 \\
\hline \multicolumn{3}{c}{13317} \\
N & \multicolumn{2}{c}{0.796} \\
$\mathrm{R}^{2}$ & 219.68 \\
F (233,13083) & \multirow{2}{c}{$* 5 \%$} \\
\hline Significance levels : & $\dagger 10 \% 1 \%$
\end{tabular}

Comparing the above estimates with the GLS results of Table 5, we see that the coefficients and standard errors are quite similar, as are the $t$ and $p$ values. Despite the rejection of normality for GLS residuals, the robust regression estimates are not very different from our baseline result, suggesting that the lack of normality is likely a minor problem. 


\section{E Preferential Trade Agreements in force through 2004}

\begin{tabular}{|c|c|c|}
\hline Agreement & Year & Notified to the WTO \\
\hline $\mathrm{AEC}$ & 1994 & $\mathrm{No}$ \\
\hline AFTA & 1992 & Yes \\
\hline Aghadir Agreement (Med-Arab FTA) & 2003 & $\mathrm{No}$ \\
\hline Albania - Macedonia & 2002 & $\mathrm{No}$ \\
\hline Andean Community - Argentina & 2000 & No \\
\hline Andean Community - Brazil & 1999 & No \\
\hline $\mathrm{ACC}$ & 1989 & $\mathrm{No}$ \\
\hline $\mathrm{AMU}$ & 1989 & No \\
\hline Argentina - Chile & 2000 & No \\
\hline Argentina - Costa Rica & 1983 & $\mathrm{No}$ \\
\hline Argentina - Cuba & 1984 & $\mathrm{No}$ \\
\hline Argentina - Ecuador & 1993 & $\mathrm{No}$ \\
\hline Armenia - Russian Federation & 1992 & $\mathrm{No}$ \\
\hline $\mathrm{ACS}$ & 1994 & $\mathrm{No}$ \\
\hline BAFTA & 1994 & Yes \\
\hline Bangkok Agreement & 1976 & Yes \\
\hline Belarus - Ukraine & 1992 & $\mathrm{No}$ \\
\hline Belarus - Uzbekistan & 1993 & No \\
\hline Bolivia - Chile & 1993 & $\mathrm{No}$ \\
\hline Bolivia - Cuba & 1995 & $\mathrm{No}$ \\
\hline Bolivia - Mexico & 1995 & $\mathrm{No}$ \\
\hline Bosnia-Herzegovina - Macedonia & 2002 & No \\
\hline Bosnia-Herzegovina - Yugoslavia & 2002 & $\mathrm{No}$ \\
\hline Botswana - Zimbabwe & 1988 & No \\
\hline Brazil - Cuba & 1987 & No \\
\hline Bulgaria - Croatia & 2001 & No \\
\hline Bulgaria - Estonia & 2002 & Yes \\
\hline Bulgaria - Israel & 2002 & Yes \\
\hline Bulgaria - Latvia & 2003 & Yes \\
\hline Bulgaria - Lithuania & 2002 & Yes \\
\hline
\end{tabular}




\begin{tabular}{|c|c|c|}
\hline Agreement & Year & Notified to the WTO \\
\hline Bulgaria - Macedonia & 2000 & Yes \\
\hline Bulgaria - Turkey & 1999 & Yes \\
\hline Burkina Faso - Cuba & 1987 & No \\
\hline Burkina Faso - Korea & 1998 & No \\
\hline Burkina Faso - Tunisia & 1993 & No \\
\hline Burkina Faso - India & 1995 & No \\
\hline $\mathrm{CACM}$ & 1961 & Yes \\
\hline CACM - Dominican Republic & 2001 & No \\
\hline CACM - Venezuela & 1993 & No \\
\hline CAN & 1988 & Yes \\
\hline Canada - Australia (CANATA) & 1960 & No \\
\hline Canada - Chile & 1997 & Yes \\
\hline Canada - Costa Rica & 2002 & Yes \\
\hline Canada - Israel & 1997 & Yes \\
\hline CARICOM & 1973 & Yes \\
\hline CARICOM - Colombia & 1995 & No \\
\hline CARICOM - Dominican Republic & 1999 & No \\
\hline CARICOM - Venezuela & 1993 & No \\
\hline CEFTA & 1993 & Yes \\
\hline CEMAC & 1999 & Yes \\
\hline CER & 1983 & Yes \\
\hline Chile - Costa Rica & 2002 & Yes \\
\hline Chile - CACM & 2002 & No \\
\hline Chile - Colombia & 1994 & No \\
\hline Chile - Ecuador & 1995 & No \\
\hline Chile - EFTA & 2004 & No \\
\hline Chile - Korea & 2004 & No \\
\hline Chile - MERCOSUR & 1996 & No \\
\hline Chile - Mexico & 1999 & Yes \\
\hline Chile - Peru & 1998 & No \\
\hline
\end{tabular}




\begin{tabular}{|c|c|c|}
\hline Agreement & Year & Notified to the WTO \\
\hline Chile - Venezuela & 1993 & No \\
\hline CIS & 1994 & Yes \\
\hline China - Macao & 2004 & No \\
\hline China - Hong Kong & 2004 & No \\
\hline Colombia - CACM & 1985 & No \\
\hline Colombia - Cuba & 1988 & No \\
\hline Colombia - Panama & 1995 & $\mathrm{No}$ \\
\hline COMESA & 1994 & Yes \\
\hline CEN-SAD & 1998 & No \\
\hline Croatia - Bosnia and Herzegovina & 2001 & Yes \\
\hline Croatia - Hungary & 2002 & No \\
\hline Croatia - Macedonia & 1997 & No \\
\hline CBI & 1998 & No \\
\hline Cuba - Chile & 1998 & No \\
\hline Cuba - Ecuador & 1995 & No \\
\hline Cuba - Uruguay & 1987 & No \\
\hline Czech - Macedonia & 1997 & No \\
\hline Czech Republic - Estonia & 1998 & Yes \\
\hline Czech Republic - Israel & 1997 & Yes \\
\hline Czech Republic - Latvia & 1997 & Yes \\
\hline Czech Republic - Lithuania & 1997 & Yes \\
\hline Czech Republic - Slovak Republic & 1993 & Yes \\
\hline Czech Republic - Turkey & 1998 & Yes \\
\hline EAC & 2000 & Yes \\
\hline EAEC & 1997 & Yes \\
\hline EC - Lebanon & 2003 & Yes \\
\hline $\mathrm{ECO}$ & 1992 & Yes \\
\hline ECCAS & 1995 & No \\
\hline CEPGL & 1977 & No \\
\hline ECOWAS & 1975 & $\mathrm{No}$ \\
\hline
\end{tabular}




\begin{tabular}{|c|c|c|}
\hline Agreement & Year & Notified to the WTO \\
\hline EEA & 1994 & Yes \\
\hline EFTA - Croatia & 2002 & Yes \\
\hline EFTA - Jordan & 2002 & Yes \\
\hline EFTA - Bulgaria & 1993 & Yes \\
\hline EFTA - Czech Republic & 1992 & Yes \\
\hline EFTA - Estonia & 1996 & Yes \\
\hline EFTA - Hungary & 1993 & Yes \\
\hline EFTA - Israel & 1993 & Yes \\
\hline EFTA - Latvia & 1996 & Yes \\
\hline EFTA - Lithuania & 1996 & Yes \\
\hline EFTA - Macedonia & 2001 & Yes \\
\hline EFTA - Mexico & 2001 & Yes \\
\hline EFTA - Morocco & 1999 & Yes \\
\hline EFTA - Palestinian Authority & 1999 & Yes \\
\hline EFTA - Poland & 1993 & Yes \\
\hline EFTA - Romania & 1993 & Yes \\
\hline EFTA - Singapore & 2003 & Yes \\
\hline EFTA - Slovak Republic & 1992 & Yes \\
\hline EFTA - Slovenia & 1995 & Yes \\
\hline EFTA - Turkey & 1992 & Yes \\
\hline EFTA (Stockholm Convention) & 1960 & Yes \\
\hline El Salvador - Guatemala & 1991 & No \\
\hline Estonia - Faroe Islands & 1998 & Yes \\
\hline Estonia - Turkey & 1998 & Yes \\
\hline Estonia - Ukraine & 1996 & Yes \\
\hline EU - Croatia & 2002 & Yes \\
\hline EU - Jordan & 2002 & Yes \\
\hline EU - Macedonia & 2001 & Yes \\
\hline EU - Algeria & 1976 & Yes \\
\hline EU - Andorra & 1991 & Yes \\
\hline
\end{tabular}




\begin{tabular}{|c|c|c|}
\hline Agreement & Year & Notified to the WTO \\
\hline EU - Azerbaijan & 1997 & No \\
\hline EU - Bulgaria & 1993 & Yes \\
\hline EU - Chile & 2003 & No \\
\hline EU - Cyprus & 1973 & Yes \\
\hline EU - Czech Republic & 1992 & Yes \\
\hline EU - Egypt & 1977 & Yes \\
\hline EU - Estonia & 1995 & Yes \\
\hline EU - Faroe Islands & 1997 & Yes \\
\hline EU - Hungary & 1992 & Yes \\
\hline EU - Iceland & 1973 & Yes \\
\hline EU - Israel & 2000 & Yes \\
\hline EU - Kyrgyz Republic & 1998 & No \\
\hline EU - Latvia & 1995 & Yes \\
\hline EU - Lithuania & 1995 & Yes \\
\hline EU - Malta & 1971 & Yes \\
\hline EU - Mexico & 2000 & Yes \\
\hline EU - Morocco & 2000 & Yes \\
\hline EU - Norway & 1973 & Yes \\
\hline EU - OCTs & 1971 & Yes \\
\hline EU - Palestinian Authority & 1997 & Yes \\
\hline EU - Poland & 1992 & Yes \\
\hline EU - Republic of San Marino & 1992 & No \\
\hline EU - Romania & 1993 & Yes \\
\hline EU - Slovak Republic & 1992 & Yes \\
\hline EU - Slovenia & 1997 & Yes \\
\hline EU - South Africa & 2000 & Yes \\
\hline EU - Switzerland and Liechtenstein & 1973 & Yes \\
\hline EU - Syria & 1977 & Yes \\
\hline EU - Tunisia & 1998 & Yes \\
\hline EU - Turkey & 1996 & Yes \\
\hline
\end{tabular}




\begin{tabular}{|c|c|c|}
\hline Agreement & Year & Notified to the WTO \\
\hline EU - Uzbekistan & 1999 & No \\
\hline EU (Treaty of Rome) & 1958 & Yes \\
\hline Faroe Islands - Iceland & 1993 & Yes \\
\hline Faroe Islands - Norway & 1993 & Yes \\
\hline Faroe Islands - Switzerland & 1995 & Yes \\
\hline Fiji - Papua New Guinea & 1996 & No \\
\hline GCC & 1982 & Yes \\
\hline Georgia - Armenia & 1998 & Yes \\
\hline Georgia - Azerbaijan & 1996 & Yes \\
\hline Georgia - Kazakhstan & 1999 & Yes \\
\hline Georgia - Russian Federation & 1994 & Yes \\
\hline Georgia - Turkmenistan & 2000 & Yes \\
\hline Georgia - Ukraine & 1996 & Yes \\
\hline Greater Arab Free Trade Area & 1998 & No \\
\hline Group of Three & 1995 & No \\
\hline GSTP & 1989 & Yes \\
\hline Guinea - Morocco & 1997 & No \\
\hline Hungary - Estonia & 2001 & Yes \\
\hline Hungary - Israel & 1998 & Yes \\
\hline Hungary - Latvia & 2000 & Yes \\
\hline Hungary - Lithuania & 2000 & Yes \\
\hline Hungary - Turkey & 1998 & Yes \\
\hline India - Bangladesh & 1980 & No \\
\hline India - Sri Lanka & 2001 & Yes \\
\hline India - Bhutan & 1995 & No \\
\hline India - Nepal & 1991 & No \\
\hline IGAD & 1986 & No \\
\hline Iran - Switzerland & 2001 & No \\
\hline Iraq - Egypt & 2001 & No \\
\hline Israel - Jordan & 1996 & No \\
\hline
\end{tabular}




\begin{tabular}{|c|c|c|}
\hline Agreement & Year & Notified to the WTO \\
\hline Israel - Turkey & 1997 & Yes \\
\hline Japan - Singapore & 2002 & Yes \\
\hline Jordan - Morocco & 1994 & No \\
\hline Jordan - Syria & 2001 & No \\
\hline Kyrgyz Republic - Armenia & 1995 & Yes \\
\hline Kyrgyz Republic - Kazakhstan & 1995 & Yes \\
\hline Kyrgyz Republic - Moldova & 1996 & Yes \\
\hline Kyrgyz Republic - Russia & 1993 & Yes \\
\hline Kyrgyz Republic - Ukraine & 1998 & Yes \\
\hline Kyrgyz Republic - Uzbekistan & 1998 & Yes \\
\hline LAIA & 1981 & Yes \\
\hline Laos - Thailand & 1991 & Yes \\
\hline Latvia - Turkey & 2000 & Yes \\
\hline Lebanon - Kuwait & 1996 & No \\
\hline Lebanon - Syria & 1998 & No \\
\hline Lebanon - UAE & 2001 & No \\
\hline Lithuania - Turkey & 1998 & Yes \\
\hline Macedonia - Yugoslavia & 1996 & No \\
\hline $\mathrm{MRU}$ & 1973 & No \\
\hline MERCOSUR & 1991 & Yes \\
\hline MERCOSUR - Bolivia & 1997 & No \\
\hline Mexico - Brazil & 2002 & No \\
\hline Mexico - Costa Rica & 1995 & No \\
\hline Mexico - Cuba & 1985 & No \\
\hline Mexico - Israel & 2000 & Yes \\
\hline Mexico - Nicaragua & 1998 & No \\
\hline Mexico - NTR & 2001 & No \\
\hline Mexico - Uruguay & 2001 & No \\
\hline Moldova - Armenia & 1995 & No \\
\hline Moldova - Azerbaijan & 1996 & No \\
\hline
\end{tabular}




\begin{tabular}{|c|c|c|}
\hline Agreement & Year & Notified to the WTO \\
\hline Moldova - Belarus & 1994 & No \\
\hline Moldova - Kazakhstan & 1996 & No \\
\hline Moldova - Russian Federation & 1993 & No \\
\hline Moldova - Turkmenistan & 1996 & No \\
\hline Moldova - Ukraine & 1996 & No \\
\hline Moldova - Uzbekistan & 1995 & No \\
\hline Morocco - Tunisia & 1999 & No \\
\hline MSG & 1993 & Yes \\
\hline NAFTA & 1994 & Yes \\
\hline Namibia - Zimbabwe & 1993 & No \\
\hline New Zealand - Singapore & 2001 & Yes \\
\hline Nicaragua - Colombia & 1985 & No \\
\hline Palestinian Authority - United States & 1996 & No \\
\hline Palestinian Authority - Egypt & 1998 & No \\
\hline Palestinian Authority - Jordan & 1995 & No \\
\hline Panama - Costa Rica & 1973 & No \\
\hline Panama - Dominican Republic & 1987 & No \\
\hline Panama - El Salvador & 1974 & No \\
\hline Panama - Guatemala & 1975 & No \\
\hline Panama - Honduras & 1974 & No \\
\hline Panama - Mexico & 1986 & No \\
\hline Panama - Nicaragua & 1974 & No \\
\hline PATCRA & 1977 & Yes \\
\hline Peru - Cuba & 1994 & No \\
\hline Poland - Faroe Islands & 1999 & Yes \\
\hline Poland - Israel & 1998 & Yes \\
\hline Poland - Latvia & 1999 & Yes \\
\hline Poland - Lithuania & 1997 & Yes \\
\hline Poland - Turkey & 2000 & Yes \\
\hline PTAES & 1981 & No \\
\hline
\end{tabular}




\begin{tabular}{|c|c|c|}
\hline Agreement & Year & Notified to the WTO \\
\hline PTN & 1973 & Yes \\
\hline Romania - Moldova & 1995 & Yes \\
\hline Romania - Turkey & 1998 & Yes \\
\hline Russia - Tajikistan & 1992 & No \\
\hline Russia - Ukraine & 1994 & No \\
\hline Russian Federation - Azerbaijan & 1992 & No \\
\hline Russian Federation - Belarus & 1995 & No \\
\hline Russian Federation - Turkmenistan & 1992 & No \\
\hline Russian Federation - Uzbekistan & 1992 & No \\
\hline SAPTA & 1995 & Yes \\
\hline Saudi Arabia - Syria & 2003 & No \\
\hline Singapore - Australia & 2003 & Yes \\
\hline Slovak Republic - Estonia & 1998 & Yes \\
\hline Slovak Republic - Israel & 1997 & Yes \\
\hline Slovak Republic - Latvia & 1997 & Yes \\
\hline Slovak Republic - Lithuania & 1997 & Yes \\
\hline Slovak Republic - Turkey & 1998 & Yes \\
\hline Slovenia - Bosnia and Herzegovina & 2002 & Yes \\
\hline Slovenia - Croatia & 1998 & Yes \\
\hline Slovenia - Estonia & 1997 & Yes \\
\hline Slovenia - Israel & 1998 & Yes \\
\hline Slovenia - Latvia & 1996 & Yes \\
\hline Slovenia - Lithuania & 1997 & Yes \\
\hline Slovenia - Macedonia & 1996 & Yes \\
\hline South Africa - Malawi & 1990 & No \\
\hline South Africa - Zimbabwe & 1964 & No \\
\hline $\mathrm{SACU}$ & 1969 & No \\
\hline SADC & 2000 & No \\
\hline SPARTECA & 1981 & Yes \\
\hline Taiwan - Panama & 2004 & No \\
\hline
\end{tabular}




\begin{tabular}{lcc}
\hline \hline Agreement & Year & Notified to the WTO \\
\hline TRIPARTITE & 1968 & Yes \\
Tunisia - Egypt & 1998 & No \\
Turkey - Slovenia & 2000 & Yes \\
Turkey - Bosnia and Herzegovina & 2003 & Yes \\
Turkey - Croatia & 2003 & Yes \\
Turkey - Macedonia & 2000 & Yes \\
Ukraine - Azerbaijan & 1996 & No \\
Ukraine - Turkmenistan & 1996 & No \\
United States - Jordan & 2001 & Yes \\
United States - Israel & 1985 & Yes \\
United States - Chile & 2004 & No \\
United States - Singapore & 2004 & No \\
Venezuela - Cuba & 1989 & No \\
Venezuela - Trinidad and Tobago & 1989 & No \\
WAEMU/UEMOA & 2000 & Yes \\
\hline
\end{tabular}

The following details the full name and country membership of abbreviated PTAs:

ACC (Arab Cooperation Council): Egypt, Iraq, Jordan, Yemen.

ACS (Association of Caribbean States): Antigua and Barbuda, Bahamas, Barbados, Belize, Colombia, Costa Rica, Cuba, Dominica, El Salvador, Grenada, Guatemala, Guyana, Haiti, Honduras, Jamaica, Mexico, Nicaragua, Panama, Dominican Republic, St Kitts and Nevis, St Lucia, St Vincent and the Grenadines, Suriname, Trinidad and Tobago, Venezuela.

AEC (African Economic Community): Algeria, Angola, Benin, Botswana, Burkina Faso, Burundi, Cameroon, Cape Verde, Central African Rep., Chad, Comoros, Congo, Congo Dem. Rep., Cote d'Ivoire, Djibouti, Egypt, Ethiopia, Equatorial Guinea, Gabon, Gambia, Ghana, Guinea, Guinea-Bissau, Kenya, Lesotho, Liberia, Libya, Madagascar, Malawi, Mali, Mauritania, Mauritius, Mozambique, Namibia, Niger, Nigeria, Rwanda, Sao Tome and Principe, Senegal, Seychelles, Sierra Lione, Somalia, Sudan, Swaziland, Tanzania, Togo, Tunisia, Uganda, Zambia, Zimbabwe.

AFTA (ASEAN Free Trade Area): Brunei Darussalam, Cambodia, Indonesia, Laos, Malaysia, Myanmar, Philippines, Singapore, Thailand, Vietnam. 
$A M U$ (Arab Maghreb Union): Algeria, Libya, Mauritania, Morocco, Tunisia.

BAFTA (Baltic Free-Trade Area): Estonia, Latvia, Lithuania.

BANGKOK (Bangkok Agreement): Bangladesh, China, India, Republic of Korea, Laos, Sri Lanka.

CACM (Central American Common Market): Costa Rica, El Salvador, Guatemala, Honduras, Nicaragua.

CAN (Andean Community): Bolivia, Colombia, Ecuador, Peru, Venezuela.

CARICOM (Caribbean Community and Common Market): Antigua and Barbuda, Bahamas,

Barbados, Belize, Dominica, Grenada, Guyana, Haiti, Jamaica, Monserrat, Trinidad and Tobago,

St. Kitts and Nevis, St. Lucia, St. Vincent and the Grenadines, Suriname.

CBI (Cross Border Initiative): Burundi, Comoros, Kenya, Madagascar, Malawi, Mauritius, Namibia, Rwanda, Seychelles, Swaziland, Tanzania, Uganda, Zambia, Zimbabwe.

CEFTA (Central European Free Trade Agreement): Bulgaria, Czech Republic, Hungary, Poland, Romania, Slovak Republic, Slovenia.

CEMAC (Economic and Monetary Community of Central Africa): Cameroon, Central African Republic, Chad, Congo, Equatorial Guinea, Gabon.

CEN-SAD (Community of Sahel-Saharan States): Benin, Burkina Faso, Central African Republic, Chad, Djibouti, Egypt, Eritrea, Gambia, Libya, Mali, Morocco, Niger, Nigeria, Senegal, Somalia, Sudan, Togo, Tunisia.

CEPGL (Economic Community of Great Lakes Countries): Burundi, Rwanda, Congo Dem. Rep.

CER (ANZCERTA - Closer Economic Relations Trade Agreement): Australia, New Zealand. CIS (Commonwealth of Independent States): Azerbaijan, Armenia, Belarus, Georgia, Moldova, Kazakhstan, Russian Federation, Ukraine, Uzbekistan, Tajikistan, Kyrgyz Republic.

COMESA (Common Market for Eastern and Southern Africa): Angola, Burundi, Comoros, Democratic Republic of Congo, Djibouti, Egypt, Eritrea, Ethiopia, Kenya, Madagascar, Malawi, Mauritius, Namibia, Rwanda, Seychelles, Sudan, Swaziland, Uganda, Zambia, Zimbabwe.

EAC (East African Community): Kenya, Tanzania, Uganda.

EAEC (Eurasian Economic Community): Belarus, Kazakhstan, Kyrgyz Republic, Russian Fed- 
eration, Tajikistan.

ECCAS (Economic Community of Central African States): Burundi, Cameroon, Central African Republic, Chad, Congo, Congo Dem. Rep., Equatorial Guinea, Gabon, Rwanda, Sao Tome and Principe.

ECO (Economic Cooperation Organization): Afghanistan, Azerbaijan, Iran, Kazakhstan, Kyrgyz Republic, Pakistan, Tajikistan, Turkey, Turkmenistan, Uzbekistan.

ECOWAS (Economic Community of West African States): Benin, Burkina Faso, Cape Verde, Gambia, Ghana, Guinea, Guinea-Bissau, Cote d'Ivoire, Liberia, Mali, Niger, Nigeria, Senegal, Sierra Lione, Togo.

EEA (European Economic Area): EU, Iceland, Liechtenstein, Norway.

EFTA (European Free Trade Association): Iceland, Liechtenstein, Norway, Switzerland.

GAFTA (Greater Arab Free Trade Area): Bahrain, Egypt, Iraq, Jordan, Kuwait, Lebanon, Libya, Morocco, Oman, Palestine, Qatar, Saudi Arabia, Somalia, Sudan, Syria, Tunisia, United Arab Emirates, Yemen.

GCC (Gulf Cooperation Council): Bahrain, Kuwait, Oman, Qatar, Saudi Arabia, United Arab Emirates.

GROUP3 (Groupt of Three): Mexico, Colombia, Venezuela.

GSTP (General System of Trade Preferences among Developing Countries): Algeria, Argentina, Bangladesh, Benin, Bolivia, Brazil, Cameroon, Chile, Colombia, Cuba, Democratic People's Republic of Korea, Ecuador, Egypt, Ghana, Guinea, Guyana, India, Indonesia, Islamic Republic of Iran, Iraq, Libya, Malaysia, Mexico, Morocco, Mozambique, Myanmar, Nicaragua, Nigeria, Pakistan, Peru, Philippines, Republic of Korea, Romania, Singapore, Sri Lanka, Sudan, Thailand, Trinidad and Tobago, Tunisia, Tanzania, Venezuela, Vietnam, Yugoslavia, Zimbabwe.

IGAD (Inter-governmental Authority on Development): Djibouti, Ethiopia, Eritrea, Kenya, Somalia, Sudan, Uganda.

LAIA (Latin American Integration Association): Argentina, Bolivia, Brazil, Chile, Colombia, Cuba, Ecuador, Mexico, Paraguay, Peru, Uruguay, Venezuela.

MAFTA (Aghadir Agreement, or Med-Arab FTA): Egypt, Jordan, Morocco, Tunisia. MERCOSUR (Southern Common Market): Argentina, Brazil, Paraguay, Uruguay. 
MRU (Mano River Union): Liberia, Sierra Lione, Guinea.

MSG (Melanesian Spearhead Group): Fiji, Papua New Guinea, Solomon Islands, Vanuatu.

NAFTA (North American Free Trade Agreement): Canada, Mexico, United States.

NTR (Northern Triangle): Honduras, Guatemala, El Salvador.

OCT (Overseas Countries and Territories): Greenland ,New Caledonia, French Polynesia, French Southern and Antarctic Territories, Wallis and Futuna Islands, Mayotte, Saint Pierre and Miquelon, Aruba, Netherlands Antilles, Anguilla, Cayman Islands, Falkland Islands, South Georgia and South Sandwich Islands, Montserrat, Pitcairn, Saint Helena ,Ascension Island, Tristan da Cunha, Turks and Caicos Islands, British Antarctic Territory, British Indian Ocean Territory, British Virgin Islands.

PTAES (Preferential Trade Area for Eastern and Southern Africa): Angola, Botswana, Burundi, Comoros, Congo Dem. Rep., Djibouti, Ethiopia, Kenya, Lesotho, Madagascar, Malawi, Mauritius, Mozambique, Rwanda, Seychelles, Somalia, Swaziland, Tanzania, Uganda, Zambia, Zimbabwe.

PTN (Protocol relating to Trade Negotiations among Developing Countries): Bangladesh, Brazil, Chile, Egypt, Israel, Mexico, Pakistan, Paraguay, Peru, Philippines, Republic of Korea, Romania, Tunisia, Turkey, Uruguay, Yugoslavia.

SACU (Southern African Customs Union): South Africa, Botswana, Lesotho, Swaziland, Namibia. SADC (Southern African Development Community): Angola, Botswana, Congo Dem. Rep., Lesotho, Malawi, Mauritius, Mozambique, Namibia, South Africa, Swaziland, Seychelles, Tanzania, Zambia, Zimbabwe.

SAPTA (South Asian Preferential Trade Arrangement): Bangladesh, Bhutan, India, Maldives, Nepal, Pakistan, Sri Lanka.

SPARTECA (South Pacific Regional Trade and Economic Cooperation Agreement): Australia, New Zealand, Cook Islands, Fiji, Kiribati, Marshall Islands, Micronesia, Nauru, Niue, Papua New Guinea, Solomon Islands, Tonga, Tuvalu, Vanuatu, Western Samoa.

TRIPARTITE (Tripartite Agreement): Egypt, India, Yugoslavia.

WAEMU (West African Economic and Monetary Union): Benin, Burkina Faso, Cote d'Ivoire, Guinea-Bissau, Mali, Niger, Senegal, Togo. 


\section{F Data sources and data management}

\section{F.1 Data source details}

With the exception of the PTA database, all data used in this paper can be readily obtained from the CEPII, the World Bank, the UN Statistics Division, and the United Nations Conference on Trade and Development (UNCTAD). The PTAs used in this paper are listed in Appendix E, while information on the other series is summarized in Table 13.

Table 13: Variables and their sources

\begin{tabular}{|c|c|c|c|}
\hline Variable & Source & Available & Name in source data \\
\hline Bilateral trade & COMTRADE & On-line or free software & Tradevalue (6-8 digit HS level) \\
\hline Bilateral tariffs & TRAINS & On-line or free software & Tariff (6-8 digit HS level) \\
\hline GDP & WDI & Subscription-based & GDP (current US\$) \\
\hline Population & WDI & Subscription-based & Population, total \\
\hline Distance & CEPII & Free on-line & dist \\
\hline Common language & CEPII & Free on-line & comlang_off \\
\hline Common border & CEPII & Free on-line & contig \\
\hline Colonial link & CEPII & Free on-line & colony \\
\hline $\begin{array}{l}\text { Note: COMTRADE } \\
\text { vision. TRAINS (TH } \\
\text { United Nations Conf } \\
\text { a comprehensive cou } \\
\text { Prospectives et d'Inf }\end{array}$ & modit & $\begin{array}{l}\text { istics) is a trade databas } \\
\text { mation System) is a trade } \\
\text { velopment (UNCTAD). } \\
\text { abase maintained by the }\end{array}$ & $\begin{array}{l}\text { aaintained by the UN Statistical Di- } \\
\text { ad tariff database maintained by the } \\
\text { I (World Development Indicators) is } \\
\text { ld Bank. CEPII is Centre d'Etudes }\end{array}$ \\
\hline
\end{tabular}

All data were collected by the author while at the World Bank, and therefore some additional steps may be required to collect the information in Table 13 for those researchers without access to World Bank software. The trade and tariff data were accessed through the WITS (World Integrated Trade Solution) software, which is a joined collaboration of the World Bank and UNCTAD. WITS is an integrated data query and numerical simulation package, and provides access to the following databases:

- The COMTRADE (Commodity Trade Statistics) database maintained by the UN Statistical Division.

- The TRAINS (TRade Analysis and INformation System) maintained by the UNCTAD.

- The IDB (Integrated Data Base) and CTS (Consolidated Tariff Schedules) databases maintained by the WTO. 
While the software is free to download at http://wits.worldbank.org/witsweb/default.aspx, access to some or all of the databases may be limited or fee-based for some users. However, the two databases used in this paper - COMTRADE and TRAINS - can be freely accessed through the home pages of the publishing agencies, although the author has not attempted downloading the required data in this way and therefore cannot guarantee their on-line availability.

The GDP and population data ${ }^{47}$ were obtained from the World Development Indicators database of the World Bank. This database was accessed by the author through an internal World Bank server, but it is also available on CD-ROM at subscribing libraries. Alternatively, the CD-ROM can be purchased from the World Bank bookstore, either in person or on-line. If the user queries the data by code rather than by name, the corresponding codes for GDP and population are NY.GDP.MKTP.CD and SP.POP.TOTL.

The CEPII distance and dummy variable data (dist_cepii.xls) is freely available for download at http://www.cepii.fr/anglaisgraph/bdd/distances.htm.

\section{F.2 Data transformation}

This section provides the STATA code used to create the final dataset from the raw data components of the previous section.

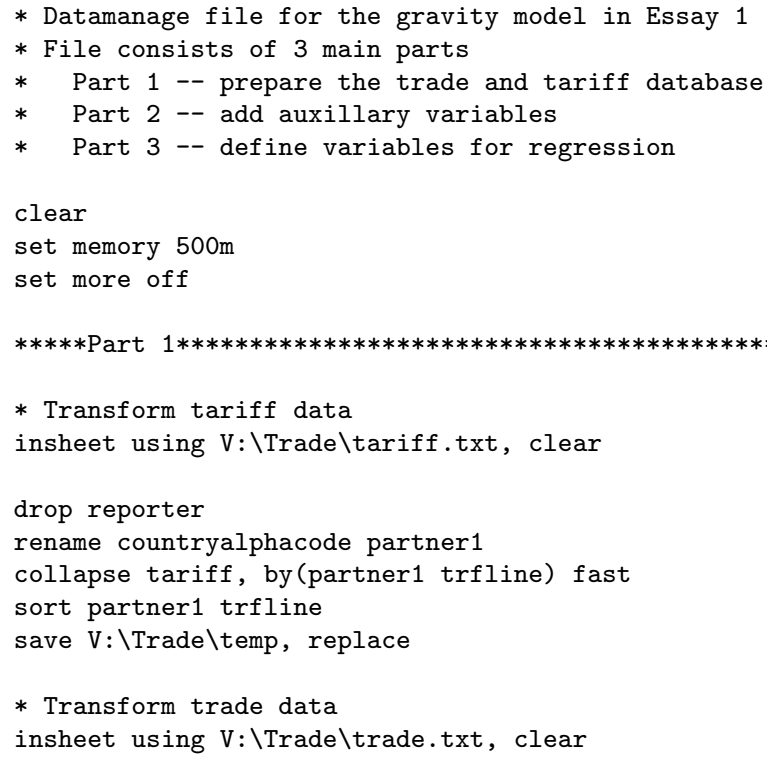

${ }^{47}$ The population data were used to calculate GDP per capita. 


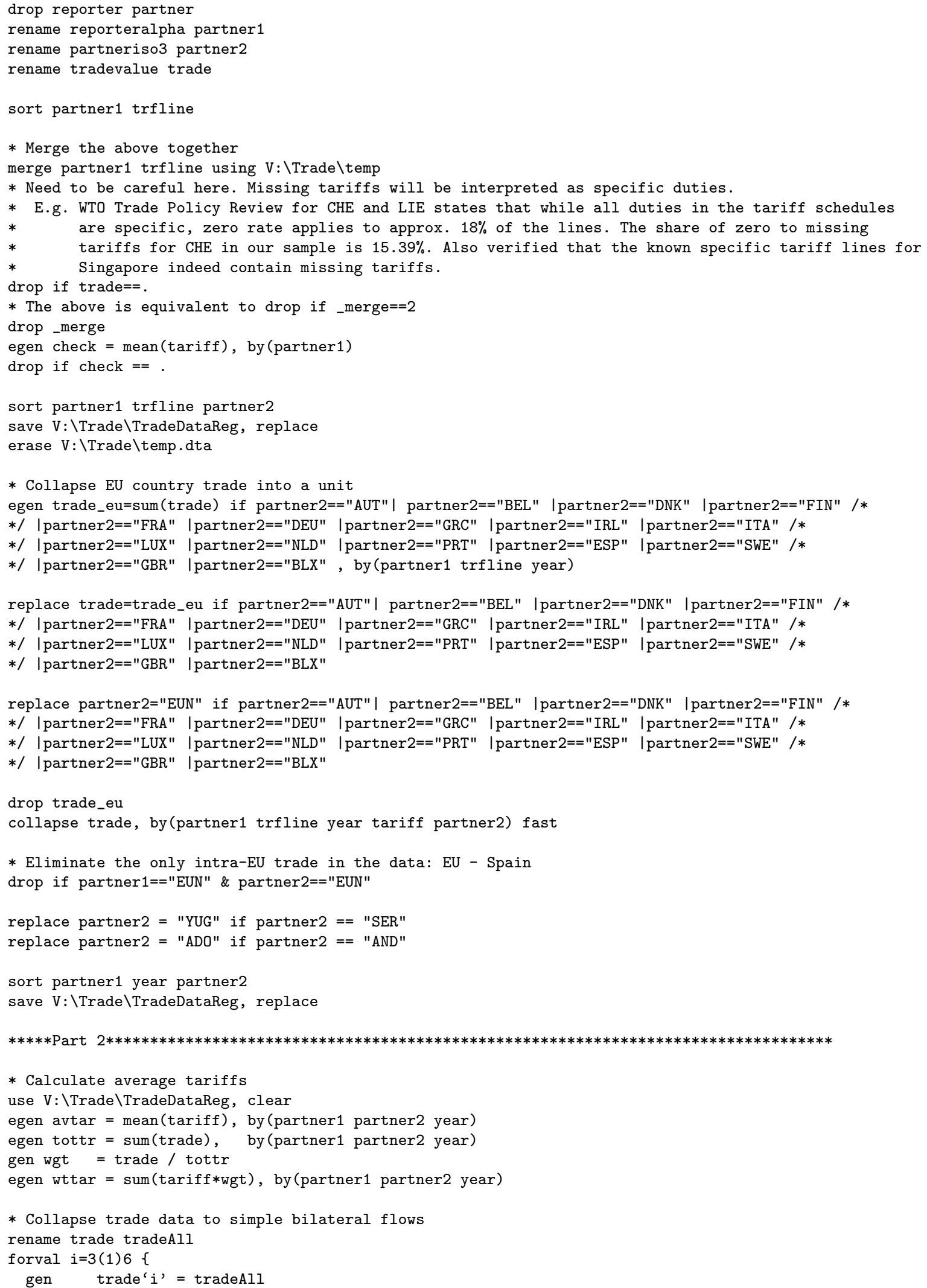




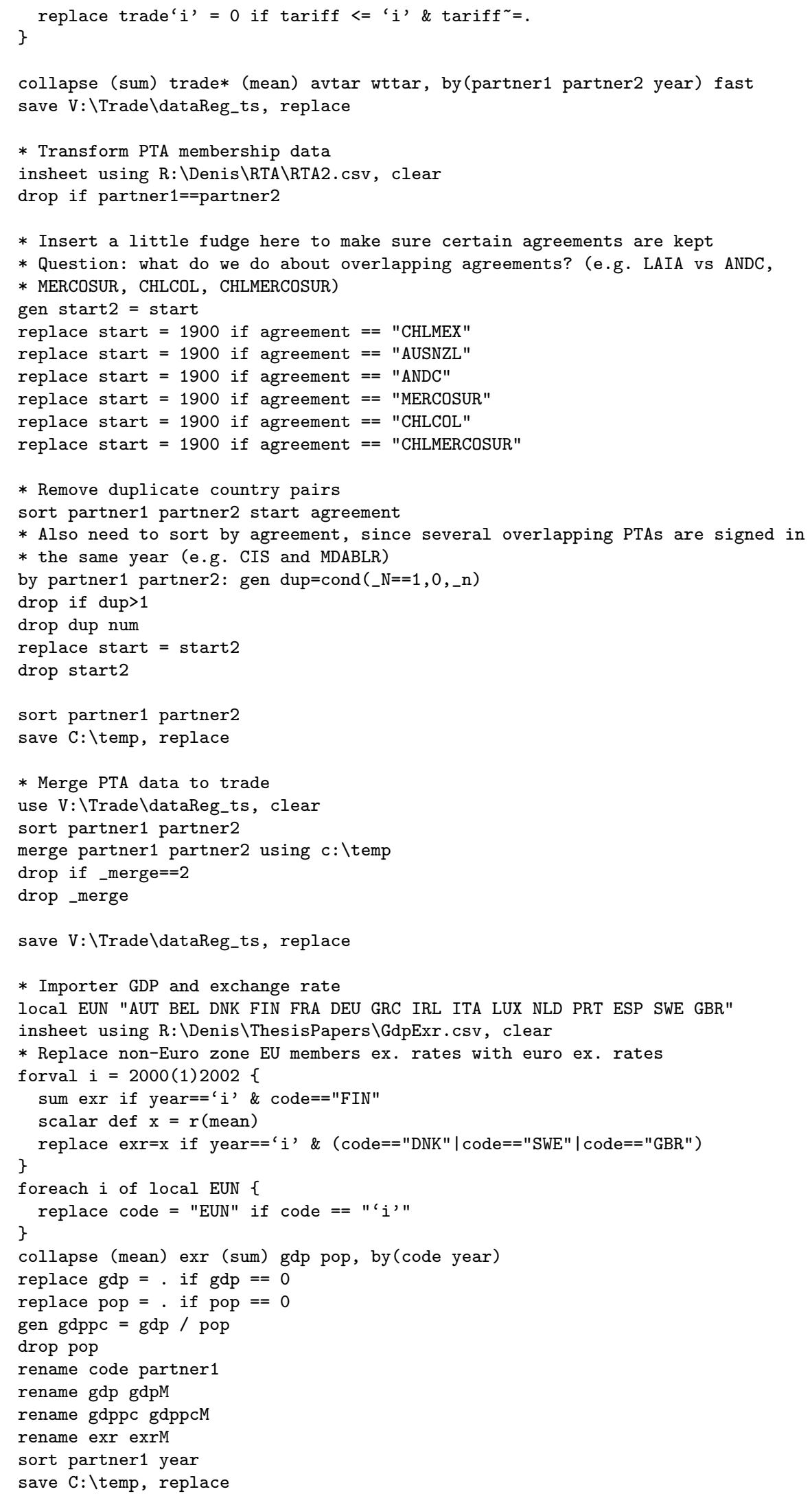




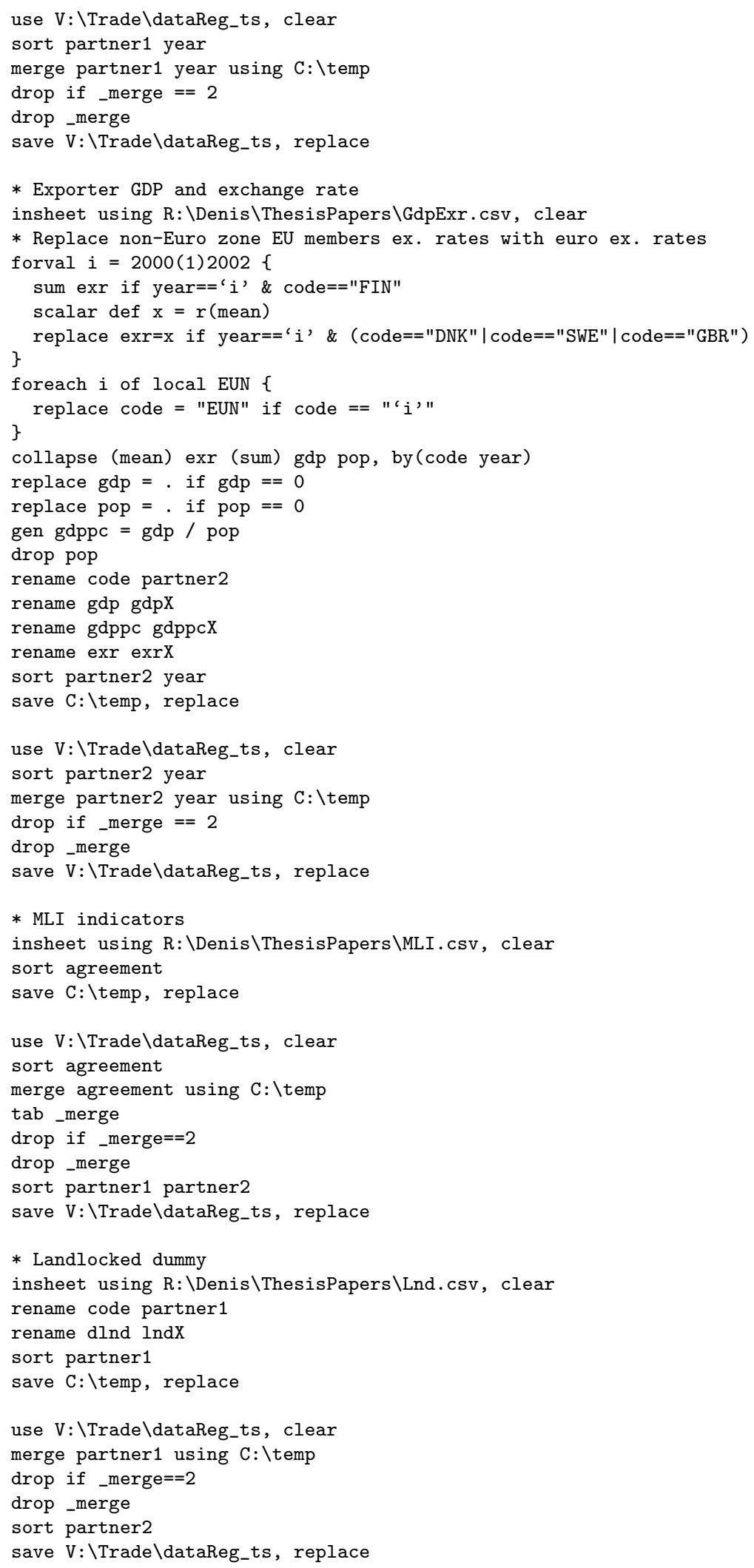




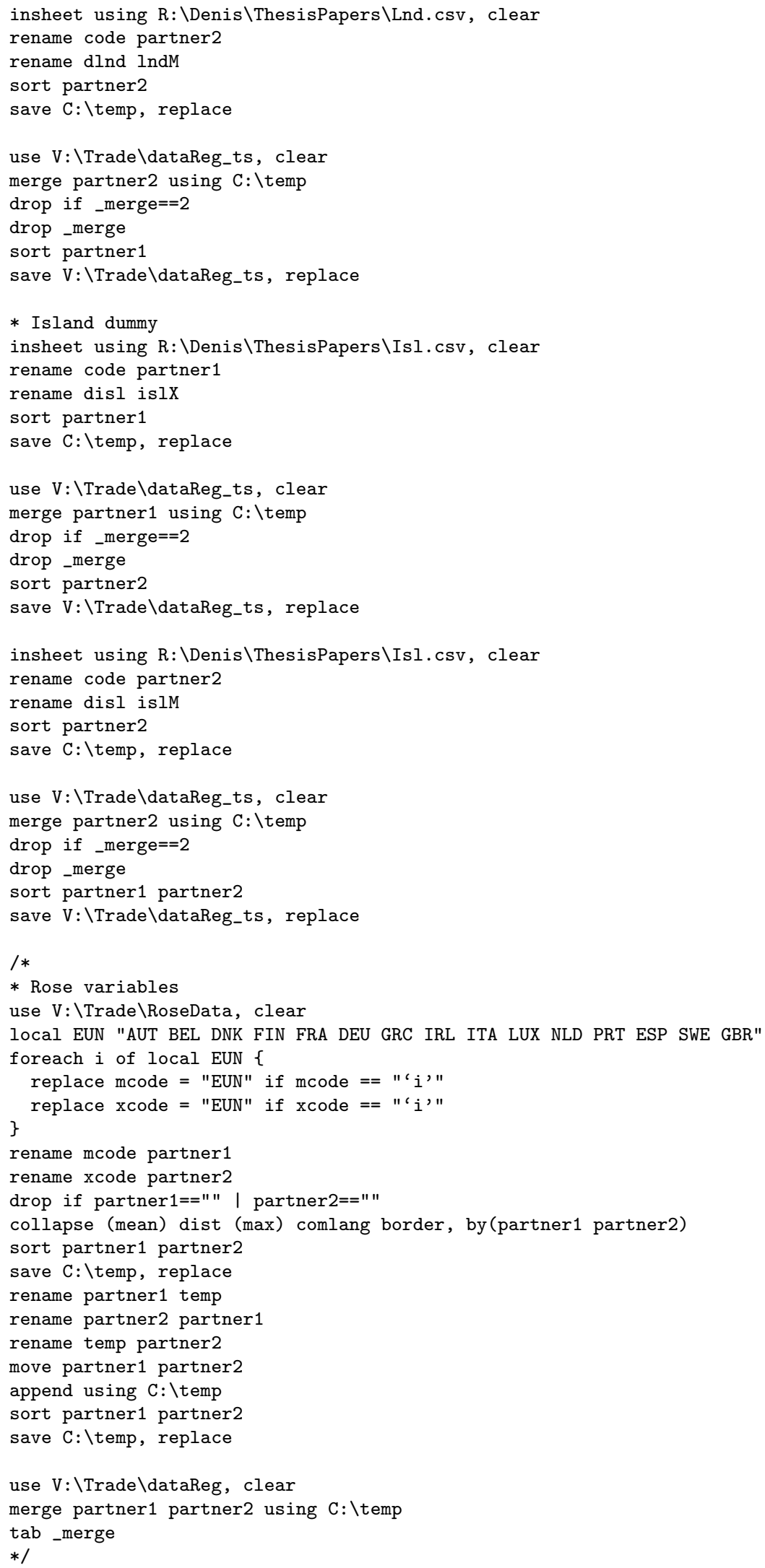




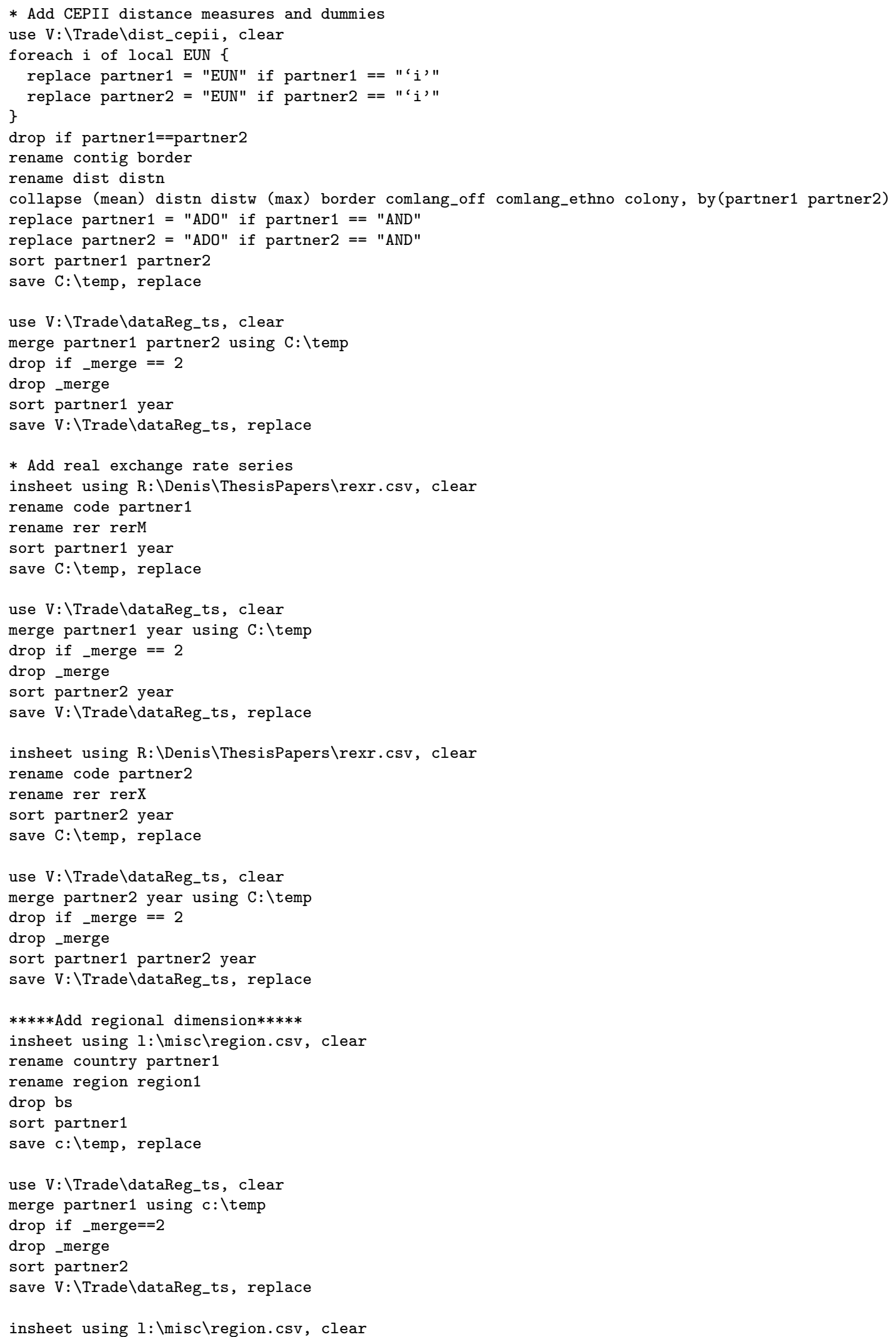




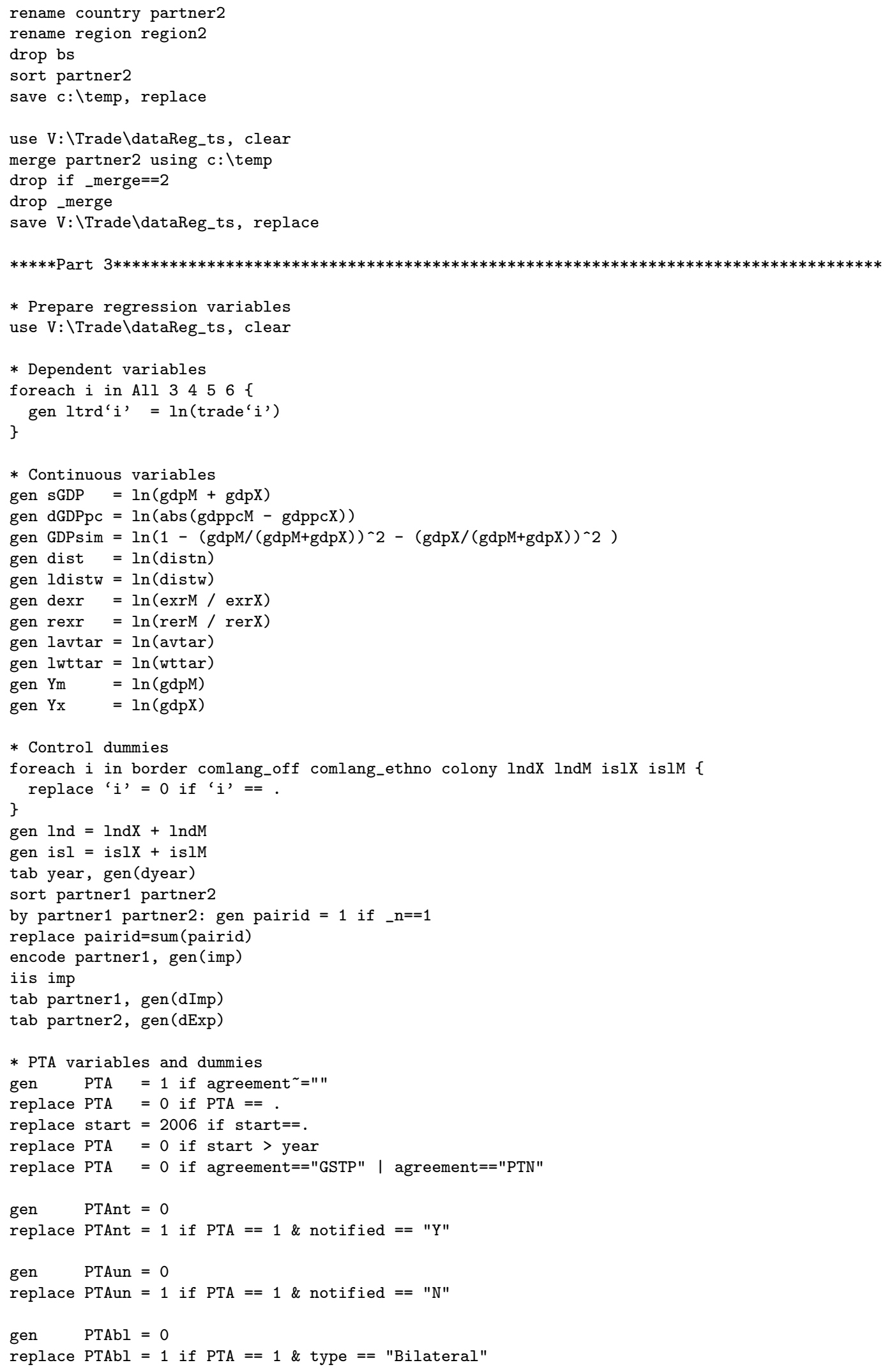




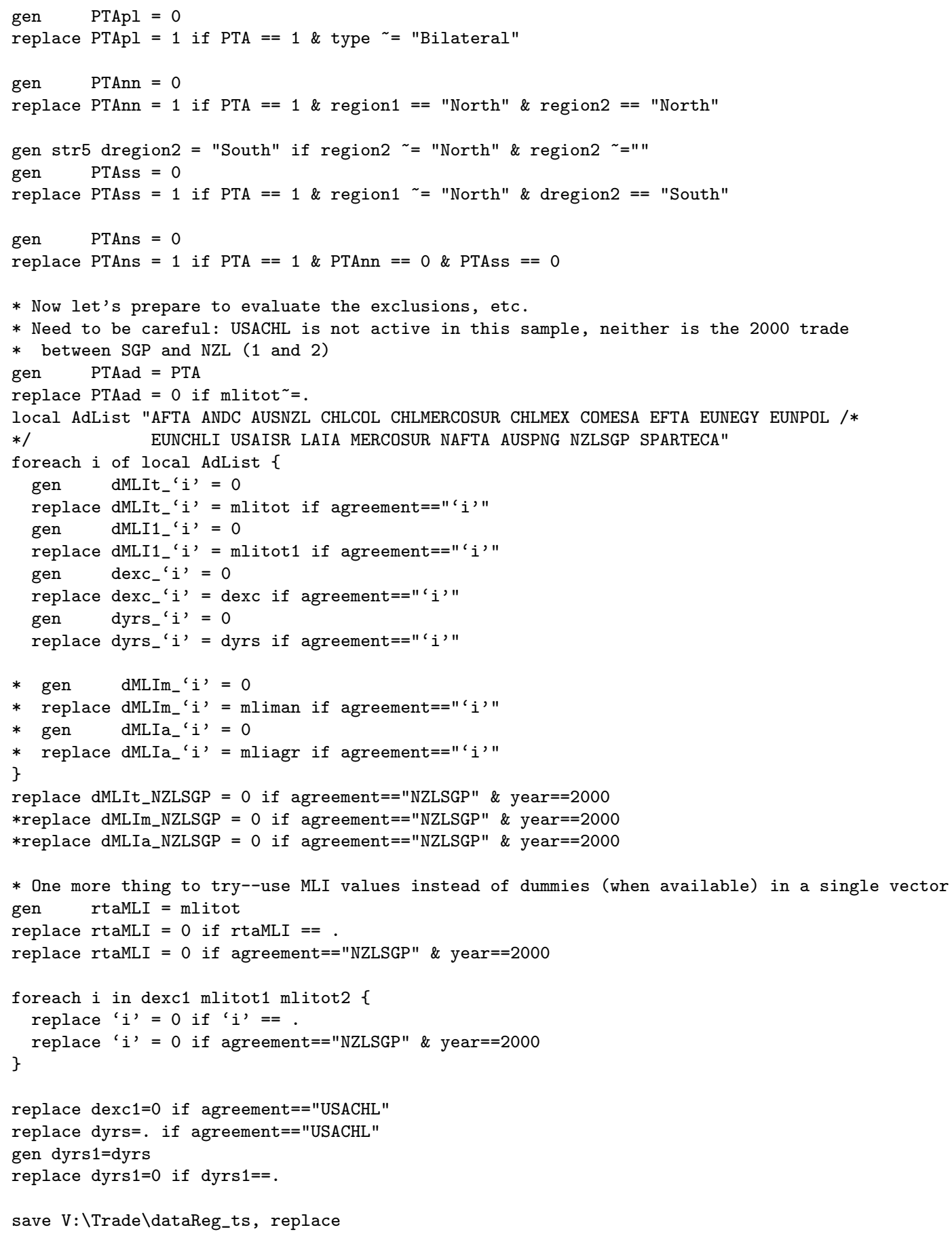




\section{References}

Adams, Richard, Philippa Dee, Jyothi Gali, and Greg McGuire (2003, May). "The trade and investment effects of preferential trading arrangements - old and new evidence." Working paper, Productivity Commission, Canberra.

ADB (2002). Asian Development Outlook 2002. New York: Oxford University Press for ADB (Asian Development Bank).

Aitken, Norman (1973). "The effect of the EEC and EFTA on European trade: A temporal cross section analysis." The American Economic Review 63(5), 881-892.

Anderson, James (1979). "A theoretical foundation for the gravity equation." The American Economic Review 69.

Anderson, James and Eric van Wincoop (2003, March). "Gravity with gravitas: A solution to the border puzzle." The American Economic Review 93(1), 170-92.

Anderson, James and Eric van Wincoop (2004, September). "Trade costs." Journal of Economic Literature 42(3), 691-751.

Anson, José, Olivier Cadot, Jaime de Melo, Antoni Estevadeordal, Akiki Suwa-Eisenmann, and Bolormaa Tumurchudur (2003). "Rules of origin in north-south preferential trading arrangements with an application to NAFTA." Discussion Paper 4166, Centre for Economic Policy Research (CEPR).

Armington, Paul (1969). "A theory of demand for products distinguished by place of production." Staff Paper 16, International Monetary Fund (IMF).

Baier, Scott and Jeffrey Bergstrand (2001, February). "The growth of world trade: tarifs, transport costs, and income similarity." Journal of International Economics 53(1), 1-27.

Baltagi, Badi H. (2001). Econometric Analysis of Panel Data (2 ed.). West Sussex, England: John Wiley \& Sons.

Bayoumi, Tamim and Barry Eichengreen (1995). "Is regionalism simply a diversion? Evidence from the evolution of the EC and EFTA." Discussion Paper 1294, Centre for Economic Policy Research (CEPR).

Brenton, Paul (2003). "Integrating the least developed countries into the world trading system: The current impact of EU preferences under Everything but Arms." Policy Research Working Paper 3018, World Bank.

Brenton, Paul and Takako Ikezuki (2004). "The initial and potential impact of preferential access to the US market under the African Growth and Opportunity Act." Policy Research Working Paper 3262, World Bank.

Brenton, Paul and Myriam Manchin (2003, May). "Making EU trade agreements work: The role of rules of origin." World Economy 26(5), 755-769. 
Burfisher, Mary, Sherman Robinson, and Karen Thierfelder (2004). "Regionalism: Old and new, theory and practice." In Anania Giovanni, ed., Agricultural Policy Reform and the WTO: Where Are We Heading? Cheltenham, UK: Edward Elgar Publishing.

Carrère, Céline and Jaime de Melo (2004, June). "Are different rules of origin equally costly? estimates from NAFTA." Discussion Paper 4437, Centre for Economic Policy Research (CEPR).

Dollar, David and Aart Kraay (2003, March). "Institutions, trade, and growth: Revisiting the evidence." Policy Research Working Paper 3004, World Bank.

Egger, Peter (2000). "A note on the proper econometric specification of the gravity equation." Economics Letters 66(1), 25-31.

Estevadeordal, Antoni (2000). "Negotiating preferential market access: The case of the North American Free Trade Agreement." Journal of World Trade 34, 141-166.

Feenstra, Robert (2004). Advanced International Trade: Theory and Evidence. Princeton, New Jersey: Princeton University Press.

Frankel, Jeffrey (1997). Regional Trading Blocs in the World Economic System. Washington DC: Institute for International Economics.

Greene, William H. (2000). Econometric Analysis (4 ed.). Upper Saddle River, New Jersey: Prentice Hall.

Grether, Jean-Marie and Marcelo Olarreaga (1999). "Preferential and nonpreferential trade flows in world trade." In Miguel Rodriguez Mendoza, Patrick Low, and Barbara Kotschwar, eds., Trade Rules in the Making: Challenges in Regional and Multilateral Negotiations. Washington, DC: Brookings Institution Press.

Herin, Jan (1986). "Rules of origin and differences between tariff levels in EFTA and the EC." Occasion paper 13, European Free Trade Association, Geneva.

Kommerskollegium (2003). Facts and Figures in World Trade and Trade Policy 2003. Stockholm: Kommerskollegium (Sweden National Board of Trade).

Lamy, Pascal (2002, November). "Stepping stones of stumbling blocks? The EU's approach towards the problem of multilateralism vs regionalism in trade policy." World Economy 25(10), 13991413.

Lawrence, Robert (1991). "Emerging regional arrangements: Building blocks or stumbling blocks?" In Richard OBrien, ed., Finance and the International Economy 5: The AMEX Bank Review Prize Essays, Volume 23-25. New York: Oxford University Press.

Leamer, Edward E. and James Levinsohn (1995). "International trade theory: The evidence." In Gene Grossman and Kenneth Rogof, eds., Handbook of International Economics, Volume 3. Amsterdam: North-Holland.

Lederman, Daniel, William Maloney, and Luis Serven (2005). Lessons from NAFTA for Latin America and Caribbean Countries: A Summary of Research Findings. Washington, DC: World Bank. 
Li, Quan (2000). "Institutional rules of regional trade blocs and their impact on international trade." In R. Switky and B Kerremans, eds., The Political Consequences of Regional Trade Blocks. London: Ashgate.

Limão, Nuno (2003). "Preferential trade agreements as stumbling blocks for multilateral trade liberalization: Evidence for the us." Working paper, University of Maryland, College Park.

McCallum, John (1995). "National borders matter: Canada-US regional trade patterns." The American Economic Review 85(3).

Moïsé, Evdokia (2002, August). "The relationship between regional trade agreements and the multilateral trading system: Rules of origin." Working Paper TD/TC/WP(2002)33/FINAL, Organisation for Economic Co-operation and Development (OECD).

Panagariya, Arvind (2002, November). "EU preferential trade arrangements and developing countries." World Economy 25(10), 1415-1432.

Redding, Stephen and Anthony Venables (2000, September). "Economic geography and international inequality." Discussion Paper 2568, Centre for Economic Policy Research (CEPR).

Rodriguez, Francisco and Dani Rodrik (2001). "Trade policy and economic growth: A skeptic's guide to the cross-national literature." In B. Bernanke and K. S. Rogoff, eds., Macroeconomics Annual 2000. Cambridge, MA: MIT Press for NBER.

Rose, Andrew (2002, September). "Estimating protectionism through residuals from the gravity model." Background paper for World Economic Outlook 2002: Trade and finance, International Monetary Fund (IMF).

Rose, Andrew (2004a). "Do we really know that the WTO increases trade?" The American Economic Review 94(1), 98-114.

Rose, Andrew (2004b). "Response to Subramanian and Wei." Mimeo, University of CaliforniaBerkeley.

Rose, Andrew and D. T. Stanley (2005, July). "A meta-analysis of the effect of common currencies on international trade." Journal of Economic Surveys 19(3), 347-368.

Rose, Andrew and Eric van Wincoop (2001). "National money as a barrier to international trade: The real case for currency union." The American Economic Review 91(2).

Saggi, Kamal (2004). "Preferential trading arrangements and multilateral tariff cooperation." Working paper, Southern Methodist University.

Saggi, Kamal and Halis Murat Yildiz (2004). "Bilateral trade agreements and the feasibility of multilateral free trade." Working paper, Southern Methodist University.

Sall, John and Bradley Jones (2004, Summer). "Leptokurtosiphobia: Irrational fear of nonnormality." JMPer Cable Newsletter 11, 1-16.

Sapir, André (1998, May). "The political economy of EC regionalism." European Economic Review $42(3-5), 717-732$. 
Schiff, Maurice and L. Alan Winters (2003). Regional Integration and Development. Washington, DC: World Bank.

Schott, Jeffrey (2004). "Assessing US FTA policy." In Jeffrey Schott, ed., Free Trade Agreements: US Strategies and Priorities. Washington, DC: Institute for International Economics.

Soloaga, Isidro and L. Alan Winters (2001). "Regionalism in the nineties: What effect on trade?" North American Journal of Economics and Finance 12(1), 1-29.

Stanley, D. T. (2001, Summer). "Wheat from chaff: Meta-analysis as quantitative literature review." Journal of Economic Perspectives 15(3), 131-150.

Winham, Gilbert (1986). International Trade and the Tokyo Round Negotiation. Princeton, NJ: Princeton University Press.

World Bank (2000). Trade Blocs. Oxford University Press.

World Bank (2001). Global Economic Prospects 2002: Making Trade Work for the Poor. Washington, DC: World Bank.

World Bank (2004). Global Economic Prospects 2005: Trade, Regionalism, and Development. Washington, DC: World Bank.

WTO (2003). World Trade Report 2003. Geneva: WTO (World Trade Organisation). 